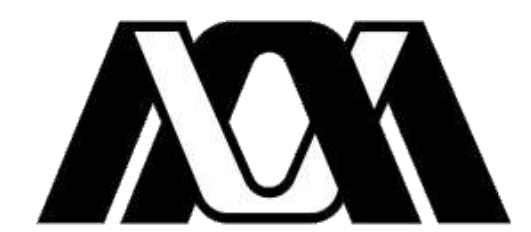

Casa abierta al tiempo
UNIVERSIDAD AUTÓNOMA METROPOLITANA.

UNIDAD IZTAPALAPA.

CIENCIAS BIOLÓGICAS Y DE LA SALUD.

DEPARTAMENTOS DE BIOLOGÍA E

HIDROBIOLOGÍA.

POSGRADO EN BIOLOGÍA.

\title{
"Biomarcadores de salud y calidad aplicados a la almeja Polymesoda caroliniana (Bosc, 1801) (Bivalva: Corbiculidae) de Tecolutla, Veracruz".
}

\section{T E S I S}

Que para obtener el grado de

MAESTRO EN BIOLOGÍA

\author{
P R E S E N T A: \\ Biólogo José Roberto Jerónimo Juárez.
}

Codirectoras:

Dra. Xochitl Guzmán García.

Dra. Isabel Guerrero Legarreta.

Asesora:

Dra. Irene de los Ángeles Barriga Sosa.

México D.F. 16 de diciembre de 2013. 
La Maestría en Biología de la Universidad Autónoma Metropolitana Unidad Iztapalapa, pertenece al Padrón Nacional de Posgrados de Calidad del CONACYT y cuenta con apoyo del mismo Consejo con el convenio PFP-2093.

Con el número de beca: 265760. 
Esta Tesis forma parte de los proyectos: "Indicadores de Integridad Ecologica y Salud Ambiental", aprobado por el departamento de Hidrobiología, Área de Manejo Integral de Recursos Acuáticos (MIRA) de la UAM-I y "Incorporación de nuevos ingredientes funcionales a alimentos como contribución a la promoción de la salud y/o a la prevención de enfermedades de la población Iberoamericana IBEROFUN - CYTED" 


\section{Comité Tutoral.}

Dra. Xochitl Guzmán García. Laboratorio de Ecotoxicología. Departamento de Hidrobiología. División de Ciencias Biológicas y de la Salud. UAM-I.

Codirectora.

Dra. María Isabel del Carmen Guerrero Legarreta. Laboratorio de Macromoléculas. Departamento de Biotecnología. División de Ciencias Biológicas y de la Salud. UAM-I. Codirectora.

Dra. Irene de los Ángeles Barriga Sosa. Laboratorio de Genética y Biología Molecular. Departamento de Hidrobiología. División de Ciencias Biológicas y de la Salud. UAM-I. Asesora. 
El jurado designado por la

División de Ciencias Biológicas y de la Salud

de la Unidad Iztapalapa, aprobó la tesis que presentó:

\section{JOSÉ ROBERTO JERÓNIMO JUÁREZ.}

El dia 16 de diciembre del año 2013.

Miembros del Jurado.

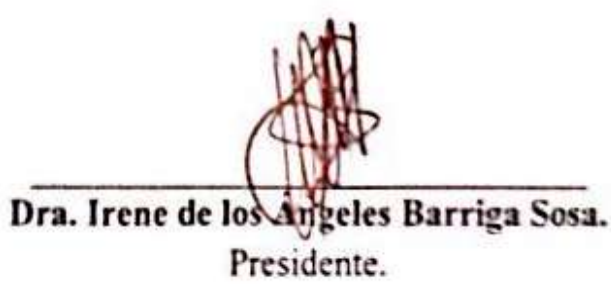

Presidente.

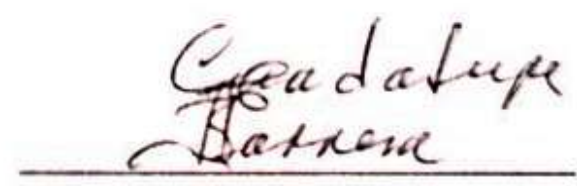

Dra. Guadalupe Barrera Escorcia.

Secretario.

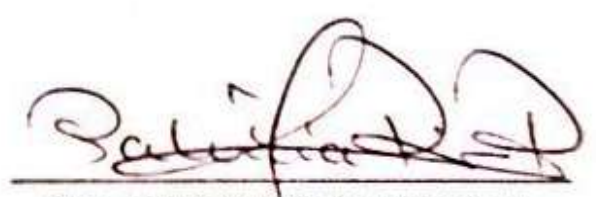

Dra. Patricia Ramirez Romero.

Sinodal.

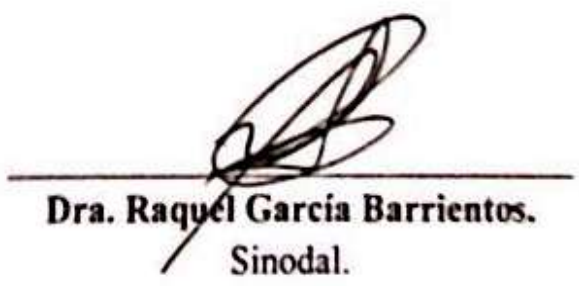




\section{Dedicatoria.}

A mis padres, la Sra. Margarita Juárez y el Sr. Ernesto Jerónimo.

Con ellos todo, sin ellos nada, los amo.

Y muy en especial a ustedes amigos sin voz pero de miradas alentadoras, amigos sin brazos humanos pero de abrazos entrañables, amigos que convertían mi llegada a casa en una verdadera fiesta, cada vez que me veían. A ustedes también mi esfuerzo, gracias por compartir toda su vida conmigo y estar siempre a mi lado... inos volveremos a ver! 


\section{Agradecimientos.}

Hablar de mi proyecto de maestría y lo que implicó elaborarlo es hablar de tantos y tantas personas que de manera directa o indirecta colaboraron para que este proyecto se concretara. Espero con esto poder expresar lo agradecido que me siento con todos y cada uno de ustedes...

A Dios por darme la vida, por dejarme llegar a este día. Gracias por todo.

A Jesús, por tu apoyo desde que empezó todo esto, gracias por alentarme a seguir adelante por hacerme reir y por enseñarme a levantarme cada vez que la vida me tiraba.

A mi familia. Mi mamá, gracias por ser quien eres, por tener siempre una respuesta a todo, por ser valiente y enseñarme a dar todo pese a las adversidades, gracias porque del $100 \%$ de este logro, el $70 \%$ te lo debo a ti, gracias por aceptarme tal y como soy. A mi papá, de quien aprendí la lección más grande e importante sobre responsabilidad, gracias por apoyar mi carrera y alentarme a seguir adelante y por enseñarme a tener siempre humildad.

A mis hermanos: Claudia, yo sé que detrás de mamá siempre has estado tu ayudándome en secreto, gracias a ti también por el apoyo económico en todo momento de mi desarrollo, por escucharme y porque con tus inseguridades acerca de mi éxito alimentaste más mi ego para demostrarte que ¡si se puede! A Tito, por apoyar mis decisiones y por escucharme siempre que lo necesité, por ser mi hermano y por enseñarme a hacer lo que me gusta, gracias también a ti por el apoyo económico y material que implicó este proyecto.

A mis sobrinos, Gustavo y Camila, hermosos niños que llenaron de felicidad y risas mis días de mayor estrés, gracias por dejarme enseñarles lo poco que yo sé, este esfuerzo es por ustedes también porque sepan que donde quiera que estén y hagan lo que hagan yo estaré siempre con ustedes. Los amo.

A mis primos que me apoyaron todo momento la Profesora Martha Vicente, Daniel Tafoya y Carlos Villeda. A mis tías y tíos preocupados siempre por mí: Rosendo, Hortensia, Ángela, Vicente, Lorenza y María. 
Académicamente, quiero agradecer muy en especial a la persona que inició todo esto y que creyó en mí desde un principio aún sin conocerme; "GRACIAS" Dra. Xochitl Guzmán García, directora del proyecto, profesora, jefa y si me permite el atrevimiento, amiga mía. Gracias por reinventarme, por hacer de mi lo que soy ahora, gracias por todas y cada una de las tareas de confianza que me encomendó, gracias por apoyarme cuando más lo necesitaba tanto económica como humanamente. Eternamente agradecido por las oportunidades importantes que me otorgó en su momento y en especial por hacer realidad mi más grande anhelo: ser profesor. Gracias por toda su atención, sus regaños (bien merecidos jeje) y por estar al pendiente en todo momento de mi desarrollo profesional. Es un placer y honor llamarme su alumno. Gracias.

A la Dra. Isabel Guerrero Legarreta, por aceptar codirigir este proyecto aún sin conocerme. Gracias por dedicarme tiempo y por abrirme las puertas de las instalaciones del laboratorio que usted dirige y por estar siempre al pendiente del proyecto y de mí con sus valiosos e invaluables conocimientos. A usted un agradecimiento especial por permitir que este examen se llevara a cabo.

A la Dra. Irene Barriga Sosa, por aceptar asesorar mi proyecto aún sin conocerme. Sorprendido estoy por todas y cada una de las veces que se sentó a mi lado y me dejó aprender de usted. Gracias por todas las consideraciones que demostró hacia mi proyecto con el fin de que llegara a este término. Muchas gracias sobre todo por la confianza que puso en mí al dejarme aventurarme y proponer alternativas sobre mi proyecto.

A la Dra. Guadalupe Barrera, por ser revisora y jurado de este proyecto. Gracias por mostrarse siempre preocupada del mismo y sobre todo de mí. Valiosas, muy valiosas enseñanzas he aprendido con sus consejos siempre acertados.

A la Dra. Rocío Zarate, por animarme a seguir siempre adelante, por mostrar su interés en mi proyecto y en mi persona. Gracias infinitas por el apoyo recibido en el análisis estadístico del proyecto.

A la Dra. Jhoana Díaz por la dirección de mi tema selecto y sus aportaciones a mi proyecto; a la Dra. Alejandra Serrato, por la dirección y procesamiento de mis muestras genéticas. 
Al Dr. Abel Sentíes y Dr. Alejandro Zavala que como coordinadores de la maestría; en su momento, atendieron siempre y de manera adecuada, mis múltiples dudas y cuestionamientos.

A las doctoras Patricia Ramírez Romero y Raquel García Barrientos por aceptar ser miembros de mi jurado en la evaluación y aprobación de este proyecto; gracias por todas y cada una de las correcciones que muy atinadamente me hicieron para mejorar este escrito.

Gracias Dra. Paty por las palabras y abrazos de aliento.

Con mucho cariño, respeto y admiración a mis amigos del laboratorio de Histopatología: Biol. Verónica Ramírez, Biol. Pedro Román, Hbiol. Sonia González, M. en C. Pamela Becerra, Pas. de Biol. Ángel Vázquez (comadre), Biol. Tania López, M. en B. Exp. Ingrid Camarena, Biol. Mar. Mirelle Dávila y Misael. Gracias por preocuparse todos los días por mí, por el interés que siempre mostraron en mi proyecto, por el apoyo en el procesamiento de las muestras y por permitirme aprender de ustedes. A los Hibiols.: Rafael Terrazas, Emilio Padilla y Carlos Fernández, por el apoyo en la colecta de las muestras.

Con mención especial a la Biol. e HT. Irma Hernández Calderas por enseñarme el arte de amar la histología, gracias a ti por la paciencia y el apoyo en el procesamiento de mis muestras histológicas. Eres un ejemplo a seguir.

A mis compañeras y profesoras del laboratorio de Biotecnología; Dra. Arisaí Hernández, gracias por mostrarte siempre atenta y solidaria con mi proyecto, muy agradecido estoy por la infinita paciencia y atención a mi proyecto, sin ti esta parte no hubiera sido la misma. Y a la Dra. Rosy Monterrosa por el apoyo desinteresado al proyecto y por nunca dejarme solo en un laboratorio que no conocía. Gracias infinitas a las dos, fue un placer trabajar con ustedes.

A mis compañeros y compañeras del laboratorio de Biología y Genética Molecular de la PExPA; gracias al M. en C. Ricardo Pliego por enseñarme todo lo que sé sobre el procesamiento del ADN, gracias por todas las aportaciones académicas a este proyecto y por ayudarme prácticamente en todo. A la M. en C. Rosa García, que con tus aportaciones académicas y ayuda en el procesamiento de mis muestras, coadyuvaste a 
mejorarlo. Al Hbiol. Benjamín López, por contagiarme con tu entusiasmo y por acompañarme en las jornadas complicadas del procesamiento, gracias por alentarme a seguir adelante. A la M. en B. Dafne Zarate, por tu apoyo en el procesamiento de mis muestras y al Dr. Gerardo Figueroa, por las observaciones atinadas hacia mi proyecto.

A los pescadores de Tecolutla por el apoyo en la colecta de los organismos. Gracias al H. Ayuntamiento de Tecolutla representado por la Biol. Laura Velazco. Gracias por las facilidades otorgadas y por apoyo bibliográfico a este proyecto.

A mis amigos siempre incondicionales: M. en B. Mali Gomezcaña, M. en B. Cristián Vela y Biol. Christian Servando. Muy en especial a ti Mali por ser quien eres conmigo, por aceptarme como soy y por compartir los mejores y peores momentos de mi vida, te quiero mucho, ipero mucho!

Al CONACyT por el apoyo económico que permitió llevar a término este proyecto.

A mi alma máter Universidad Autónoma Metropolitana, por ser mi segunda casa y por formar parte de mi vida; con enorme orgullo y honor puedo decir que yo soy UAM.

Por último, pero no menos importante a los organismos que dieron su vida en este proyecto, animales encantadores, muy pequeños pero con un propósito enorme en el mundo, tengan por seguro que su vida ha valido la pena.

¡Gracias! 


\section{Índice}

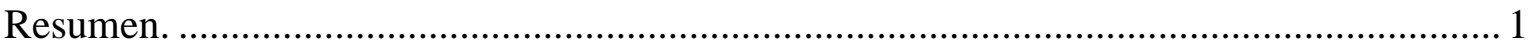

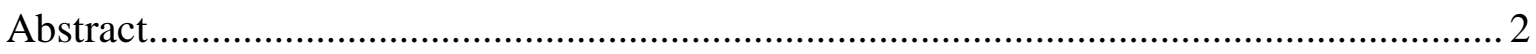

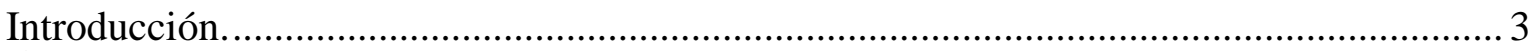

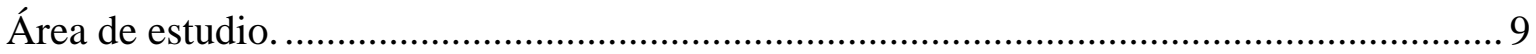

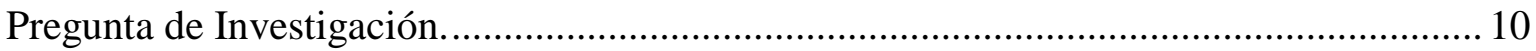

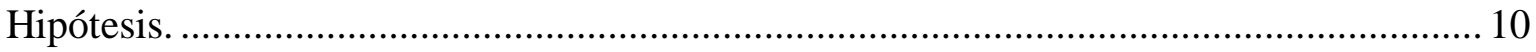

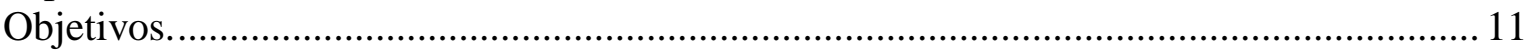

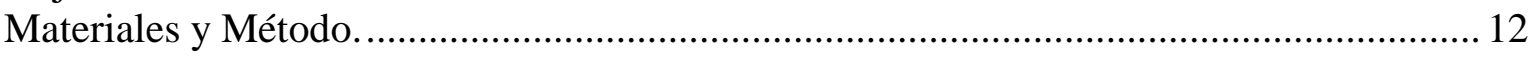

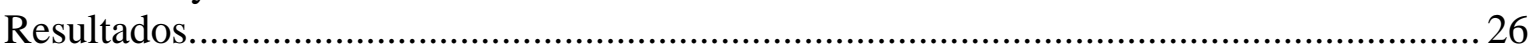

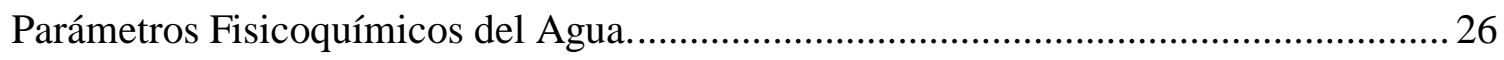

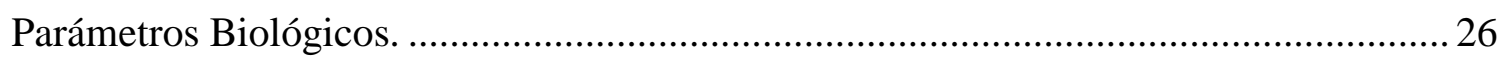

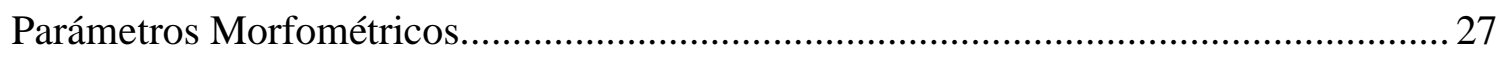

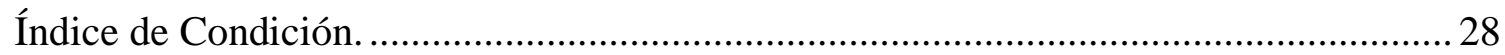

Determinación Taxonómica de la Especie de Estudio.......................................................29

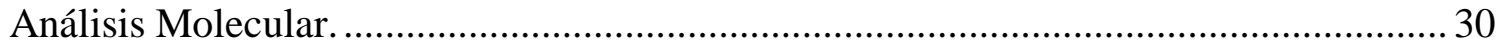

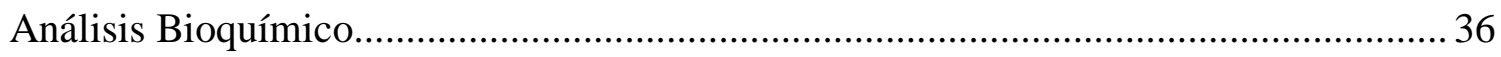

Identificación y caracterización parcial de proteínas de almeja.................................... 36

Determinación del contenido proteíco por el método de Kjeldahl............................... 41

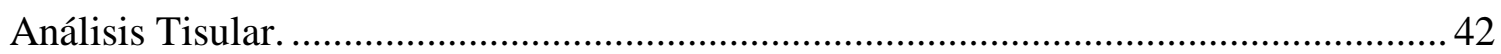

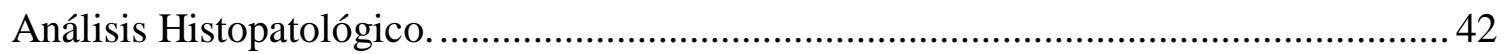

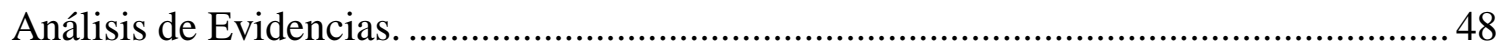

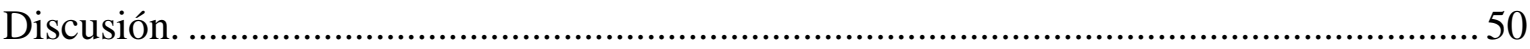

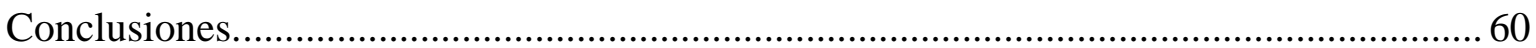

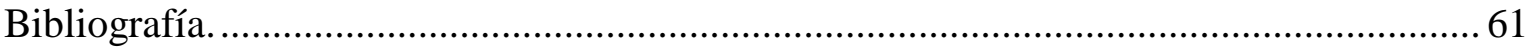

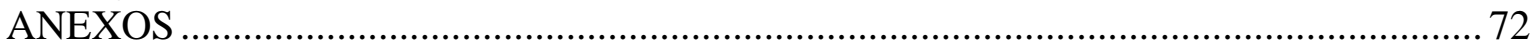




\section{Índice de Figuras.}

Figura 1. Almejas explotadas comercialmente en el Golfo de México. a) Almeja gallito, Rangia cuneata; b) Almeja casco o escudo, Rangia flexuosa y c) Almeja negra o prieta, Polymesoda caroliniana. Tomado de Wakida-Kusunoki \& MacKenzie Jr. (2004).

Figura 2. Esquema de un bivalvo, con la valva izquierda removidas. Tomado de Mikkelsen

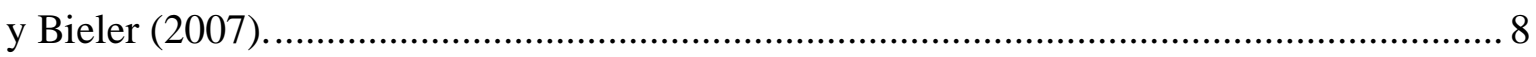

Figura 3. Mapa de Tecolutla Veracruz. Se muestran las zonas de colecta (ZC). ................. 9

Figura 4. Curva patrón de concentración de proteína.................................................. 19

Figura 5. Porcentaje de organismos asociados (en gris) encontrados para la época de lluvias (derecha) y secas (izquierda) a partir del total de organismos analizados (en negro)......... 27 Figura 6. Índice de condición para ambas épocas de colecta, calculado a partir de la fórmula de Devenport \& Chen (1987). En donde ( $\leq 2.0=$ delgado; $2.0-4.0=$ moderado $y \geq$ 4= robusto).

Figura 7, a) Exterior de las conchas de la almeja Polymesoda caroliniana de Tecolutla, Veracruz mostrando promedios de longitud (superior) y ancho (inferior) y b) Detalle de la charnela y dientes cardinales en el interior de la concha de las almejas.

Figura 8. Extracciones de ADN. A la izquierda la extracción de ADN a partir de la branquia. Se resalta el organismo \#049. A la derecha el extracción a partir de manto del organismo \#017 Ambas extracciones utilizando el protocolo de QIAGEN@. El resto de las bandas corresponden a otras extracciones que no tuvieron éxito en el proceso de

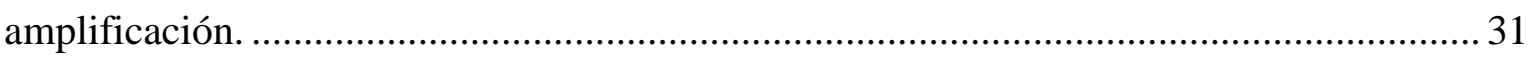

Figura 9. Amplificación de los genes genes r16S (izquierda) y $28 \mathrm{~S}$ (derecha). $\mathrm{G}=49.5^{\circ} \mathrm{C}$; $\mathrm{E}=51.9^{\circ} \mathrm{C}$ y $\mathrm{C}=55.4{ }^{\circ} \mathrm{C}$

Figura 10. Resultado del análisis de Blastn de la secuencia \#049 con la secuencia del gen r16S de la especie Corbicula colorata (Corbiculidae), con el cual muestra un $77 \%$ de identidad

Figura 11. Resultado del análisis de Blastn de la secuencia \#017 con la secuencia del gen 28S de la especie Polimesoda caroliniana (Corbiculidae), con el cual muestra un $99 \%$ de identidad 34

Figura 12. Topología obtenida a partir del método de Máxima verosimilitud para el gen r16S.

Figura 13. Topología obtenida a partir del método de Máxima verosimilitud para el gen $28 \mathrm{~S}$.

Figura 14. Actividad proteolítica específica (U/mg) para cada órgano estudiado.

Figura 15. Actividad proteolítica del extracto de branquia de almeja $P$. caroliniana y almeja comercial a diferentes $\mathrm{pH}$.

Figura 16. Actividad proteolítica a diferente temperatura de extracto de branquia de almeja P. caroliniana y almeja comercial. 38 Figura 17. Electroforesis (SDS-PAGE) de extracto de la almeja comercial y de $P$. caroliniana. $\mathrm{P}=$ pie; $\mathrm{M}=$ manto y $\mathrm{B}=$ branquia. 
Figura 18. Densitograma de los pesos moleculares de marcadores. $1=$ miosina $200 \mathrm{kDa}$, $2=\beta$-galactosidasa $112 \mathrm{kDa}, 3=$ suero de albumina $91 \mathrm{kDa}, 4=$ glutamato $62 \mathrm{kDa}, 5=$ ovoalbúmina $46 \mathrm{kDa}$, 6= anhidrasa carbónica $38 \mathrm{kDa}, 7=$ mioglobina $26 \mathrm{kDa}, 8=$ lisosima $19 \mathrm{kDa}$ y $9=$ aprotina $9 \mathrm{kDa}$.

Figura 19. Proteínas en el pie de la almeja Polymesoda caroliniana. Los números en los picos corresponden al número de proteínas detectadas. 40

Figura 20. Proteínas en el manto de la almeja Polymesoda caroliniana. Los números en los picos corresponden al número de proteínas detectadas. 40

Figura 21. Proteínas en la branquia de la almeja Polymesoda caroliniana. Los números en los picos corresponden al número de proteínas detectadas. 40 Figura 22. Fotomicrografías del manto. En a y b se detalla el manto en aparente estado normal de salud. En c y d se observan inclusiones eosinófilas, mientras que en e y f se observan inclusiones esféricas en tonalidades pardas. Cortes transversales. $5 \mu \mathrm{m}$. Tinción H-E.

Figura 23. Fotomicrografías de branquia. Se observan láminas y filamentos branquiales en estado de salud normal (a y b). En c-f se detallan gránulos de lipofuscina en diferentes tamaños. Cortes transversales, tinción H-E, nivel de corte $5 \mu \mathrm{m}$ 46 Figura 24. Fotomicrografías del pie. En a y b se observa la porción anterior el pie en estado normal de salud. En c y d se observa tejido conectivo laxo con separaciones importantes. En e y f se detallan secreciones vacuoladas eosinofilas. Cortes transversales. Tinción H-E. Nivel de corte $5 \mu \mathrm{m}$.

Figura 25. Cortes transversales de branquia ( $\mathrm{a} \mathrm{y} \mathrm{b)} \mathrm{y} \mathrm{de} \mathrm{manto} \mathrm{(} \mathrm{c}$ y d) en los que se muestran inclusiones esféricas en lo que pareciera ser un tipo de parasito. Tinción con H-E. 


\section{Índice de Tablas.}

Tabla 1. Parámetros fisicoquímicos del agua para ambas épocas de colecta.....................26

Tabla 2. Parámetros morfométricos y análisis estadístico para ambas épocas de colecta... 28

Tabla 3. Cuantificación de extracciones ADNt a partir del manto...................................... 31

Tabla 4. Cuantificación de extracciones ADNt por órgano............................................... 31

Tabla 5. Cálculo de distancias genéticas con el modelo T93 para el gen 28S ..................... 36

Tabla 6. Concentración de proteínas de la almeja Polymesoda caroliniana y de la almeja

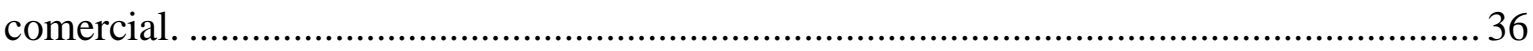

Tabla 7. Porcentaje de proteína para los tres órganos de la almeja Polymesoda caroliniana.

Tabla 8. Porcentaje de humedad y materia seca para los tres órganos de la almeja $P$. caroliniana.

Tabla 9. Porcentaje de órganos con respuestas tisulares por época climática y zona de

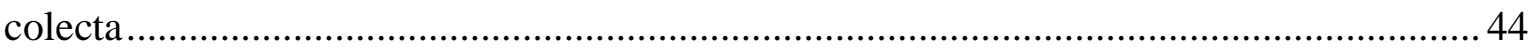

Tabla 10. Análisis de evidencias de las respuestas tisulares en la almeja P. caroliniana... 49

Tabla 11. Análisis de evidencias del análisis bioquímico en la almeja $P$. caroliniana....... 49 


\section{Índice de Anexos.}

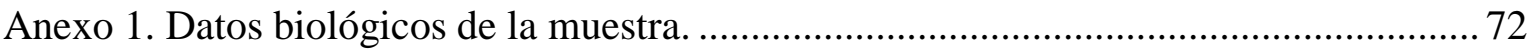

Anexo 2. Protocolo de Extracción de ADN (DNEASY ® Blood \& Tissue Kit de QIAGEN

(B)

Anexo 3. Protocolo de Purificación (WIZARD ® SV Gel and PCR Clean-Up System de

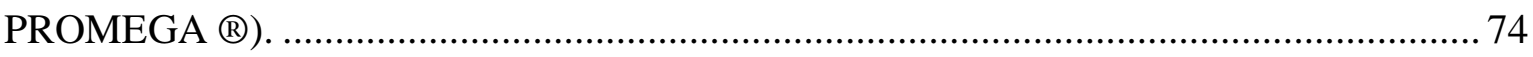

Anexo 4. Protocolo de Purificación (QIAQUICK ® PCR Purification Kit de QIAGEN ®).

75

Anexo 5. Secuencias utilizadas en el análisis filogenético............................................... 76

Anexo 6. Soluciones utilizadas en el análisis bioquímico............................................... 80

Anexo 7. Secuencia de Deshidratación, Infiltración y Aclaramiento.................................... 82

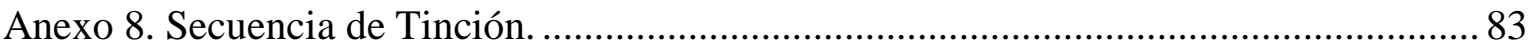




\section{Resumen.}

Las actividades antropogénicas han perjudicado al ambiente y a diversos organismos que en él habitan. Las almejas se han propuesto como bioindicadores ya que permiten una visión integral y retrospectiva de las cualidades del medio en el que se desarrollan. En México existen sitios de importancia turística, comercial y riqueza biológica que carecen de información básica que permita el buen manejo y control de calidad de sus productos, por lo que es importante incentivar la realización de estudios que evalúen la riqueza, calidad y potencial comercial de las especies acuáticas. La calidad de los organismos acuáticos, tales como las almejas, está directamente relacionada su crecimiento y fundamentalmente con la composición del tejido, el valor nutritivo y las características comestibles de ellos como alimento. Además de estas características, otras de tipo fisiológico y bioquímico, como las enzimas, refieren el uso de este tipo de molusco como candidato potencial para estudios ecotoxicológicos y de funcionalidad bioquímica para la evaluación de la calidad de los recursos naturales silvestres. El objetivo de este trabajo fue elucidar la posición taxonómica, composición parcial bioquímica y la condición fisiológica de la almeja de Tecolutla, Veracruz. El estudio se realizó en épocas climáticas contrastantes (lluvias y secas) y en dos zonas de colecta (ZC1 y ZC2). Se registraron parámetros fisicoquímicos del agua, y se realizó la recolección de 109 almejas. Los ejemplares recolectados fueron transportados al laboratorio donde se analizaron parámetros biológicos y morfométricos. Con los datos morfométricos se calculó el índice de condición (IC) utilizando la fórmula de Devenport y Chen (1987). La identidad de la especie de estudio se determinó mediante claves específicas y se corroboró genéticamente mediante la amplificación y secuencias de los genes r16s (mitocondrial) y 28S (nuclear). Se calculó la actividad proteolítica a diferente $\mathrm{pH}$ y temperatura. Se realizó una caracterización parcial de proteínas vía SDS-PAGE y se calculó el porcentaje en el manto, branquia y pie mediante el método de Kjeldahl. De manera análoga se realizó un análisis histopatológico para determinar la condición fisiológica de los organismos analizados. El análisis de los parámetros fisicoquímicos del agua indican que las condiciones generales del sistema están dentro de los intervalos recomendados para cultivo de bivalvos, no se observaron lesiones macroscópicas aparentes y los parámetros morfométricos estiman una longitud promedio de $50 \mathrm{~mm}$ y $50 \mathrm{~g}$ de peso. El cálculo del IC fue de 2 a 4 el cual establece que los organismos presentan una nutrición moderada. La determinación taxonómica y el análisis molecular permitieron corroborar la identidad de Polymesoda caroliniana. Se observó la mayor actividad enzimática en la branquia (126.8 U/mg), seguida del manto $(86.4$ $\mathrm{U} / \mathrm{mg}$ ) y con la menor actividad, el pie reportó valores de $(44.6 \mathrm{U} / \mathrm{mg})$, lo cual se relaciona directamente con su función y composición tisular. La temperatura a la cual las enzimas presentaron mayor actividad enzimática fue de los 30 hasta los $70^{\circ} \mathrm{C}$. El porcentaje de proteínas fue de $2 \%$ para el manto, $7 \%$ para la branquia y de $8 \%$ para el pie. Se reconocieron las características tisulares de los órganos estudiados. Se encontraron gránulos de lipofuscina e inclusiones esféricas en el manto mayormente en la época de lluvias ( $\mathrm{ZC} 1=17 \%$ y $Z \mathrm{ZC} 2=33 \%)$; la branquia evidenció gránulos de lipofuscina en un porcentaje mayor para la ZC1 de la época de lluvias (83\%); el pie mostró inflamaciones en un $18 \%$ para la ZC1 de lluvias. La almeja $P$. caroliniana es un recurso de interés para estudios biotecnológicos futuros, debido a que se evidenció un intervalo amplio de actividad enzimática a diferente $\mathrm{pH}$ y temperatura, así como un alto contenido de proteínas, además de que la condición fisiológica de la almeja aún no se ve comprometida. Se recomienda continúen los estudios ecotoxicologicos sobre la determinación de los contaminantes presentes en Tecolutla, la identificación de las enzimas presentes en la almeja, así como planes y programas que permitan el uso sustentable de este recurso. 


\section{Abstract.}

Anthropogenic activities have harmed the environment and the diverse organisms that dwell therein. Clams have been proposed as bioindicators, they enable a comprehensive overview and retrospective of the environmental qualities in which these organisms develop. In Mexico there are important tourist sites, commercial and biological richness lacking basic information to support enable good management and quality control of their products, so it is important to encourage studies to evaluate the richness, quality and commercial potential of these species. Aquatic organisms' quality is directly related to their growth and especially with their tissue composition, nutritional value and edible characteristics as seafood. Besides these attributes, other physiological and biochemical ones, such as enzymes, have been mentioned in mollusks such as potential candidates in ecotoxicological and biochemical functionality studies for evaluating wild natural resources' quality. The aim of this study was to elucidate the taxonomic position, partial biochemical composition and physiological condition of the clams from Tecolutla, Veracruz. The study was conducted in contrasting climatic seasons (rainy and dry) and in two areas of collection (AC1 and AC2). Physicochemical water parameters were recorded and 109 clams were collected. Clams were transported to the laboratory where biological and morphometric parameters were analyzed. Morphometric data were used to calculate the condition index (CI) using Devenport and Chen's (1987) formula. The species identity was determined using specific taxonomic keys, and genetically confirmed with amplified sequences of r16S (mitochondrial) and 28S (nuclear) genes. Proteolytic activity was calculated at different $\mathrm{pH}$ and temperature. Partial characterization of proteins via SDS -PAGE was performed and the percentage was calculated on the mantle, gill and foot using Kjeldahl's method. Also histopathological analysis was performed to determine the physiological condition of the organisms analyzed. Water's physico-chemical parameters indicate that general conditions of the system are within the recommended intervals for bivalve farming, no apparent gross lesions were observed and morphometric parameters estimated an average length of $50 \mathrm{~mm}$ and $50 \mathrm{~g}$ in weight. The CI was 2-4 which means these organisms have a moderate nutrition. The taxonomic determination as well as molecular analysis corroborated the identity of Polymesoda caroliniana. The highest enzyme activity was observed in the gill (126.8 U/mg), followed by the mantle $(86.4 \mathrm{U} / \mathrm{mg})$ and with the lowest activity, the foot reported values of 44.6 $\mathrm{U} / \mathrm{mg}$, which is directly related to its function and tissue composition. The temperature ranges at which the enzymes showed higher enzyme activity was 30 to $70^{\circ} \mathrm{C}$. The protein content was $2 \%$ for the mantle, gill $7 \%$ and $8 \%$ for the foot. Tissue characteristics of the studied organs were recognized. Lipofuscin granules and spherical inclusions in the mantle were found mostly in the rainy season $(\mathrm{AC} 1=17 \%$ and $\mathrm{AC} 2=33 \%)$; gill lipofuscin granules showed a higher percentage for AC1 in the rainy season (83\%), as well as foot swelling in (18\%). The clam P. caroliniana is a resource of interest for future biotechnology research because it showed a broad range of enzymatic activity at different $\mathrm{pH}$ and temperature, and is high in protein; also the physiological condition of the clam is not compromised. It is recommended to continue the ecotoxicological studies on the determination of contaminants in Tecolutla, the identification of the enzymes present in the clam, along with plans and programs for the sustainable use of this resource. 


\section{Introducción.}

Las actividades antropogénicas han perjudicado al ambiente y a diversos organismos que en él habitan (Villanueva \& Botello, 1998). Esto tiene un severo impacto no solo en el medio físico, sino que trasciende al romper los complejos ciclos biológicos que cada organismo lleva a cabo en un ecosistema, ocasionado pérdidas irreparables (Mendoza et al., 2007).

Los cambios y los efectos en el ambiente debidos a la contaminación son objeto de estudio de la ecotoxicología, misma que puede ser definida como la "ciencia que estudia la contaminación, su origen, su evolución, e interacciones con las moléculas que integran dinámicamente los ecosistemas". Esta disciplina busca con su evaluación coadyuvar en la toma de medidas de prevención, remediación y legislación (Capó-Martí, 2007).

Los compuestos tóxicos en determinadas concentraciones y durante ciertos tiempos de exposición, afectan o modifican los procesos bioquímicos o fisiológicos, pudiendo ocasionar incluso la muerte de los organismos expuestos (Martínez-Jerónimo, 1991). Estos agentes tóxicos, dependiendo de la sensibilidad de cada organismo producen respuestas biológicas, mismas que se han utilizado en el monitoreo de la contaminación, para ello en los estudios ecotoxicológicos se ha propuesto el uso de organismos bioindicadores, es decir organismos vivos que cumplen con ciertas características que reflejan las condiciones del medio en el que habitan (De la Lanza et al., 2000).

Los organismos bioindicadores son propios o comunes de un medio ambiente, cuantifican la magnitud del estrés, las características del hábitat y el grado de exposición al estresor o el grado de respuesta ecológica a la exposición. El uso de bioindicadores permite una visión integral y retrospectiva de las cualidades del medio en el que se desarrollan los organismos acuáticos. Al seleccionar un bioindicador se deben tomar en cuenta, entre 
otras, las siguientes características: su relevancia biológica, relevancia social, sensibilidad a estresores, y su amplitud de respuesta a estresores y sitios (Farris \& Van Hassel, 2007). Los organismos bioindicadores son sensibles a los cambios que en su medio se presenten y son capaces de ofrecer información sobre estos, mismos que se relacionan y traducen directamente en su estructura o fisiología. Esta capacidad dependerá entonces de factores genéticos, de su propio desarrollo y de las condiciones ambientales donde habite (CapóMartí, 2007).

El monitoreo de los efectos biológicos se pueden evaluar a través de diversos métodos como son bioensayos, biomarcadores en respuestas de poblaciones y comunidades (Stagg, 1998; U.S. EPA, 1996). Algunos trabajos enfatizan que los estudios en la biota integran las respuestas ambientales revelando la historia de los sistemas donde se desarrollan.

Los moluscos han sido ampliamente utilizados en estudios de monitoreo de la contaminación, debido a su naturaleza filtradora, su posición sésil en el ambiente y la organización de sus tejidos (Salazar \& Salazar, 1991). Estos organismos son de importancia tanto ecológica como económica, y allí radica la importancia de utilizarlos como bioindicadores.

Existen programas internacionales de biomonitoreo como "Mussel watch" (Goldberg \& Bertine, 2000), MEDPOL (Gabrieldes, 1997) OSPAR, BIOMAR (Banni et al., 2005; Narbonne et al., 2005) los cuales tienen como propósito la evaluación del riesgo ecológico a través de la extrapolación de datos químicos o el proponer el estudio de los efectos biológicos de los contaminantes a través del uso de biomarcadores (Dondero et al., 2006). Los biomarcadores o indicadores biológicos se definen como señales identificables evaluadas por cambios en fluidos corporales, células y tejidos, que proporcionan 
advertencias tempranas del daño provocado por agentes tóxicos o contaminantes (Koeman, 1991).

Los biomarcadores son respuestas biológicas de los organismos que han sido expuestos, o afectados por agentes xenobióticos. Las señales pueden incluir cambios bioquímicos, histológicos, morfológicos, fisiológicos, o de expresión genética (RNA y proteínas y pueden ser observadas en cualquier parte del organismo) (Ryan \& Hightwer, 1996).

En México los estudios de biomonitoreo están en la fase de desarrollo y se requiere generar información que ayude a la planeación y gestión ambiental (PRONAME, 2007). Así algunos sitios de importancia turística comercial y con riqueza biológica carecen de información básica que permita el buen manejo y control de calidad de sus productos, como es el caso de la "almeja chocolata" cuya explotación se desarrolla en Tecolutla, Veracruz.

Actualmente para el Golfo de México se tienen reportadas las almejas "gallito" (Rangia cuneata), "burra" ( $R$. flexuosa) y las especies Anadara baughmani y Mercenaria mercenaria (DOF, 2006). Sin embargo en el municipio de Tecolutla, Veracruz, se encuentra como parte de la fauna silvestre marina y se autoconsume, la coloquial y localmente conocida como "almeja chocolata", la cual representa una importante fuente de ingresos económicos y sin lugar a duda un recurso explotable a nivel comercial. Con este mismo nombre común se reconoce para el Pacifico Mexicano a la almeja Megapitaria squalida (Sowerby, 1835), para la cual se han reportado aspectos sobre su biología (Villalejo et al., 2000; Tanja et al., 2006; Vázquez et al., 2011;) y algunos estudios ecotoxicológicos (Garate-Lizárraga et al., 2004).

Comercialmente, en el Golfo de México son muy explotadas las especies del género Rangia y Polymesoda, siendo la especie Polymesoda californiana característica también 
del Golfo (García-Cubas \& Reguero, 2007) (Figura 1). Desafortunadamente los estudios en particular de este sistema (Tecolutla), son escasos o casi nulos, por lo que este estudio pretende contribuir al conocimiento biológico del estado de Veracruz.

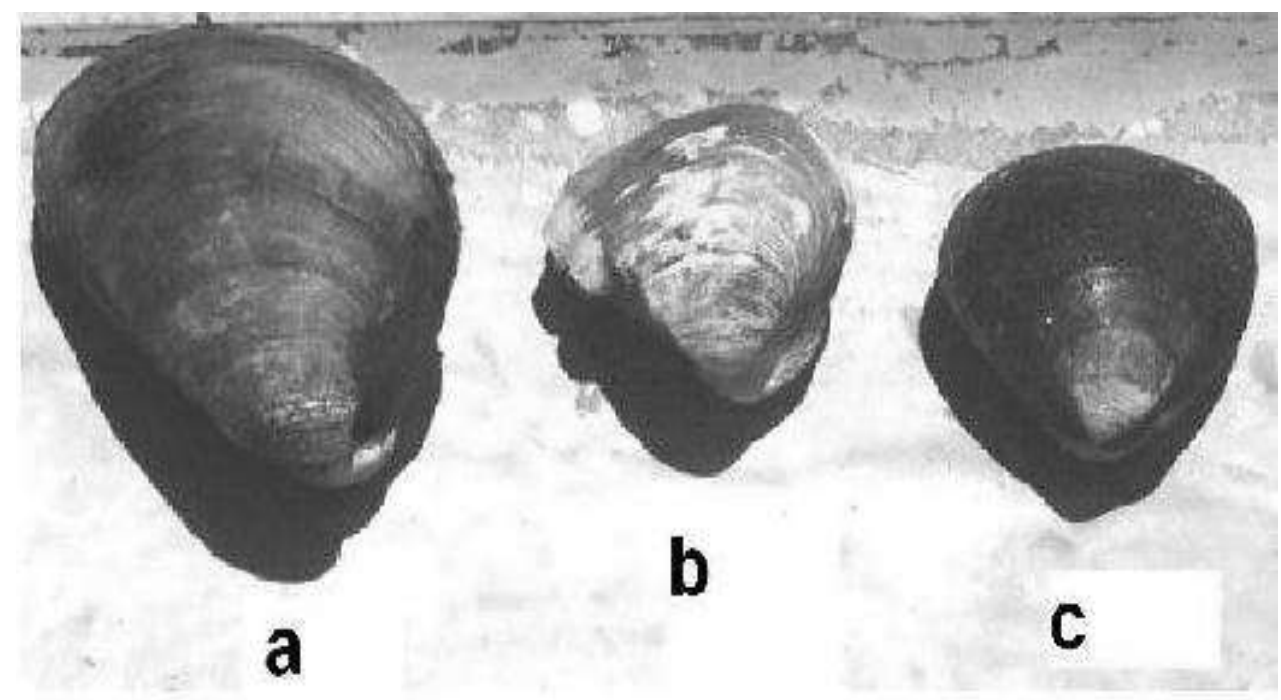

Figura 1. Almejas explotadas comercialmente en el Golfo de México. a) Almeja gallito, Rangia cuneata; b) Almeja casco o escudo, Rangia flexuosa y c) Almeja negra o prieta, Polymesoda caroliniana. Tomado de Wakida-Kusunoki \& MacKenzie Jr. (2004).

Desde la década de los años 1970, las herramientas de la biología molecular, particularmente las secuencias de genes mitocondriales, han permitido elucidar una gran cantidad de identidades genéticas en una gran variedad de taxa, por ejemplo, en pulpos (Barriga-Sosa et al., 1995), peces (Barriga-Sosa et al., 2005), crustáceos (Barriga-Sosa et al., 2010) y más recientemente con el objetivo de identificar a todos los taxa eucariontes y procariontes del planeta (CBOL, 2011). La aplicación de estas técnicas en especies de interés comercial y ecológico, facilita la realización de estudios que pretenden evaluar la riqueza, calidad y potencial comercial de las especies acuáticas.

La calidad de los organismos acuáticos está directamente relacionada con el crecimiento de estos y fundamentalmente con la composición del tejido, el valor nutritivo y las características comestibles de los alimentos marinos (Hernández-Sámano, 2010). Además de estas características, otras de tipo fisiológico y bioquímico, como las enzimas, refieren 
el uso de este tipo de molusco como candidato potencial para estudios ecotoxicológicos y de funcionalidad bioquímica para la evaluación de la calidad de los recursos naturales silvestres. Este trabajo en consecuencia, pretende utilizar técnicas moleculares, estudios de calidad y funcionalidad bioquímica a fin de establecer la identidad de la almeja chocolata de Tecolutla, Veracruz, así como determinar su composición parcial bioquímica y su estado de salud.

\section{Almejas.}

Las almejas son organismos que pertenecen al grupo de los moluscos (Phylum Mollusca), ubicadas dentro de la clase Bivalva por poseer dos conchas unidas mediante un ligamento y una serie de dientes que hacen las veces de cierre denominados charnela (Harrison, 1997). La masa visceral esta comprimida lateralmente, presenta un pie musculoso unido antero-ventralmente a la masa visceral, de ahí que también que se les conozca con el nombre de pelecípodos, "pie en forma de hacha" (Hickman et al., 2005).

El manto en su parte posterior está modificado en dos aberturas, una dorsal (sifón exhalante) y una ventral (sifón inhalante) por medio de los cuales circula el agua que baña las branquias. Precisamente por medio de las branquias estos organismos realizan el intercambio gaseoso, por lo que estas se encuentran modificadas dada su naturaleza filtradora y están formadas por varias láminas a modo de placas con muchos tubos verticales en el interior para la conducción del agua. Son organismos filtradores, que se alimentan de partículas que entran con el agua por medio de sus sifones (Figura 2) (Hickman et al., 2005).

Generalmente dioicos y con fecundación externa en la mayoría de los casos, aunque se ha reportado autofecundación en ciertas circunstancias (Lewbart, 2010). 


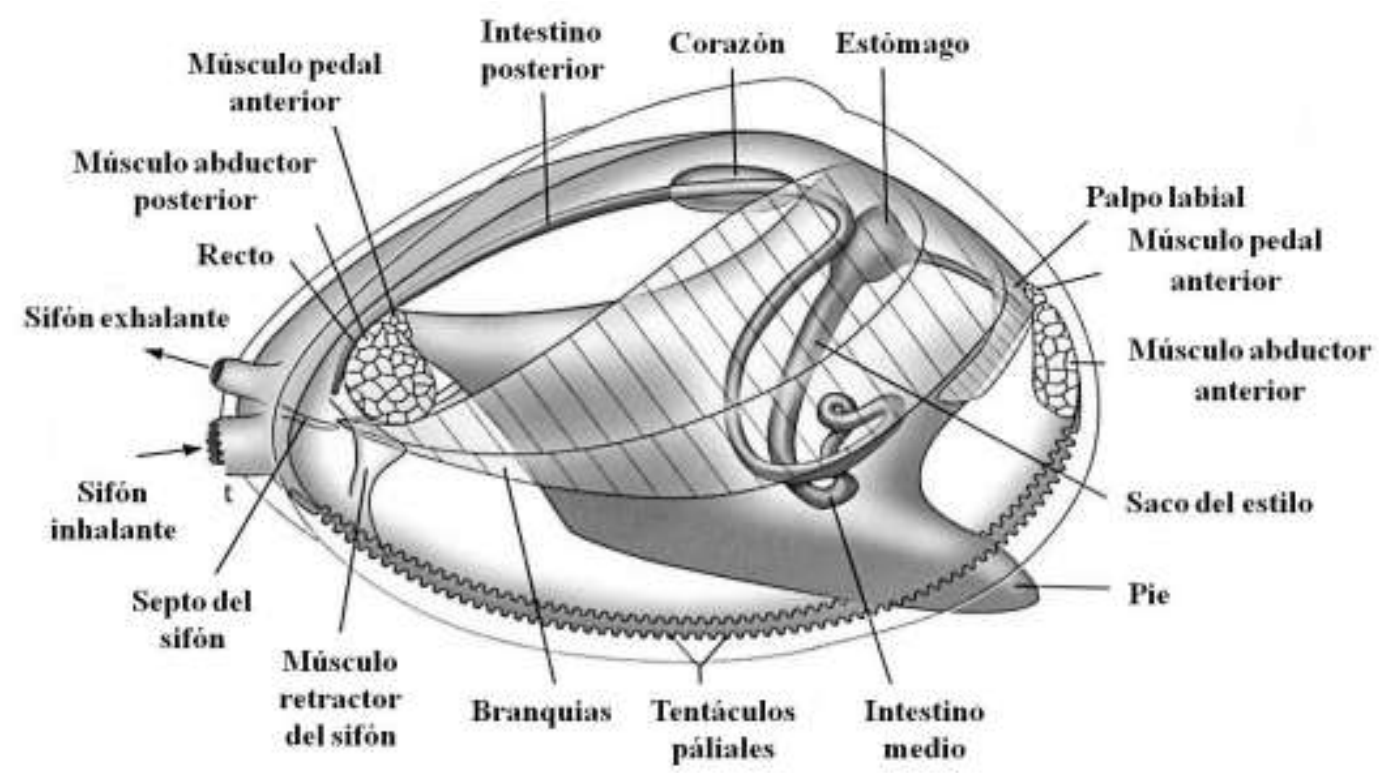

Figura 2. Esquema de un bivalvo, con la valva izquierda removidas. Tomado de Mikkelsen y Bieler (2007).

\section{Ecología y Distribución.}

Las almejas son organismos sésiles y filtradores sedentarios que dependen de las corrientes ciliares producidas por las branquias para capturar el alimento (Hickman et al., 2005).

La mayor parte de su vida la viven enterradas en el limo de la zona intermareal, lo que facilita su captura con fines de consumo humano (Wakida-Kusunoki \& MacKenzie Jr., 2004). Al estar desprovistas de mecanismos de protección; el enterrarse en el sedimento les confiere protección antes sus predadores naturales, como peces o cangrejos. Estudios recientes indican que las almejas detectan a sus predadores mediante señales químicas más que por señales hidrodinámicas (Delbert \& Weissburg, 2006). 


\section{Área de estudio.}

El área de estudio del presente trabajo se encuentra en el estado de Veracruz, México; en el municipio de Tecolutla, el cual colinda al norte con Papantla, al sur con los municipios de Martínez de la Torre y San Rafael, al oeste con Gutiérrez Zamora y al este con el Golfo de México. El área de estudio se ubica entre los paralelos $96^{\circ} 59^{\prime} 849^{\prime \prime} \mathrm{W}$ y $20^{\circ} 27^{\prime} 628^{\prime \prime} \mathrm{N}$. Tecolutla es una importante zona turística (la playa más cercana al Distrito Federal) del estado (Figura 3); conocida por sus playas tranquilas, fiestas populares y comida exótica. Es un lugar donde una parte de la población se dedica a la agricultura y otro tanto a la pesca. Sin embargo es una región para la cual existen escasos estudios en cuanto a su riqueza faunística y calidad del sistema.

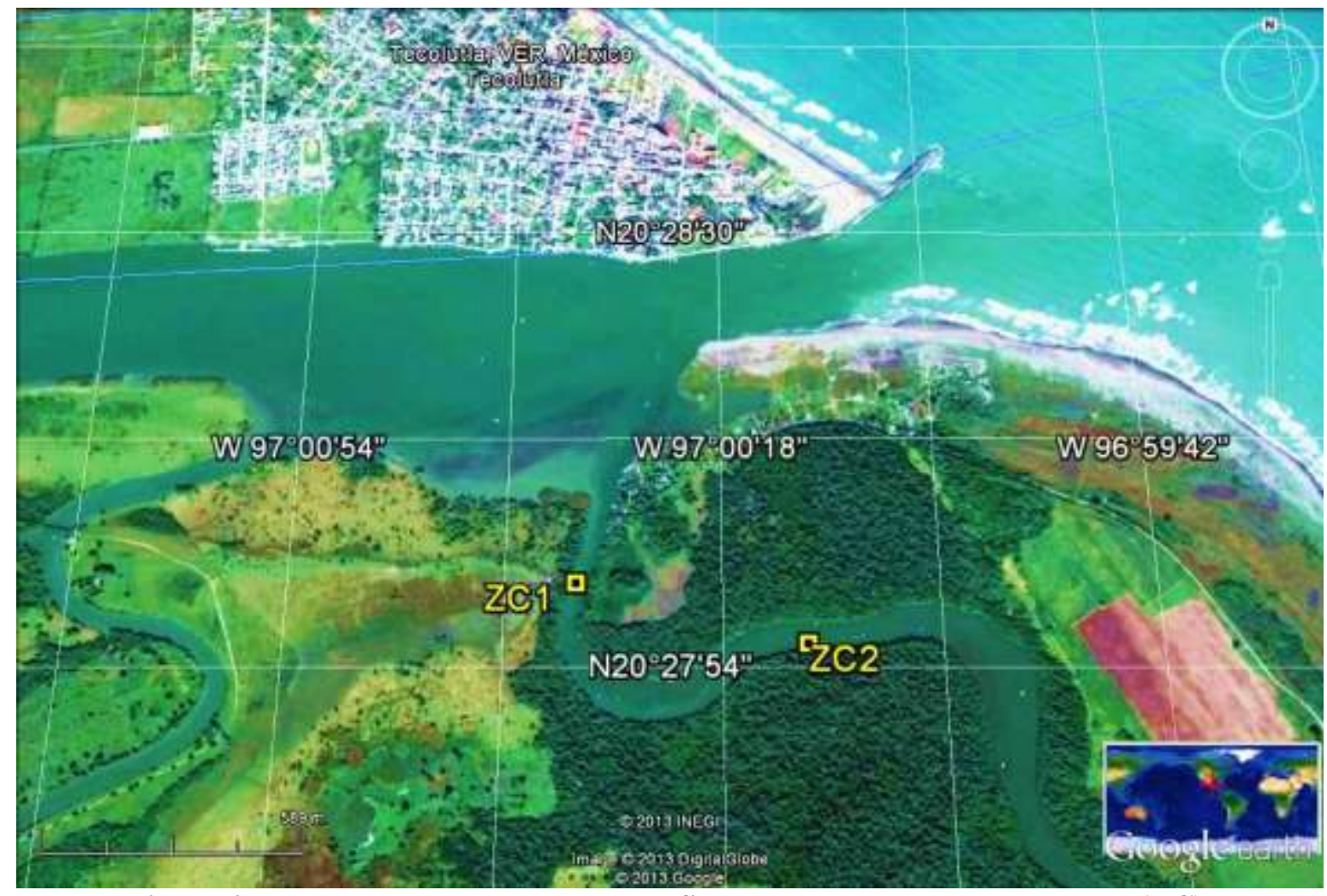

Figura 3. Mapa de Tecolutla Veracruz. Se muestran las zonas de colecta (ZC). 


\section{Pregunta de Investigación.}

¿Permitirán las pruebas genéticas, bioquímicas e histopatológicas determinar la ubicación taxonómica, el valor nutricional y el estado de salud de la almeja de Tecolutla, Ver.; con el fin de establecer su identidad genética, la calidad nutricional y su valor ecotoxicológico?

\section{Hipótesis.}

Si las pruebas aplicadas a la almeja de estudio permiten determinar la identidad genética, la calidad nutricional y su estado de salud, entonces se podrá establecer su posición taxonómica, el potencial nutricional y el valor ecotoxicológico. Sin embargo si las pruebas aplicadas a la almeja de estudio no permiten delimitar la identidad genética, la calidad nutricional y su estado de salud, entonces no se podrá establecer la posición taxonómica y la calidad nutricional así como su valor ecotoxicológico serán evidencia del potencial acuícola del recurso. 


\section{Objetivos.}

\section{General.}

Determinar la identidad taxonómica, la calidad nutricional y el estado de salud en la almeja de Tecolutla por medio de técnicas moleculares, análisis bioquímicos y biomarcadores tisulares, con el fin de establecer su posición taxonómica, calidad nutricional y valor ecotoxicológico.

\section{Particulares.}

- Registrar algunos parámetros fisicoquímicos del agua durante la colecta, como patrón de referencia del ambiente.

- Observar y registrar parámetros biológicos macroscópicos.

- Registrar parámetros morfométricos con el fin de evaluar el índice de condición.

- Elucidar por medio de claves taxonómicas y técnicas moleculares la identidad genética de la especie.

- Determinar la composición o patrones de funcionalidad bioquímica mediante el análisis de proteínas.

- Caracterizar y analizar la estructura tisular del manto, branquia y pie.

- Observar las respuestas tisulares para realizar un análisis histopatológico.

- Establecer el potencial de nutricional y valor ecotoxicológico de la almeja de Tecolutla por medio de un análisis de líneas de evidencia. 


\section{Materiales y Método.}

\section{Recolecta de Muestras.}

Los sitios de donde se extrajeron los organismos se denominaron Zona de Colecta 1 y Zona de Colecta 2 (en lo sucesivo: ZC1 y ZC2), la designación de estos nombres se hizo en función del proyecto interno aprobado por la UAM-I “Indicadores de Integridad Ecológica y Salud Ambiental", del cual forma parte el presente trabajo. Por otro lado, la selección de estas zonas se realizó considerando la disposición de bancos de almejas en el sistema y la distancia entre ellas (aprox. $8 \mathrm{~km}$ entre sí). Las colectas se realizaron en dos épocas climáticas características de Tecolutla, denominadas como lluvias (febrero 2012) y secas (mayo 2012).

El traslado desde el embarcadero hasta las zonas de colecta se realizó mediante una lancha de motor, delineándose un transecto en cada zona de $40 \mathrm{~m}$ aproximadamente, en el que se recolectaron los organismos de manera manual y aleatoria.

Se recolectaron 109 organismos para los diferentes análisis; así, en la época de lluvias se obtuvieron un total de 59 organismos, como sigue y de acuerdo a la técnica a realizar: 25 se canalizaron para la técnica histológica (15 de ZC1 y 10 de ZC2), 20 para el índice de condición (10 de cada zona), 4 para el análisis molecular (3 de ZC1 y 1 de ZC2) y 10 para la técnica de proteínas (5 organismos de cada zona). Mientras que en la época de secas se recolectaron 50 organismos: 30 para histología (15 de cada zona) y 20 para índice de condición (10 de cada zona).

\section{Parámetros Fisicoquímicos del Agua.}

En cada zona de colecta y como parte del proyecto del que forma parte este trabajo, el equipo de investigación tomó parámetros físicos y químicos del agua: temperatura, salinidad y oxígeno disuelto, con un multinanalizador marca HACH® modelo DR/2000s; 
además, se determinaron las coordenadas geográficas de cada zona de colecta utilizando un geoposicionador (GPS) marca GARMIN® COLORADO.

\section{Parámetros Biológicos.}

Se realizó una evaluación macroscópica de cada organismo recolectado considerando parámetros como: perforaciones en conchas, presencia de vermes y/o ectoparásitos, presencia de lo que pudieran ser hongos y/o bacterias, así como la percepción de malos olores en la masa visceral. El registro de cada parámetro se realizó en tablas estandarizadas dentro del área de Histopatología en el laboratorio de Ecotoxicología denominado "Datos biológicos de la muestra" (Anexo 1).

\section{Parámetros Morfométricos.}

Mediante un calibrador vernier marca CALIPER® de precisión $0.02 \mathrm{~mm}$, se tomó la longitud total, ancho y altura de los organismos y con una balanza marca OHAUS® modelo CT6000-S, se obtuvo el peso total, el peso de las valvas y el peso de la masa visceral; finalmente con una probeta de $20 \mathrm{~mL}$ se recuperó el volumen del líquido intervalvar de cada almeja.

\section{Índice de Condición.}

Para el cálculo del índice de condición (IC) se utilizaron los pesos secos de la masa visceral y de la concha. Para el cálculo de los pesos secos, se colocó cada parte mencionada en cajas petri de cristal previamente etiquetadas y pesadas en una balanza analítica marca OHAUS ${ }^{\circ}$ modelo AP110S y se registró el peso inicial. Todas las muestras se metieron en una estufa de secado marca FELISA ${ }^{\circledR}$ modelo 131 a una temperatura de $60^{\circ} \mathrm{C}$ durante 10 días hasta peso constante, y se registró el peso final. El cálculo del IC se realizó mediante la fórmula de Devenport \& Chen (1987): 


$$
I C=\frac{\text { Peso seco de la masa visceral }(g)}{\text { Peso seco de las conchas }(g)} x 100
$$

\section{Determinación Taxonómica de la Especie de Estudio.}

La identificación taxonómica de las almejas se realizó a partir de dos estrategias metodológicas: 1) a partir de caracteres morfológicos diagnóstico, utilizando la clave de Mille-Pagaza et al., (1993) apoyado con literatura específica de García-Cubas, (1981) y 2) a partir de un análisis molecular de los genes r16S (mitocondrial) y 28S (nuclear), como se describe a continuación:

\section{Análisis molecular.}

Para este análisis, de los cuatro organismos recolectados, se dispuso un lote de dos organismos, uno de cada zona de colecta de la época de lluvias. Cada organismo se preservó en alcohol al 96\% hasta su llegada y procesamiento en el Laboratorio de Genética y Biología Molecular de la Planta Experimental de Producción Acuícola (PExPA).

\section{Extracción de ADNt.}

Se extrajo el ADNt de los cuatro organismos recolectados y a partir de dos tejidos, branquia y manto. Una porción de aproximadamente $9.5 \mathrm{mg}$ de la branquia y $14.7 \mathrm{mg}$ del manto, fue utilizada para extraer el ADNt utilizando el protocolo DNEASY® Blood \& Tissue Kit de QIAGEN@ y siguiendo las recomendaciones del fabricante (Anexo 2). Los productos obtenidos se cuantificaron y cualificaron mediante un fluorómetro marca EPPENDORF® Bio Photometer, con el fin de determinar la cantidad y calidad del ADNt obtenido. Dichas extracciones; además, se visualizaron mediante procedimientos electroforéticos con geles de agarosa al 1.2\%. 
Amplificación del gen mitocondrial r16S y nuclear ribosomal 28S.

Para determinar las condiciones térmicas óptimas de amplificación de los dos genes se realizó un gradiente de temperatura y los siguientes ciclos: un ciclo inicial de 2 min a 94 ${ }^{\circ} \mathrm{C}, 30$ ciclos que comprende tres pasos (uno de desnaturalización a $94{ }^{\circ} \mathrm{C}$ por $45 \mathrm{~s}$, el gradiente térmico de anillamiento de $49.2{ }^{\circ} \mathrm{C}$ a $58.6{ }^{\circ} \mathrm{C}$ [para r16S] y de $57.5^{\circ} \mathrm{C}$ a $59.8^{\circ} \mathrm{C}$ [para 28S] por $45 \mathrm{~s}$, un paso final de extensión a $72{ }^{\circ} \mathrm{C}$ por $1: 30 \mathrm{~min}$ ), finalmente un último ciclo de $72{ }^{\circ} \mathrm{C}$ por 10 min. Cada reacción de PCR se realizó en un termociclador marca BIORAD ${ }^{\circledR}$ MyCycler. Las cantidades de reactivos se mantuvieron estándar para las pruebas realizadas con los dos genes: $2 \mu \mathrm{l}$ de $25 \mathrm{mM} \mathrm{MgCl}_{2}$ (PROMEGA®), $1 \mu \mathrm{l}$ de 10mM dNTP's (PROMEGA ${ }^{\circledR}$ ), $5 \mu \mathrm{l}$ de buffer 5X (PROMEGA ${ }^{\circledR}$ ), $1 \mu \mathrm{l}$ de $10 \mu \mathrm{M}$ cada primer (16S “16sar", 5'-CCGGTCTGAACTCAGATCACGT-3', “16sbr” 5'CGCCTGTTTATCAAAAACAT-3' (Simon et al., 1991); o 28S “bvLSUDlf”, 5'GGGTGGTAAACTCCAYCTAARGC-3' CTRCGGACCTCCATCAGAGTTTCC-3' (Hosoi et al., 2004)), $0.15 \mu l$ de Taq polimerasa $5 \mathrm{U} / \mu \mathrm{l}\left(\mathrm{PROMEGA}{ }^{\circledR}\right)$, de 1 a $3 \mu \mathrm{l}$ de $\mathrm{ADN}$ (estas porciones se agregaron en función de la concentración y la intensidad de la banda obtenida durante la extracción) y se aforó con agua bidestilada a un volumen final de $25 \mu 1 /$ reacción. Posteriormente se comprobaron, visualizaron y fotodocumentaron los resultados de las amplificaciones mediante electroforesis en geles de agarosa al 1.2\% en TBE (Tris + Ácido Bórico + EDTA 0.5\% PROMEGA®) con un tiempo de corrimiento de 45 minutos a $95 \mathrm{~V}$ (fuente de poder marca THERMO® EC 135-90), y con el fotodocumentador marca SYNGENE® Bio Imagen System; utilizando además, el software Gene Snap de SYNGENE® para el análisis y edición de las imágenes obtenidas. Finalmente se imprimieron los resultados positivos en una impresora marca SONY® modelo UP-D89T. 


\section{Purificación de genes amplificados.}

Para el gen r16S, el producto obtenido de la reacción de PCR se purificó utilizando el protocolo WIZARD® SV Gel and PCR Clean-Up System de PROMEGA® con la única modificación de los dos últimos pasos: elución (30 $\mu 1$ de agua libre de nucleasas) y tiempo de incubación (10 minutos a temperatura ambiente) (Anexo 3). Finalmente se envió a secuenciar al Laboratorio Divisional de Biología Molecular de la UAM-I. Mientras que para $28 \mathrm{~S}$ el protocolo utilizado fue QIAQUICK® PCR Purification Kit de QIAGEN® siguiendo las recomendaciones del fabricante para purificación vía bandas de PCR (Anexo 4).

\section{Reacción de secuenciación y purificación.}

La reacción de secuenciación de ambos genes amplificados y para las dos hebras monocatenarias se realizó con las siguientes condiciones: $1 \mu \mathrm{l}$ de cada primer utilizado en la reacción de PCR (según el gen), $2 \mu 1$ de buffer 2.5 x, $2 \mu 1$ de Dye (BIG DYE®, Applied Biosystems), de 3.5 a $4 \mu 1$ del producto purificado (cantidad que depende de la calidad del purificado) y se aforó con agua bidestilada hasta $10 \mu \mathrm{l} /$ reacción. Cada reacción se procesó en un termociclador marca $\mathrm{BIORAD}{ }^{\circledR}$ MyCycler con las siguientes condiciones térmicas: 25 ciclos de tres pasos, uno a $96{ }^{\circ} \mathrm{C}$ por 10 segundos, posteriormente un paso que utiliza la temperatura de anillamiento de cada gen (descrita anteriormente) por un tiempo de 5 segundos, un tercer paso a $60{ }^{\circ} \mathrm{C}$ por 4 minutos, finalmente un último ciclo a $4{ }^{\circ} \mathrm{C}$ para mantener la muestra por el tiempo indeterminado.

La purificación de la reacción obtenida se realizó utilizando el protocolo QIAQUICK® PCR Purification Kit de QIAGEN®. Finalmente se enviaron los productos amplificados a secuenciar al Laboratorio Divisional de Biología Molecular de la UAM-I, donde fueron 
procesadas directamente por medio del secuenciador automático ABI PRISM® Modelo 3100 Avant.

\section{Edición de secuencias y determinación de identidad genética.}

Las secuencias obtenidas se verificaron a partir de un análisis de BLASTN (Basic Local Alignment Search Tool, por sus siglas en inglés) (Altschul et al., 1990) en el banco de datos National Center for Biotechnology Information NCBI GenBank. Las secuencias verificadas se alinearon a partir del análisis Clustal W implementado por el programa MEGA® 5.10 (Tamura et al., 2011).

La determinación de la identidad genética de la especie de estudio se realizó a partir de un análisis de inferencia filogenética utilizando secuencias de regiones homólogas de representantes de las familias Mactridae, Veneridae y Corbiculidae (Anexo 5). Las inferencias filogenéticas se realizaron a partir de dos métodos de aproximación: 1) parsimonia y 2) probabilísticos. Para la primera aproximación se utilizó el análisis de Máxima Parsimonia, mientras que para el segundo se utilizó el análisis de Máxima Verosimilitud.

Para el análisis de máxima parsimonia, los árboles de máxima parsimonia (MP) fueron construidos con la opción de búsqueda heurística, utilizando la optimización ACCTRAN (Accelerated Character Transformation), caracteres sin ordenar y con igual peso y las inserciones-deleciones fueron tratadas como datos ausentes y quinta base. El programa Modeltest 3.7 fue utilizado para encontrar el modelo evolutivo de sustitución de nucleótidos que más se ajustó a los datos en el análisis de Máxima Verosimilitud (HKY85, Hasegawa et al., 1985), tratando a las inserciones-deleciones como datos ausentes. El modelo fue seleccionado utilizando dos criterios: la prueba de la razón de verosimilitud (LRT) y el criterio de información de Akaike como está implementado en el programa 
Modeltest 3.7 con un nivel de significancia de 0.01. Cuando el modelo evolutivo fue encontrado se estimaron parámetros como: distribución gamma, proporción de sitios invariables y frecuencia y proporción de bases. Con los modelos evolutivos estimados se corrieron posteriormente análisis bayesianos donde se corrieron 5 cadenas de Monte Carlo, muestreando 1 árbol cada 1000 generaciones para un total de 5 millones de generaciones.

Se evaluó la estabilidad de las ramas internas en los cladogramas mediante análisis de bootstrap (Felsenstein, 1985) implementados en PAUP. Se realizaron 1000 réplicas en los análisis de Máxima Parsimonia y 100 en Máxima Verosimilitud.

\section{Análisis Bioquímico.}

Este análisis consistió en dos partes: la primera parte se llevó a cabo para la identificación y caracterización parcial de proteínas de la almeja y en la posible actividad proteolítica de extractos proteícos de las branquias. En la segunda parte se analizó el contenido proteíco de los órganos estudiados.

\section{Identificación y caracterización parcial de proteínas de almeja.}

Con el fin de tener un marco comparativo esta técnica se estandarizó previamente con una almeja adquirida en un establecimiento comercial (aparentemente "almeja chocolata"), analizando manto, branquia y pie. Posteriormente se utilizaron las almejas colectadas en la estación de lluvias para las dos zonas de colecta empleando los mismos tejidos que en la almeja comercial.

\section{Obtención de extracto enzimático crudo.}

El extracto proteolítico se obtuvo pesando cada tejido en una báscula marca CITIZEN® scale modelo CG 2202, este se mezcló con amortiguador de fosfatos a $20 \mathrm{mM} \mathrm{y} \mathrm{pH} \mathrm{7,} \mathrm{en}$ una proporción 1:2 (Anexo 6 a). Se homogenizaron las muestras en un homogenizador 
marca BIOSPEC $®$ modelo 9611. El homogenizado se centrifugó a 12,000 rpm a $4{ }^{\circ} \mathrm{C}$ durante 15 minutos en una centrífuga marca BEACKMAN®, el sobrenadante conteniendo las proteínas solubles se filtró y se mantuvo en refrigeración $\left(4{ }^{\circ} \mathrm{C}\right)$ durante todo el procesamiento.

\section{Determinación de la concentración de proteína.}

La concentración de proteína fue determinada a través del método de biuret (Battaner, 1993), (Anexo 6 b) utilizando albúmina de huevo como estándar. Se mezclaron $250 \mu 1$ del extracto y $750 \mu \mathrm{l}$ del reactivo de biuret, cubriéndose de la luz por un periodo de 20 minutos y se leyó la absorbancia a $540 \mathrm{~nm}$ en un espectrofotómetro marca BEAKMAN® modelo DU 650. Esta lectura de absorbancia se interpoló en una curva estándar previamente construida, obteniendo el contenido proteíco. La ecuación de la curva fue: $\mathrm{x}=(\mathrm{y}-$ 0.0025)/0.0571, obtenida de la curva realizada (Figura 4).

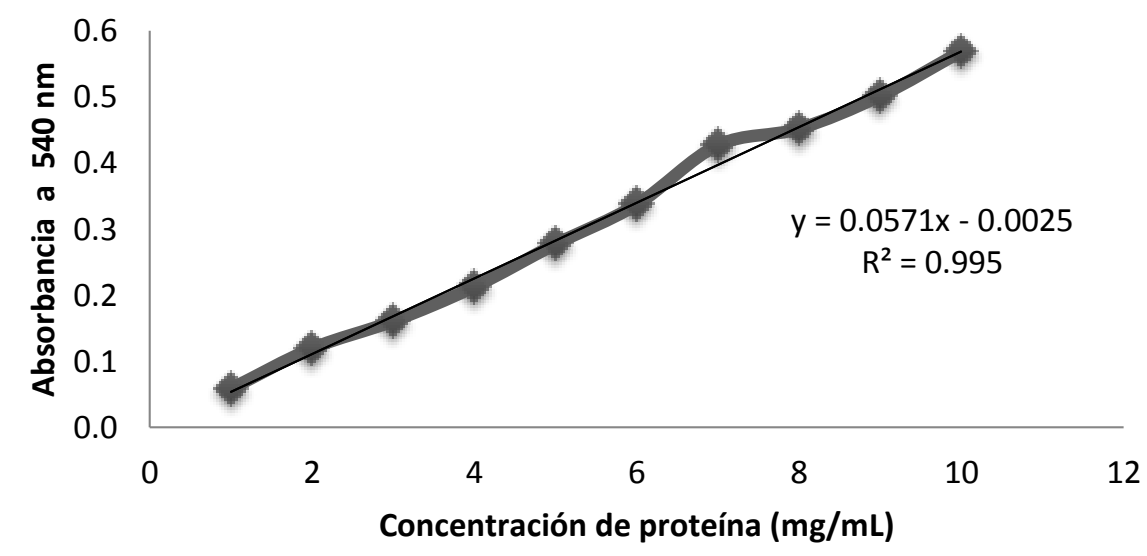

Figura 4. Curva patrón de concentración de proteína.

\section{Ensayo de actividad proteolítica a diferente pH y temperatura.}

La actividad proteolítica fue analizada mediante la hidrólisis de hemoglobina $1 \%(\mathrm{p} / \mathrm{v})$ y caseína $1 \%$ (p/v) por los métodos de Anson (1938) y Kunitz (1946), respectivamente. Se preparó caseína al $1 \%(\mathrm{p} / \mathrm{v})$ en amortiguador de fosfatos $20 \mathrm{mM}, \mathrm{pH}$ 7, y se ajustó a pH de 6 a 10. La hemoglobina fue preparada en una solución de ácido bórico 0.025 M, ácido 
fosfórico $0.025 \mathrm{M}$ y ácido acético $0.25 \mathrm{M}$ y se ajustó a pH de 2 a 5 . El estudio se realizó para los tres tejidos a $\mathrm{pH} 7$ y $37{ }^{\circ} \mathrm{C}$ y se seleccionó el órgano con mayor actividad significativa $(\mathrm{p}<0.001)$ (branquia) para los estudios posteriores de actividad proteolítica a diferente $\mathrm{pH}$ y temperatura para determinar las condiciones óptimas. En cada parámetro el procedimiento fue similar, se dispuso de $250 \mu \mathrm{l}$ del sustrato (hemoglobina o caseína) y 80 $\mu \mathrm{l}$ del extracto. En el caso de la actividad a diferente $\mathrm{pH}$, las muestras se colocaron en un baño a $37{ }^{\circ} \mathrm{C}$ durante 10 minutos; mientras que para las reacciones destinadas a calcular la actividad a diferente temperatura, el tiempo de reacción fue el mismo, cambiando solo la temperatura de reacción $\left(0,10,20,30,40,50,60,70,80\right.$ y $\left.90{ }^{\circ} \mathrm{C}\right)$ y utilizando el sustrato al pH óptimo determinado. Transcurrido ese tiempo, se detuvo la reacción con $175 \mu \mathrm{l}$ de TCA 20\% (Ácido Tricloro Acético) y se centrifugaron a 12, $000 \mathrm{rpm}$ en una centrífuga marca SORVALL® MC12C por 15 minutos. Finalmente se leyeron las absorbancias a 280 nm en un espectrofotómetro marca BEAKMAN® DU 650. El cálculo de la actividad se realizó mediante la ecuación de Yamaguchi et al., (1983):

$$
U=\frac{A b s x F D}{0.001 x(m l \text { del extracto }) x T R}
$$

Donde:

$\mathrm{U}=$ Unidades de actividad proteolítica.

Abs $=$ Absorbancia a $280 \mathrm{~nm}$.

$\mathrm{FD}=$ Factor de dilución.

$\mathrm{TR}=$ Tiempo de reacción en minutos.

Donde una unidad de actividad proteolítica se define como el incremento en la absorbancia en 0.01 a $280 \mathrm{~nm}$. Los resultados se reportaron como actividad específica (U/mg proteína).

\section{Análisis electroforético.}

Los extractos proteolíticos se evaluaron mediante procedimientos electroforéticos con geles de poliacrilamida con dodecil sulfato de sodio (SDS-PAGE) de acuerdo al método de 
(García-Pérez, 2000). Se prepararon geles discontinuos al 12\% de acrilamida (gel de separación y gel de concentración) (Anexo 6 c). Para la corrida de las muestras, se utilizó un sistema de electroforesis vertical marca BIORAD®. Para la colocación de las muestras en el gel, estas se sometieron a un tratamiento previo que consistió en sumergir cada una de ellas en agua en ebullición durante 1 minuto. El análisis se llevó a cabo con las siguientes condiciones: voltaje constante de 200 V, 500 mA y temperatura ambiente. Para conocer el peso molecular de las proteínas resultantes, se utilizó un marcador de peso molecular estándar marca AMRESCO® tipo K973 de 200 kDa a 9 kDa (miosina 200 kDa, $\beta$-galactosidasa $112 \mathrm{kDa}$, suero de albumina $91 \mathrm{kDa}$, glutamato $62 \mathrm{kDa}$, ovoalbúmina 46 kDa, anhidrasa carbónica $38 \mathrm{kDa}$, mioglobina $26 \mathrm{kDa}$, lisosima 19 kDa y aprotina 9 kDa). Los geles electroforéticos fueron teñidos con una solución de azul de Coomassie R-250 al $0.1 \%$, metanol al $10 \%$ y ácido acético $40 \%$ y desteñidos con una solución de metanol $40 \%$ y ácido acético $10 \%$.

Finalmente se realizó una electroforesis en un gel de poliacrilamida (PAGE) en condiciones no desnaturalizantes bajo las siguientes condiciones $200 \mathrm{~V}, 15 \mathrm{~mA}$ por gel y temperatura ambiente. Posteriormente se sumergieron los geles en caseína $2 \%$ y se mantuvieron en refrigeración $\left(4{ }^{\circ} \mathrm{C}\right)$ durante 2 hs; transcurrido ese tiempo se pasaron los geles a una incubadora marca CRAFT ${ }^{\circledR}$ por 2 horas a $43{ }^{\circ} \mathrm{C}$. Se hicieron lavados con agua destilada para eliminar el exceso de caseína y se tiñeron durante una 1 h. con la solución teñidora ya descrita. Se destiñeron hasta que las zonas bioactivas fueron visibles. Cada gel se escaneó con un escáner marca EPSON® Scan modelo CX5600, para el análisis de la imagen. El análisis electroforético incluyó la revisión de los densitogramas obtenidos a partir del cálculo del Rf y la intensidad de las bandas obtenidas. 


\section{Análisis estadístico.}

Todos los análisis se llevaron a cabo por triplicado, los datos se sujetaron a análisis de varianza y comparación múltiple de medidas de Duncan empleando un programa NCSS2001 \& PASS Trial.

\section{Determinación del contenido proteíco por el método de Kjeldahl.}

\section{Digestión.}

Este procedimiento se realizó por triplicado para cada órgano y una muestra testigo. Se tomó el órgano completo de cada organismo dado el peso (pie $=0.5 \mathrm{~g}$, branquia $=0.3 \mathrm{~g}$ y manto $=0.3 \mathrm{~g}$ ). Cada órgano se envolvió en papel filtro (peso conocido) y se colocó dentro de matraces Kjeldahl, se adicionaron $0.8 \mathrm{~g}$ de mezcla catalítica (sulfato de potasio y sulfato de cobre) y $5 \mathrm{~mL}$ de ácido sulfúrico concentrado. Los matraces se colocaron de forma inclinada en un digestor Micro-Kjeldahl marca LABCONCO® modelo 60011 y se comenzó el calentamiento de manera gradual hasta alcanzar el nivel máximo de temperatura del digestor (Nivel 8 de 8). Se giraron constantemente hasta que el contenido digerido cambio de color de negro a verde y se dejaron enfriar completamente antes de continuar.

\section{Destilación.}

Para este procedimiento se utilizó un destilador marca LABCONCO® modelo 246400. Por la parte superior del destilador se vertió la muestra enjuagando con un poco de agua destilada del matraz de Kjeldahl. Por otro lado el tubo de salida del destilador se sumergió en un matraz de $100 \mathrm{~mL}$ que contenía $20 \mathrm{~mL}$ de ácido bórico al $4 \%$ y 4 gotas de la mezcla de indicadores (solución alcohólica de rojo de metilo al $0.1 \%$ con solución alcohólica de verde de bromocresol al $0.1 \%$ ). Para hacer comenzar la reacción se agregaron $10 \mathrm{~mL}$ de 
hidróxido de sodio al $40 \%$ después de colocar la muestra. Se dejaron en ebullición hasta recuperar $40 \mathrm{ml}$ de la destilación.

\section{Reacción de titulación.}

Cada muestra se tituló con ácido clorhídrico $0.1 \mathrm{~N}$ hasta que viró el indicador (rosa pálido).

Calculo del porcentaje de nitrógeno y porcentaje proteína cruda.

Para el cálculo del porcentaje de nitrógeno se siguió la siguiente fórmula:

$$
\% N=\frac{(m l \mathrm{HCl})(\mathrm{N} \mathrm{HCl})(1.4)}{\text { peso de la muestra }}
$$

Donde:

$\mathrm{mL} \mathrm{HCL}=$ mililitros de $\mathrm{HCl}$ gastados durante la titulación.

$\mathrm{N} \mathrm{HCL}=$ normalidad del $\mathrm{HCl}$.

1.4= peso atómico del nitrógeno dividido en 10 para expresar en porcentaje.

Se obtuvo el contenido de proteína cruda multiplicar el contenido de nitrógeno obtenido en el análisis (en porcentaje) por el factor de 6. Se calculó también el porcentaje de humedad y de materia seca de cada órgano mediante las siguientes fórmulas:

$$
\begin{aligned}
& \% \text { Humedad }=\frac{P S(g)}{P M(g)} X 100 \\
& \% M S=100-\% \text { Humedad } .
\end{aligned}
$$

Donde:

$\mathrm{PS}=$ Peso seco de la muestra.

$\mathrm{PM}=$ Peso de la muestra.

$\% \mathrm{MS}=$ Porcentaje de materia seca. 


\section{Análisis Tisular.}

\section{Disección y fijación.}

Los 55 organismos destinados al análisis histopatológico fueron disectados en tres partes proporcionales respecto a su eje de simetría (anterior, media y posterior), llegando incluso a cortar en algunos casos hasta 5 partes proporcionales de su cuerpo dada la extensión que impedía su colocación de manera adecuada en los cassettes histológicos marca SIMPORT ${ }^{\circledR}$ modelo Histossete I. Cada proporción cortada se dispuso en un cassette histológico orientando el tejido hacia un corte transversal. Los tejidos ya en los cassettes, fueron fijados en formol amortiguado al $10 \%$ por un periodo de 48 hs. para tejidos blandos (una gran proporción del cuerpo); sin embargo para los músculos aductores las muestras se dejaron fijar durante un mes dada la consistencia de dichos tejidos.

\section{Deshidratación, infiltración y aclarado de los tejidos.}

Transcurrido ese tiempo se deshidrataron, aclararon e infiltraron por un periodo de $18 \mathrm{hs}$. en programa estándar para moluscos bivalvos en un procesador de tejidos marca LEICA® modelo TP1020 (Anexo 7).

\section{Inclusión.}

Los tejidos ya deshidratados e infiltrados se incluyeron en un medio de parafina marca PARAPLAST® de Leica Microsystems, mediante un centro de inclusión marca LEICA® modelo EG1140-H dejándose solidificar en una placa enfriadora marca LEICA® modelo EG1140-C.

\section{Corte y tinción.}

Los tejidos se cortaron a un nivel de 5 micras con dos réplicas cada uno mediante un micrótomo rotatorio marca MICROM® modelo HM3156, haciendo especial énfasis en el 
manto, branquia y pie de cada organismo. Una vez recuperados los tejidos en los portaobjetos, éstos se colocaron en una estufa de secado marca FELISA® modelo 131 a $60^{\circ} \mathrm{C}$ durante $1 \mathrm{~h}$. Cada tejido fue teñido mediante la técnica de hematoxilina-eosina por tiempos ya estandarizados (Anexo 8). Para cubrir los tejidos se utilizó una solución a base de xilol y resina sintética de montaje marca GOLDEN BELL® al 50\% dejándose secar en una estufa FELISA® modelo 131 por un periodo de $24 \mathrm{hs}$.

\section{Análisis Histopatológico.}

Cada laminilla obtenida del proceso histológico se observó con un microscopio óptico marca CARL ZEISS® Primo Star acoplado a una cámara marca CANON® modelo Power Shot G10 y a un ordenador marca TOSHIBA® modelo Satellite, tomándose fotografías de las regiones objetivo mediante el software CANON® Utilities Remote Capture DC versión 3.1.0.5 (2008). Las fotomicrografías obtenidas se editaron mediante el software CARL ZEISS® AxiVs 40V versión 4.8.0.0 (2006-2009) y se procedió a realizar el análisis.

El análisis histopatológico se realizó mediante la construcción de una matriz de prevalencia de lesiones encontradas en cada uno de los órganos estudiados, posteriormente se calculó el porcentaje de prevalencia de cada una por zona y por época de colecta.

\section{Análisis de Evidencias.}

A partir de los resultados del análisis histopatológico y las pruebas bioquímicas realizadas a la almeja, se construyeron dos tablas de evidencias. La primera concentró las respuestas tisulares observadas en la almeja, a las cuales se les asoció un factor de importancia de acuerdo a Bernet et al., (1999). La tabla de evidencias de los análisis bioquímicos consideró los valores obtenidos para cada órgano y se compararon entre ellos. Cada parámetro se asoció con valores analogos al factor de importancia. 


\section{Resultados.}

\section{Parámetros Fisicoquímicos del Agua.}

En la Tabla 1 se resumen los parámetros fisicoquímicos del agua obtenidos para las dos épocas muestreadas (secas y lluvias). Al analizar dicha tabla es muy claro observar que las diferencias entre cada uno de los parámetros es mínima, esto sugiere que las condiciones del sistema se mantienen estables durante ambas épocas; además, de acuerdo a estos parámetros, la salinidad obtenida es típica de sistemas de agua salobre, mientras que el oxígeno disuelto y $\mathrm{pH}$ coinciden con ambientes de tipo eurihalinos.

\begin{tabular}{|c|c|c|c|c|}
\hline \multirow{3}{*}{ Parámetro } & \multicolumn{2}{|c|}{ Lluvias (febrero) } & \multicolumn{2}{|c|}{ Secas (mayo) } \\
\hline & $\mathrm{ZC} 1$ & $\mathrm{ZC} 2$ & ZC 1 & $\mathrm{ZC} 2$ \\
\hline & N $20^{\circ} 27^{\prime} 41.6^{\prime \prime}$ & N $20^{\circ} 28^{\prime} 6.2^{\prime \prime}$ & N $20^{\circ} 27^{\prime} 41.6^{\prime \prime}$ & N $20^{\circ} 28^{\prime} 2.4^{\prime \prime}$ \\
\hline Geoposición & O 96 $59^{\prime \prime} 54.9^{\prime \prime}$ & $\mathrm{O} 97^{\circ} 0^{\prime} 29.2^{\prime}$ & O $96^{\circ} 59^{\prime \prime} 54.9^{\prime \prime}$ & $\mathrm{O} 97^{\circ} 0^{\prime} 28.2^{\prime \prime}$ \\
\hline $\begin{array}{c}\text { Oxígeno } \\
\text { disuelto }(\mathrm{mg} / \mathrm{L})\end{array}$ & 5.4 & 6.6 & 5.4 & 6.6 \\
\hline pH & 7.7 & 7.8 & 7.7 & 7.8 \\
\hline Salinidad $\% / 00$ & 0.7 & 0.9 & 0.7 & 0.9 \\
\hline $\begin{array}{c}\text { Temperatura } \\
\left({ }^{\circ} \mathrm{C}\right)\end{array}$ & 22.3 & 19.8 & 22.3 & 19.3 \\
\hline
\end{tabular}

\section{Parámetros Biológicos.}

El conteo de los parámetros biológicos evidenció la presencia de cuatro organismos asociados de tipo vermes y en dos fue positiva la presencia de organismos asociados, principalmente cirrípedos, en la época de lluvias. Este número representa el $13 \%$ de organismos con algún parámetro biológico, respecto al lote sometido al análisis histológico e índice de condición. Por otro lado, en la época de secas se encontraron 12 organismos asociados de tipo gusanos poliquetos y cuatro con presencia de lo que se presume pueda ser algún tipo de hongo y/ o bacteria en las conchas, evidenciado por el aspecto de manchas verdosas en las mismas. De acuerdo al número total de organismos para histología e índice de condición para esta época, el número de organismos con presencia de 
algún parámetro de este tipo fue igual al 32\% (Figura 5). Fue evidente el aumento de organismos asociados a algún parámetro biológico en la época de secas respecto a la época de lluvias.

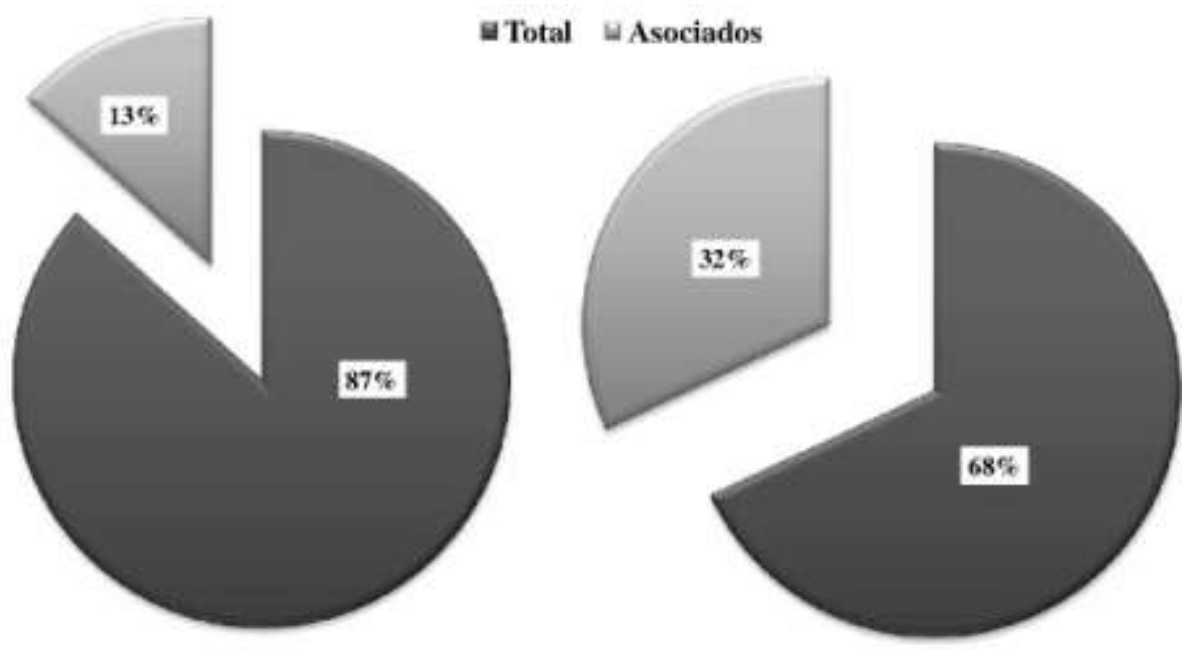

Figura 5. Porcentaje de organismos asociados (en gris) encontrados para la época de lluvias (derecha) y secas (izquierda) a partir del total de organismos analizados (en negro).

\section{Parámetros Morfométricos.}

Las almejas colectadas en la época de lluvias presentaron promedios de longitud que van de 54.5 a $55.2 \mathrm{~mm}$, de 32.1 a $49.5 \mathrm{~mm}$ de alto, de 48.3 a $38.5 \mathrm{~mm}$ de ancho y un peso que osciló entre los 53.9 y 46.6 g, para las zonas de colecta 1 y 2 respectivamente. Mientras que para la época de secas la longitud fue desde 55.1 a $54.3 \mathrm{~mm}$, la altura osciló de 32.9 a $31.2 \mathrm{~mm}$, el ancho de 49.7 a $46.7 \mathrm{~mm}$ y el peso que presentaron estas almejas estuvo entre 53.07 y 49 g, para la zona de colecta 1 y 2 respectivamente. Los resultados obtenidos del análisis estadístico demostraron que las almejas son significativamente diferentes en ancho y alto, mientras que no presentan diferencias ni en longitud ni en peso. Esto resultado se presentó tanto en zonas de colecta por época, como entre épocas (Tabla 2). 


\begin{tabular}{|c|c|c|c|c|}
\hline Parámetros & Lluvias & Secas & $\begin{array}{c}\text { Promedio } \\
\text { general }\end{array}$ & $\begin{array}{c}\text { Estadística } \\
\alpha=0.05\end{array}$ \\
\hline Longitud (mm) & 54.8 & 54.7 & 54.7 & $\begin{array}{c}\text { No hay } \\
\text { diferencias } \\
\left(t^{\prime}=0.1086 ;\right. \\
P=0.914158)\end{array}$ \\
\hline Altura (mm) & 40.8 & 32 & 36.4 & $\begin{array}{c}\text { Diferencias } \\
\text { significativas. } \\
\left(\mathrm{t}^{\prime}=3.3855 ;\right. \\
\mathrm{P}=0.002315)\end{array}$ \\
\hline $\operatorname{Ancho}(\mathbf{m m})$ & 43.4 & 48.2 & 45.8 & $\begin{array}{c}\text { Diferencias } \\
\text { significativas. } \\
(\mathrm{U}=2.1309 ; \\
\mathrm{P}=0.033096)\end{array}$ \\
\hline Peso total (g) & 50.2 & 51 & 50.6 & $\begin{array}{c}\text { No hay } \\
\text { diferencias. } \\
\left(t^{\prime}=0.0243 ;\right. \\
P=0.980767)\end{array}$ \\
\hline $\begin{array}{l}\text { Peso masa } \\
\text { visceral }(\mathrm{g})\end{array}$ & 6.2 & 10.3 & 8.2 & $\begin{array}{c}\text { Diferencias } \\
\text { significativas. } \\
\quad(\mathrm{t}=73299 ; \\
\mathrm{P}=0.00001)\end{array}$ \\
\hline $\begin{array}{c}\text { Volumen } \\
\text { intervalvar }(\mathbf{m l})\end{array}$ & 10.2 & 9 & 9.6 & $\begin{array}{c}\text { No hay } \\
\text { diferencias. } \\
\left(t^{\prime}=1.6938 ;\right. \\
P=0.098521)\end{array}$ \\
\hline
\end{tabular}

\section{Índice de Condición.}

En la Figura 6 se muestran los valores obtenidos a partir de la fórmula de Devenport \& Chen (1987). Los resultados evidenciaron valores de IC mayores para la ZC2 en ambas épocas (lluvias=2.6 y secas=3.4). Mientras que la ZC1 presentó los valores más bajos (lluvias $=2.3$ y secas $=2.8$ ). De acuerdo a los rangos establecidos por Devenport $\&$ Chen (1987), todos los valores de IC obtenidos para las almejas recolectadas consideran como "moderados" $(\leq 2.0=$ delgado; $2.0-4.0=$ moderado $\mathrm{y} \geq 4=$ robusto $)$. Al comparar las zonas de colecta de cada época climática, estas no mostraron ser diferentes entre épocas: lluvias $(\mathrm{t}=-0.9332 ; \mathrm{P}=0.3630 ; \alpha=0.05) ; \mathrm{y} \operatorname{secas}(\mathrm{t}=-1.7803 ; \mathrm{P}=0.0919 ; \alpha=0.05)$. 


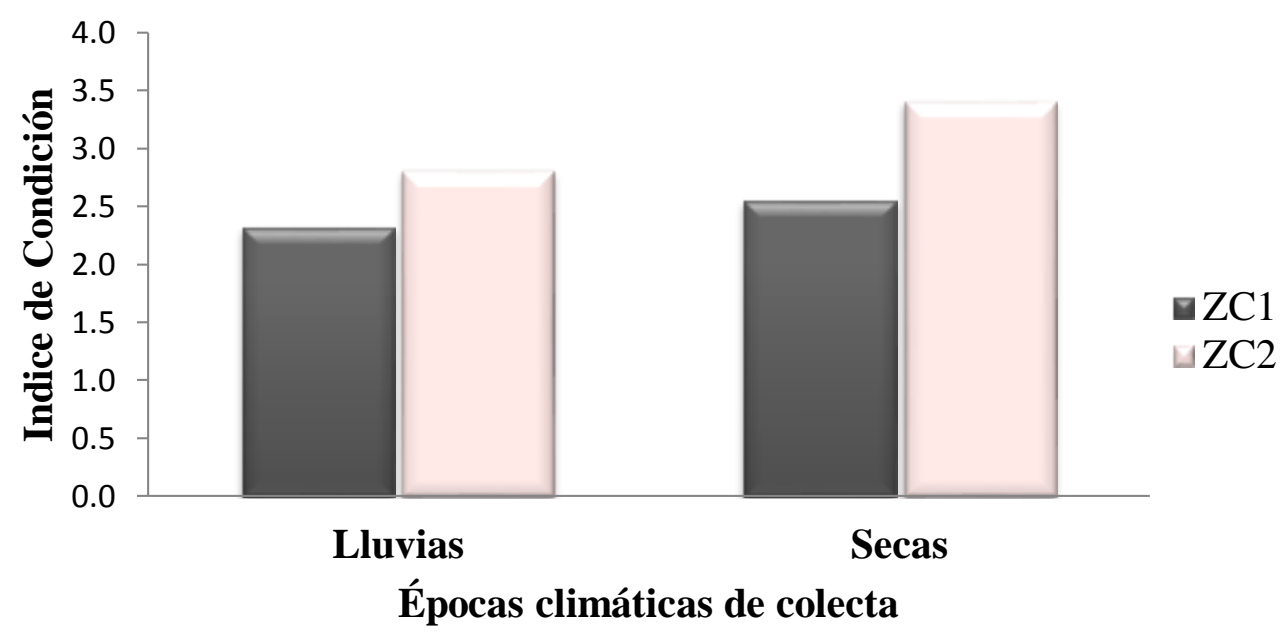

Figura 6. Índice de condición para ambas épocas de colecta, calculado a partir de la fórmula de Devenport \& Chen (1987). En donde ( $\leq 2.0=$ delgado; $2.0-4.0=$ moderado $y \geq 4=$ robusto).

\section{Determinación Taxonómica de la Especie de Estudio.}

Las conchas de la almeja colectada en Tecolutla presentaron externamente los siguientes caracteres diagnóstico característicos de la especie Polymesoda caroliniana: conchas no muy largas y ovaladas con líneas concéntricas sin umbo terminal, con una hendidura posterior bien desarrollada, periostraco de color negro-café y con umbos erosionados (Figura 7 a). Internamente, las conchas evidenciaron la presencia de dos impresiones musculares de tamaño semejante, marca peleal con seno paleal posterior tenue, interior porcelanoso blanco-azulado tornándose rosa salmón hacia la parte dorsal. La charnela es de tipo no taxodonta con dos dientes cardinales en cada valva y sin condróforo. De acuerdo a estos caracteres y a lo que indica la clave de Mille-Pagaza et al., (1993) apoyado con literatura específica de García-Cubas \& Reguero, (2007) para moluscos bivalvos del Golfo de México; refieren la especie de la almeja colectada a Polymesoda caroliniana. Esta especie de almeja se diferencia de otras como Rangia cuneata en el tamaño y color de su periostraco, así como en las características del interior de su concha (Figura 7 b). 


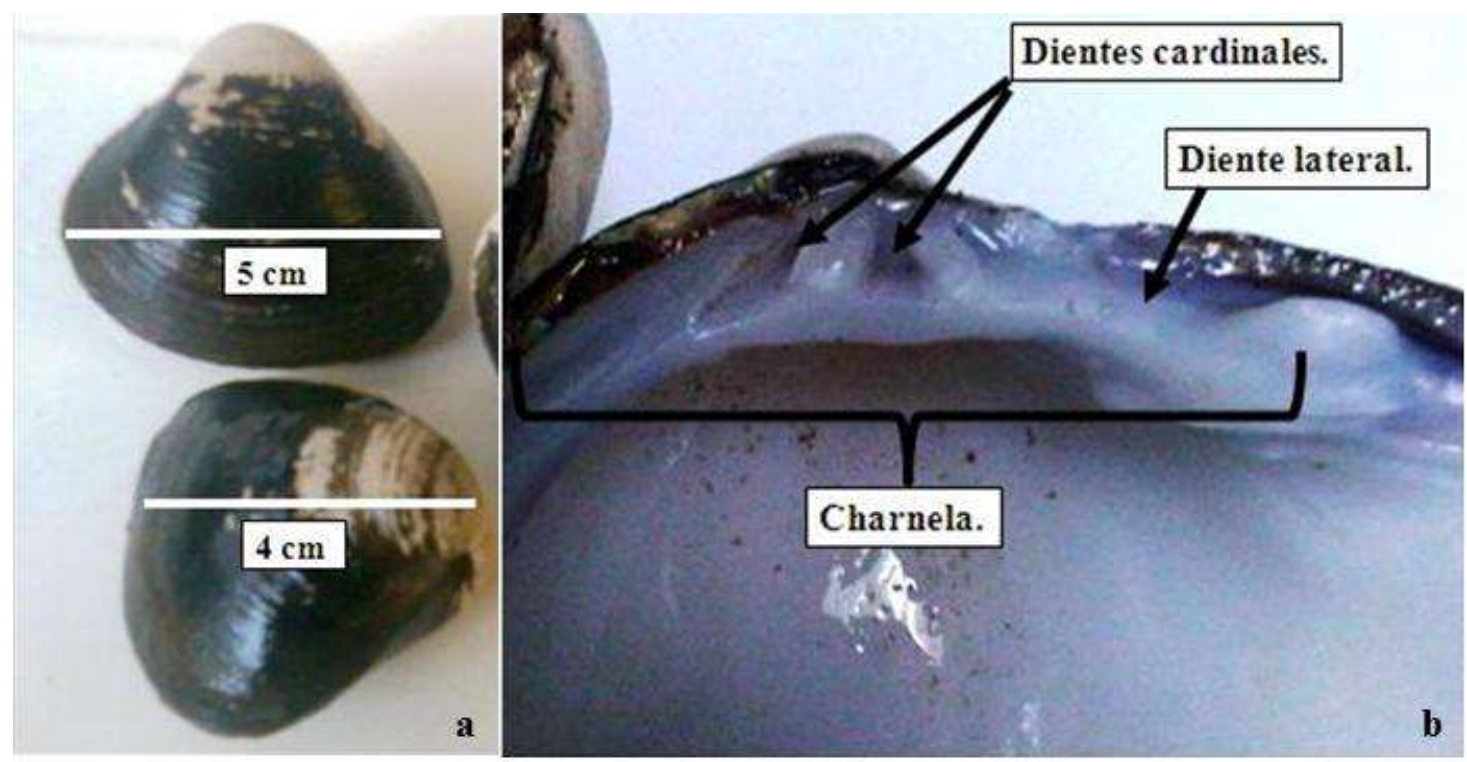

Figura 7, a) Exterior de las conchas de la almeja Polymesoda caroliniana de Tecolutla, Veracruz mostrando promedios de longitud (superior) y ancho (inferior) y b) Detalle de la charnela y dientes cardinales en el interior de la concha de las almejas.

\section{Análisis Molecular.}

Los ADNt extraídos de los cuatro organismos y a partir de los tejidos de branquia y manto presentaron buena calidad y concentración. En la Figura 8 se muestran las electroforesis de dicho material y hacen evidente la presencia de bandas bien definidas. Las concentraciones del ADNt se presentan en la Tabla 3 y 4, con valores que van 172 a $206 \mathrm{ng} / \mu \mathrm{l}$ para la branquia y el manto, respectivamente. La calidad de cada una de las extracciones también se encontró dentro de los valores referenciados como aceptables para realizar procesos de manipulación posterior de $\mathrm{ADNt}\left(\mathrm{OD}_{260 / 280}>1.7\right)$. 


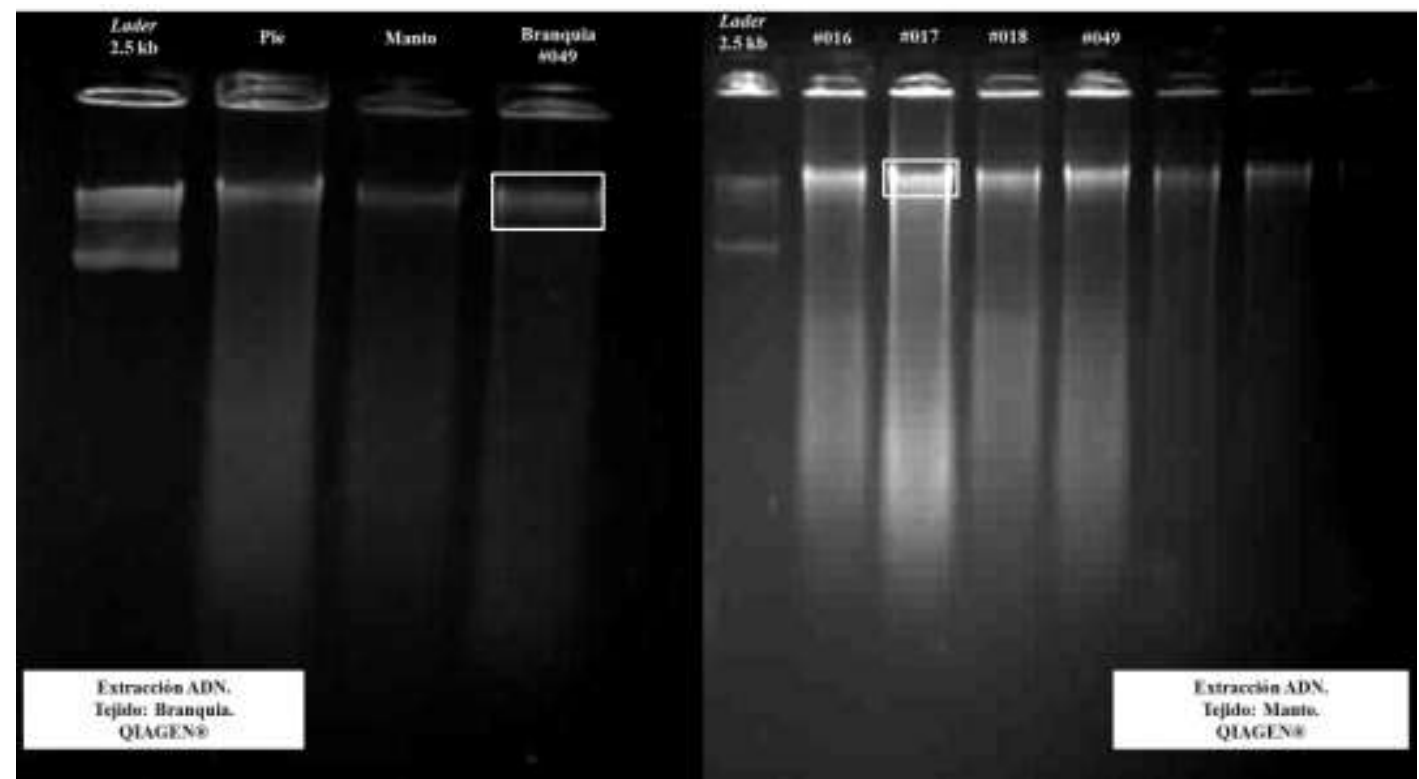

Figura 8. Extracciones de ADN. A la izquierda la extracción de ADN a partir de la branquia. Se resalta el organismo \#049. A la derecha el extracción a partir de manto del organismo \#017 Ambas extracciones utilizando el protocolo de QIAGEN®. El resto de las bandas corresponden a otras extracciones que no tuvieron éxito en el proceso de amplificación.

Tabla 3. Cuantificación de extracciones ADNt a partir del manto.

\begin{tabular}{|c|c|c|c|c|c|c|c|}
\hline Muestra & $\begin{array}{c}\text { Cantidad } \\
n g / \mu \mathrm{l}\end{array}$ & $\overline{O D_{230}}$ & $\overline{O D_{260}}$ & $\mathrm{OD}_{280}$ & $O D_{320}$ & $\mathrm{OD}_{260 / 280}$ & $\mathrm{OD}_{260 / 230}$ \\
\hline$\# 016$ & 198 & 0.146 & 0.114 & 0.080 & 0.035 & 1.75 & 0.71 \\
\hline \#017 & 206 & 0.058 & 0.084 & 0.046 & 0.001 & 1.83 & 1.45 \\
\hline \#018 & 174 & 0.144 & 0.097 & 0.066 & 0.028 & 1.81 & 0.60 \\
\hline \#049 & 63 & 0.022 & 0.027 & 0.018 & 0.002 & 1.58 & 1.26 \\
\hline
\end{tabular}

\begin{tabular}{cccccccc}
\hline \hline \multicolumn{7}{c}{ Tabla 4. Cuantificación de extracciones ADNt por órgano. } \\
\hline \hline Muestra & $\begin{array}{c}\text { Cantidad } \\
\text { ng/ } \boldsymbol{\mu l}\end{array}$ & $\mathbf{O D}_{\mathbf{2 3 0}}$ & $\mathbf{O D}_{\mathbf{2 6 0}}$ & $\mathbf{O D}_{\mathbf{2 8 0}}$ & $\mathbf{O D}_{\mathbf{3 2 0}}$ & $\mathbf{O D}_{\mathbf{2 6 0 / 2 8 0}}$ & $\mathbf{O D}_{\mathbf{2 6 0} / 230}$ \\
\hline \hline Manto & 95 & 0.019 & 0.041 & 0.025 & 0.003 & 1.72 & 2.33 \\
\hline Branquia (\#049) & 172 & 0.058 & 0.084 & 0.046 & 0.001 & 1.83 & 1.45 \\
\hline Pie & 367 & 0.112 & 0.159 & 0.091 & 0.013 & 1.88 & 1.48 \\
\hline
\end{tabular}

$\mathrm{OD}=$ Absorbancia. $\mathrm{OD}_{260 / 280}>1.7=$ se considera buena calidad de ADN. 


\section{Amplificación del gen mitocondrial r16S y nuclear ribosomal 28S.}

Los productos amplificados para ambos genes r16S y 28S se muestran en la Figura 9. De tres diferentes temperaturas de anillamiento probadas, las condiciones óptimas de anillamiento para el gen r16S, fueron a $58{ }^{\circ} \mathrm{C}$ (Figura 9 izquierda), mientras que para el gen $28 \mathrm{~S}$ las condiciones óptimas de anillamiento fueron de $59.8^{\circ} \mathrm{C}$ (Figura 9 derecha). En ambas fotografías se pueden observar bandas de dímeros y barridos superiores a los amplificados, producto de moléculas de alto peso molecular.

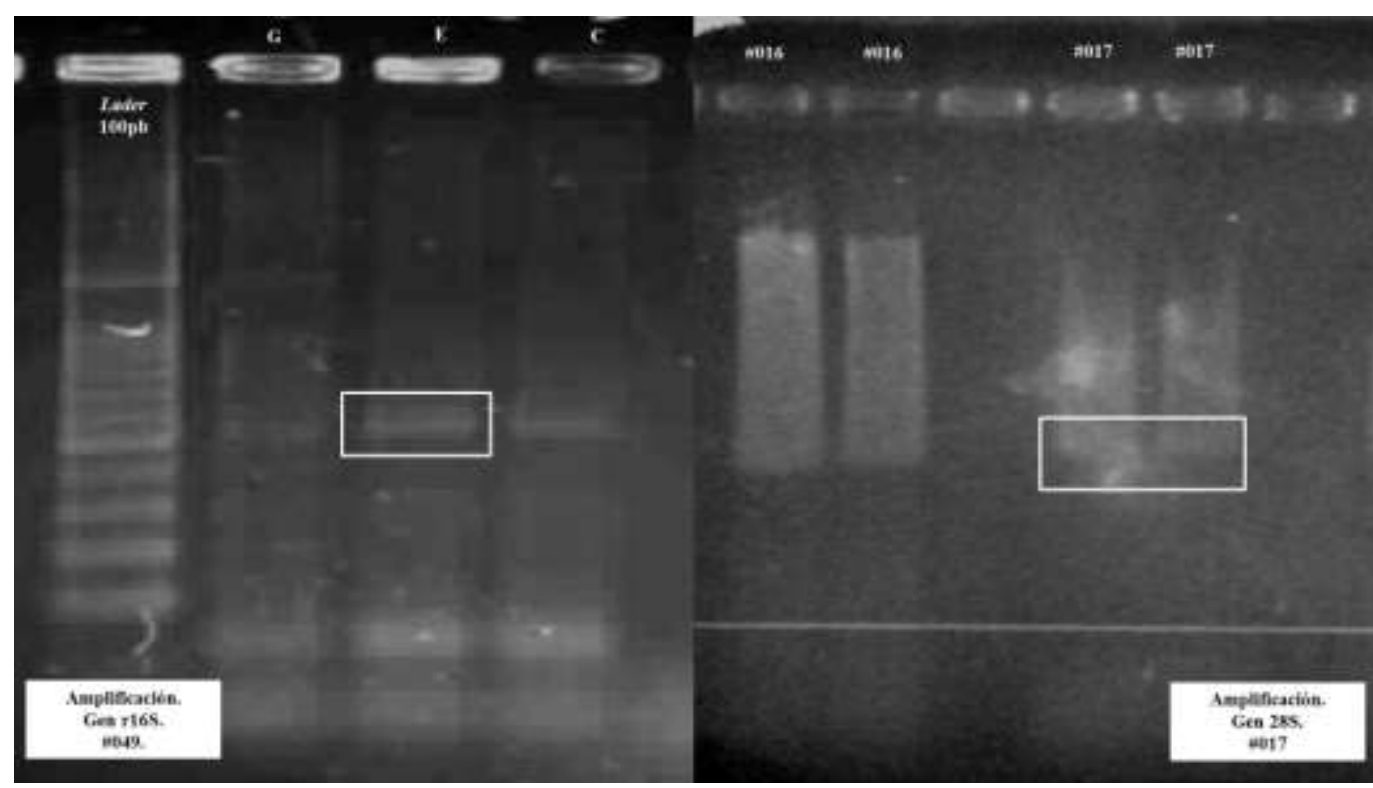

Figura 9. Amplificación de los genes genes r16S (izquierda) y $28 \mathrm{~S}$ (derecha). $\mathrm{G}=49.5$ ${ }^{\circ} \mathrm{C} ; \mathrm{E}=51.9^{\circ} \mathrm{C}$ y $\mathrm{C}=55.4^{\circ} \mathrm{C}$.

Los productos amplificados, purificados y secuenciados de las muestras \#049 y \#017, para los genes r16S y $28 \mathrm{~S}$ respectivamente, permitieron obtener secuencias limpias y nítidas. Permitiendo resolver a partir del análisis de Blastn la identidad de las secuencias, por ejemplo, la secuencia del organismo \#049 tuvo un 77\% de identidad con una secuencia homóloga del gen 16S de la especie Corbicula colorata (JX399588.1) (Figura 10). 


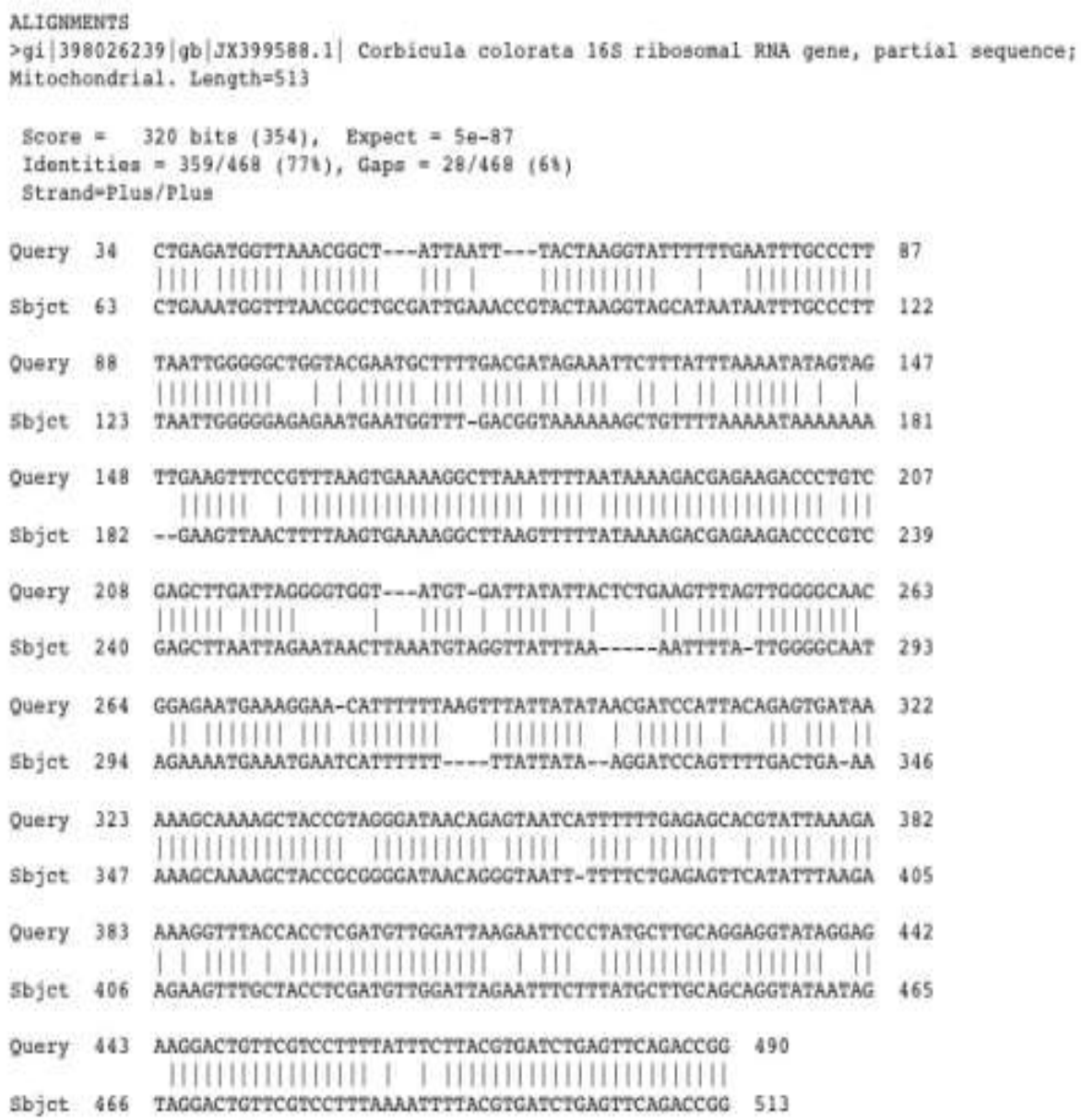

Figura 10. Resultado del análisis de Blastn de la secuencia \#049 con la secuencia del gen r16S de la especie Corbicula colorata (Corbiculidae), con el cual muestra un $77 \%$ de identidad

La secuencia del organismo \#017 tuvo un 99\% de identidad con una secuencia homóloga del gen 28S de la especie Polymesoda caroliniana (AF131011) (Figura 11). 
Polymesoda caroliniana 285 ribosomal RNA gene, partial sequence Sequence ID: gb|AF131011.1|AF131011 Length: 1065 Humber of Matches: 1

\begin{tabular}{|c|c|c|c|c|}
\hline Score & Expect & Identities & Gaps & Strand \\
\hline 551 bits(298) & $2 e-153$ & $303 / 305(99 \%)$ & $1 / 305(0 \%)$ & Plus/Minus \\
\hline
\end{tabular}

\begin{tabular}{|c|c|c|c|}
\hline Query & 19 & 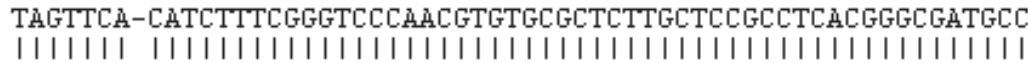 & 77 \\
\hline Sbjet & 961 & TAGTTCACCATCTTTCGGGTCCCAACGTGTGCGCTCTTGCTCCGCCTCACGGGCGATGCC & \\
\hline Query & 78 & 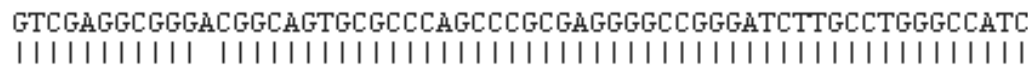 & \\
\hline Sbjet & 901 & GTCGAGGCGGGCCGGCAGTGCGCCCAGCCCGCGAGGGGCCGGGATCTTGCCTGGGCCATC & \\
\hline Query & 138 & 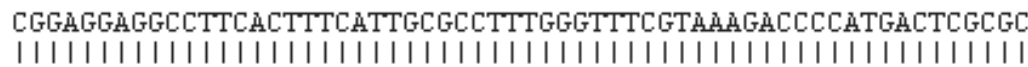 & \\
\hline Sbjet & 841 & CGGAGGAGGCCTTCACTTTCATTGCGCCTTTGGGTTTCGTAAAGACCCCATGACTCGCGC & \\
\hline Query & 198 & 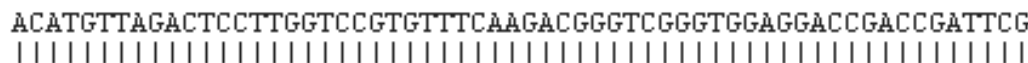 & \\
\hline Sbjet & 781 & ACATGTTAGACTCCTTGGTCCGTGTTTCAAGACGGGTCGGGTGGAGGACCGACCGATTCG & \\
\hline Query & 258 & 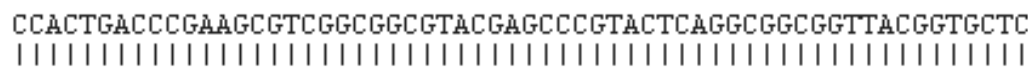 & \\
\hline Sbjet & 721 & CСАCTGACCCGAAGCGTCGGCGGCGTACGAGCCCGTACTCAGGCGGCGGTTACGGTGCTC & \\
\hline Query & 318 & TGCAA $\quad 322$ & \\
\hline sbjet & 661 & TGCAB 657 & \\
\hline
\end{tabular}

Figura 11. Resultado del análisis de Blastn de la secuencia \#017 con la secuencia del gen $28 \mathrm{~S}$ de la especie Polimesoda caroliniana (Corbiculidae), con el cual muestra un $99 \%$ de identidad

El análisis de inferencia filogenética utilizando secuencias de regiones homólogas de representantes de las familias Mactridae, Veneridae y Corbiculidae con los dos métodos de aproximación utilizados, Parsimonia y Máxima Probabilidad resolvieron la misma topología para las secuencias del gen r16S, posicionando a la almeja de Tecolutla dentro del clado de la familia Corbiculidae con altos valores de soporte de bootstrap (Figura 12). Los resultados observados en las topologías son soportados por los valores obtenidos del análisis de distancias genéticas con el modelo T93; Tamura \& Nei (2003) observándose los valores de distancia genética más bajos entre el organismo \#017 y la secuencia de $P$. caroliniana de GenBank (0.017), sugiriendo una estrecha relación genética entre estas dos especies y el resto de las especies analizadas (Tabla 5). 


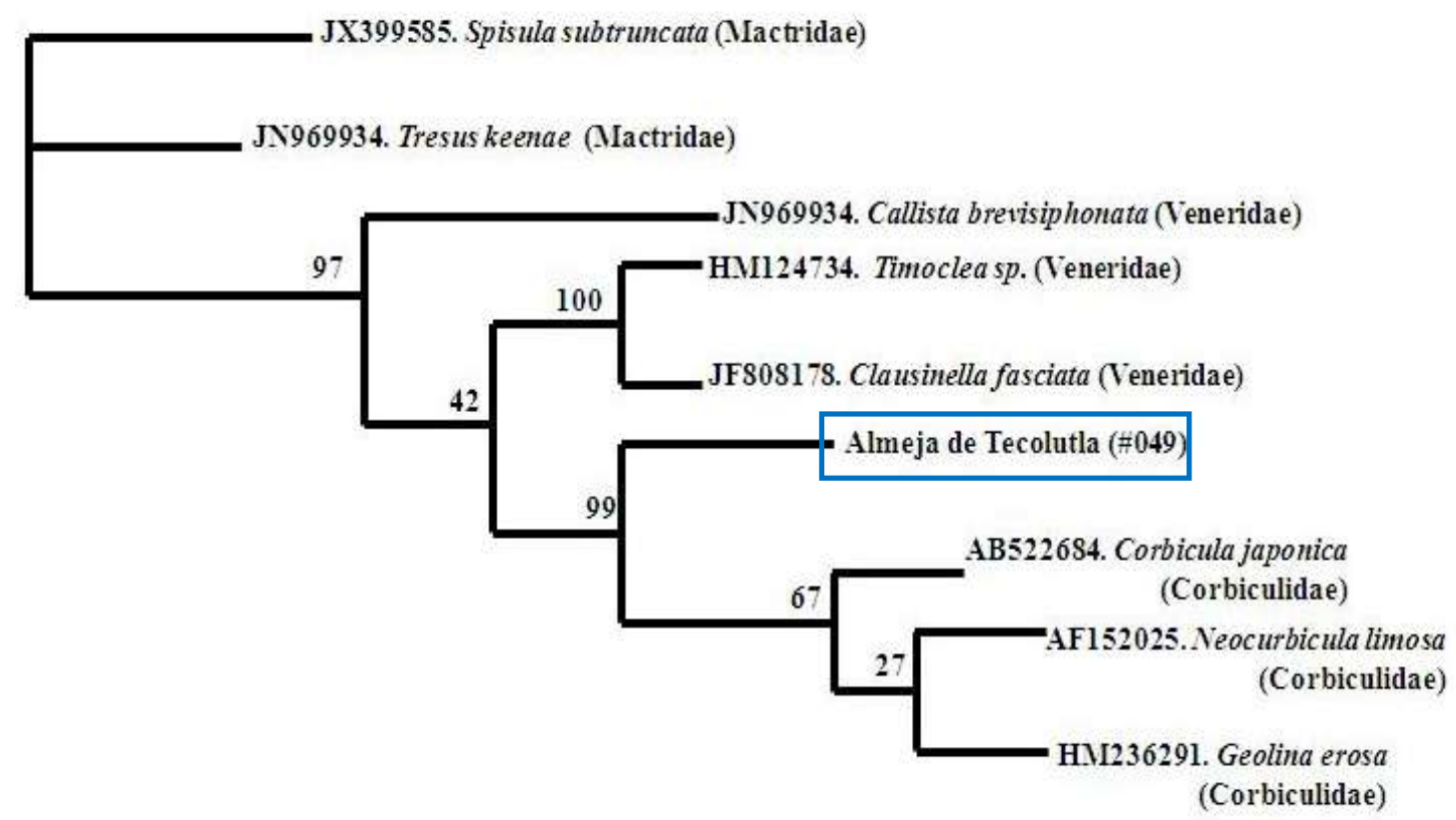

Figura 12. Topología obtenida a partir del método de Máxima verosimilitud para el gen r16S. Para la secuencia obtenida del gen $28 \mathrm{~S}$, se muestran las topologías realizadas con los mismos métodos que para el gen $16 \mathrm{~S}$, sin embargo estas se compararon con especies de los géneros Polymesoda, Corbicula, Neocorbicula y Venus, resultando las 3 topologías en una cercanía importante (de 84 a 99\%) a la secuencia de Polymesoda caroliniana (AF131011) (Figura 13).

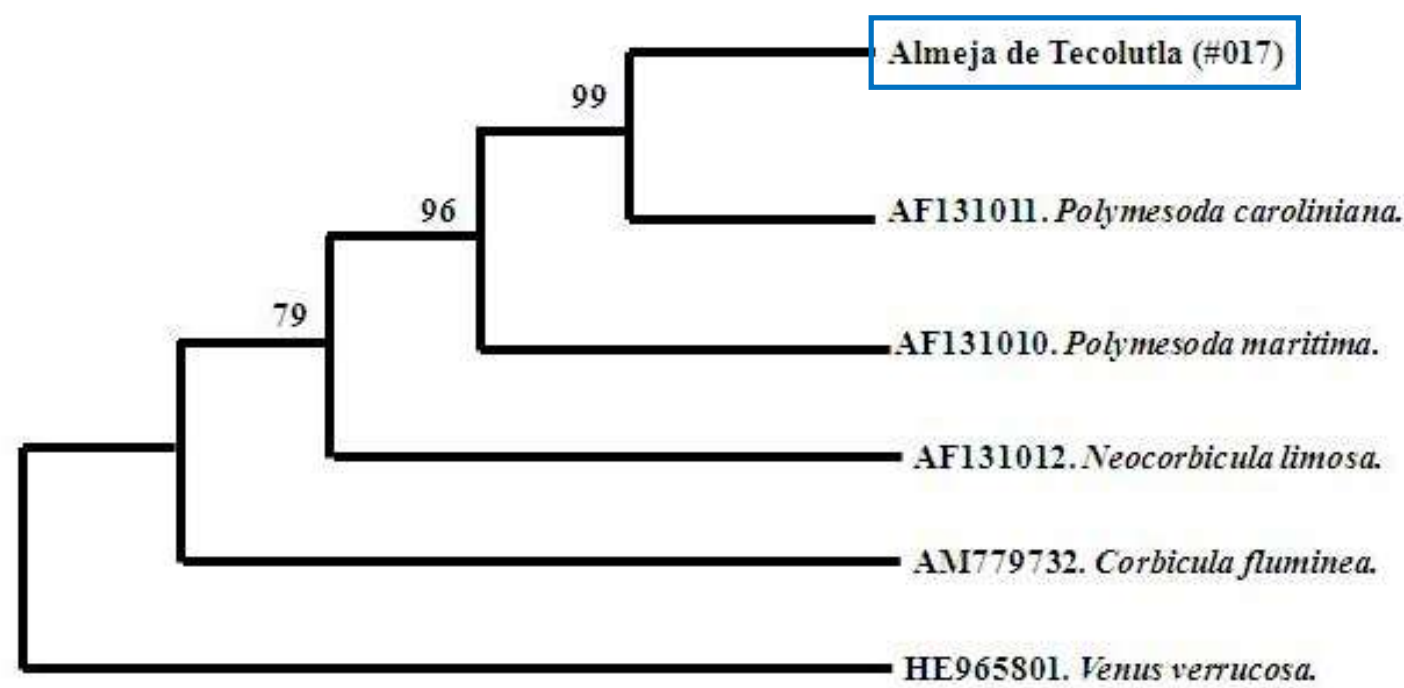

Figura 13. Topología obtenida a partir del método de Máxima verosimilitud para el gen $28 S$. 
Tabla 5. Cálculo de distancias genéticas con el modelo T93 para el gen $28 \mathrm{~S}$

\begin{tabular}{llcccccc}
\hline \multicolumn{1}{c}{ Especies } & 1 & 2 & 3 & 4 & 5 & 6 \\
\hline \hline 1 & Organismo_No.017 & & & & & & \\
2 & AF131010_Polymesoda_maritima & 0.039 & & & & & \\
3 & AF131011_Polymesoda_caroliniana & $\mathbf{0 . 0 1 7}$ & $\mathbf{0 . 0 2 1}$ & & & & \\
4 & AF131012_Neocorbicula_limosa & $\mathbf{0 . 0 5 3}$ & $\mathbf{0 . 0 3 2}$ & $\mathbf{0 . 0 3 3}$ & & & \\
5 & AM779732.1_Corbicula_fluminea & 0.107 & $\mathbf{0 . 0 8 2}$ & $\mathbf{0 . 0 8 3}$ & $\mathbf{0 . 0 6 8}$ & & \\
6 & HE965801.1_Venus_verrucosa & 2.757 & 2.208 & 2.367 & 2.093 & 2.207 \\
\hline \hline
\end{tabular}

\section{Análisis Bioquímico.}

\section{Identificación y caracterización parcial de proteínas de almeja}

En la Tabla 6 se muestra el contenido de proteínas obtenida para cada uno de los órganos utilizados en la técnica. Se puede observar que el manto presenta la mayor concentración de proteínas 6.1 y $17 \mathrm{mg} / \mathrm{mL}$, para la almeja $P$. caroliniana y almeja comercial respecto a los otros órganos.

\begin{tabular}{lcc}
\hline \multicolumn{2}{c}{$\begin{array}{l}\text { Tabla 6. Concentración de proteínas de la almeja } \\
\text { Polymesoda caroliniana y de la almeja comercial. }\end{array}$} \\
\hline Órgano. & \multicolumn{2}{c}{ Concentración $(\mathbf{m g} / \mathbf{m L})$} \\
\hline & P. caroliniana & Almeja comercial \\
\hline \hline Manto. & 6.1 & 17 \\
Branquia. & 5.2 & 5.5 \\
Pie. & 5.9 & 8.5 \\
\hline \hline
\end{tabular}

Al calcular las unidades de actividad específica, se evidenció la mayor actividad en la branquia de ambas almejas 126.8 y $391 \mathrm{U} / \mathrm{mg}$, seguido del manto 86.4 y $119.8 \mathrm{U} / \mathrm{mg}$ y con la menor actividad, el pie que reportó valores de 44.6 y $83.3 \mathrm{U} / \mathrm{mg}$, para la almeja $P$. caroliniana y la almeja comercial, respectivamente (Figura 14). Para los siguientes análisis se utilizó solo la branquia, al ser esta la que presentó mayor actividad. 


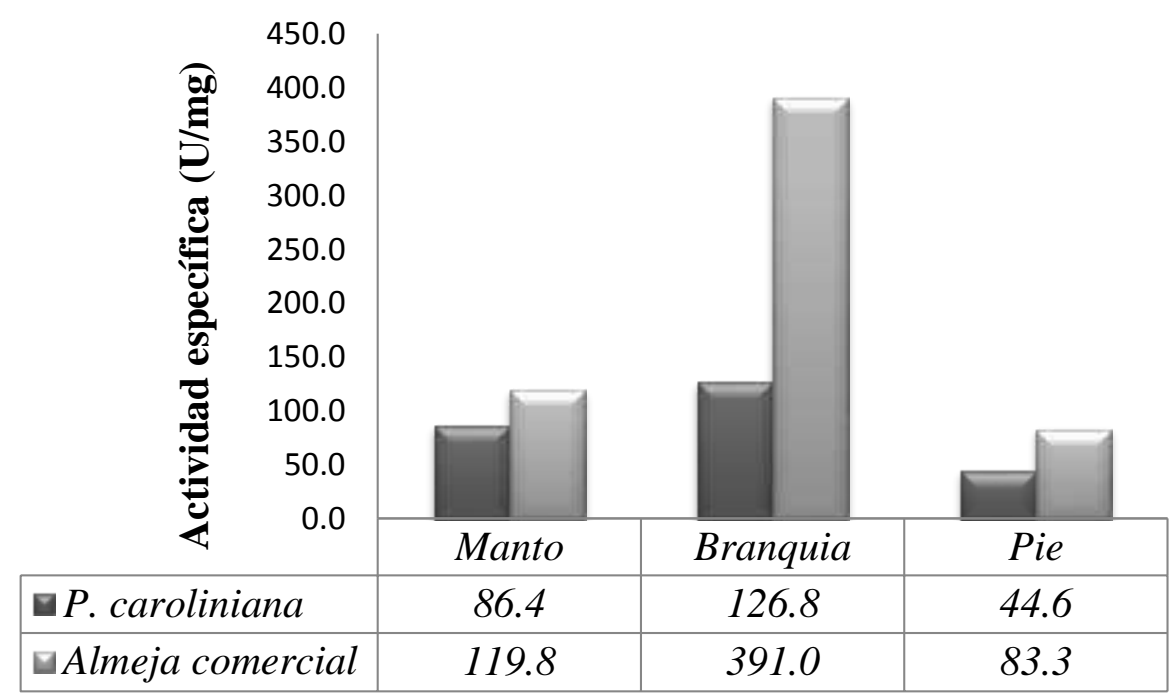

Figura 14. Actividad proteolítica específica (U/mg) para cada órgano estudiado.

Al medir la actividad a diferente pH para las dos tipos de almeja (comercial y muestras recolectadas), utilizando la branquia como órgano objetivo, se observó que el intervalo de pH óptimo para la actividad para la almeja comercial fue de 6 a 7 , mientras que para la almeja $P$. caroliniana el pH reportado se encontró en el intervalo de 8 a 10 (Figura 15).

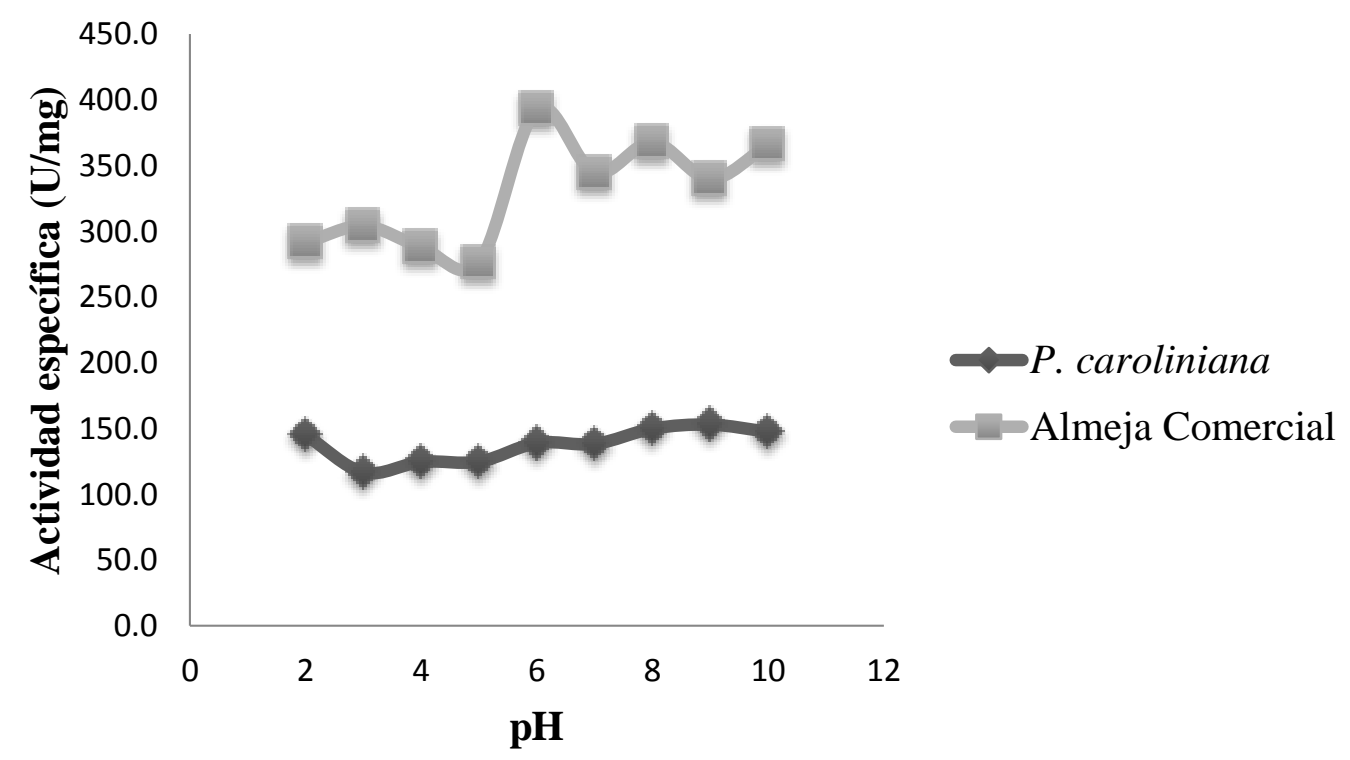

Figura 15. Actividad proteolítica del extracto de branquia de almeja $P$. caroliniana y almeja comercial a diferentes pH. 
De los valores de actividad obtenidos a diferentes temperaturas se observó actividad a 50

${ }^{\circ} \mathrm{C}$ para la almeja comercial y de 50 a $70{ }^{\circ} \mathrm{C}$ para la almeja colectada en de Tecolutla (Figura 16).

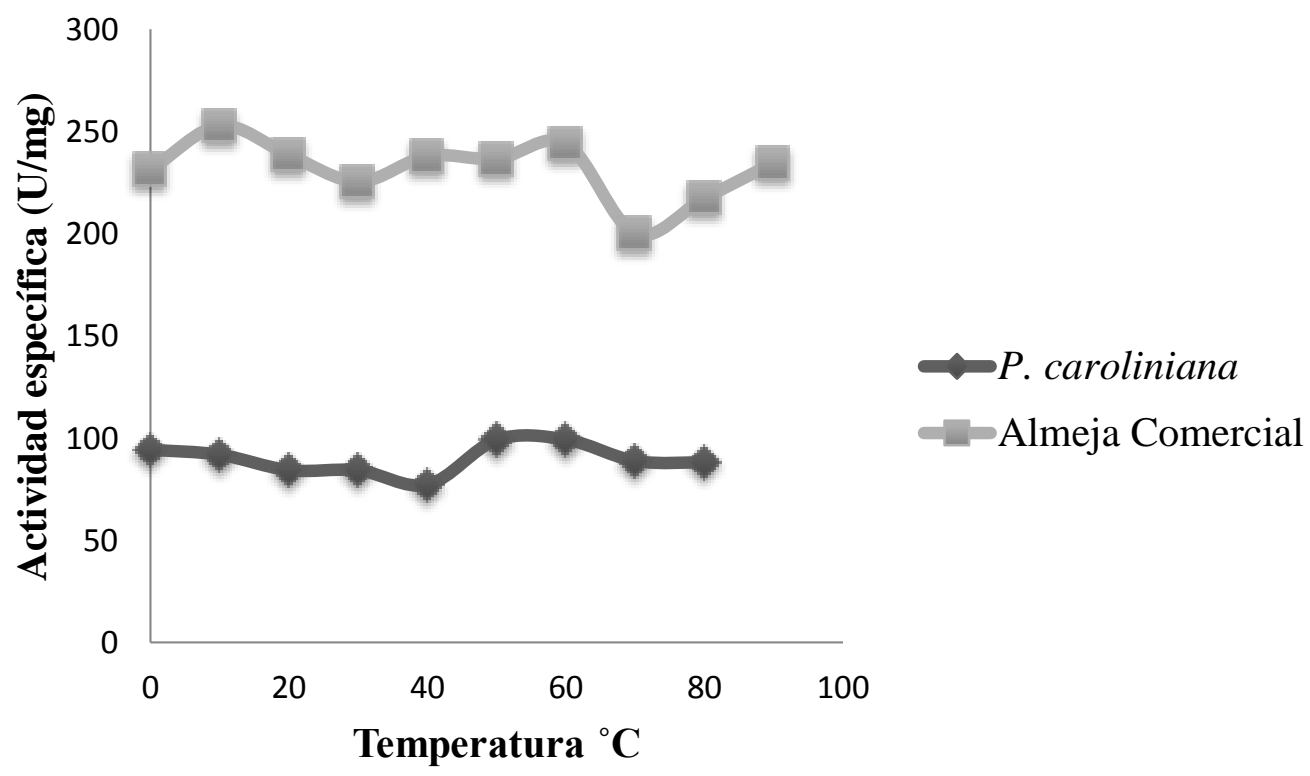

Figura 16. Actividad proteolítica a diferente temperatura de extracto de branquia de almeja $P$. caroliniana y almeja comercial.

La electroforesis de los extractos proteícos de los tres órganos estudiados se muestran en la Figura 17. Los pesos moleculares aproximados de las proteínas en almeja comercial y $P$. caroliniana fueron diferentes. Las proteínas encontradas en la almeja comercial tuvieron u peso molecular entre 26 y $38 \mathrm{kDA}$, mientras que en $P$. caroliniana, se encontraron proteínas entre 9 y $120 \mathrm{kDA}$. 
Comercial

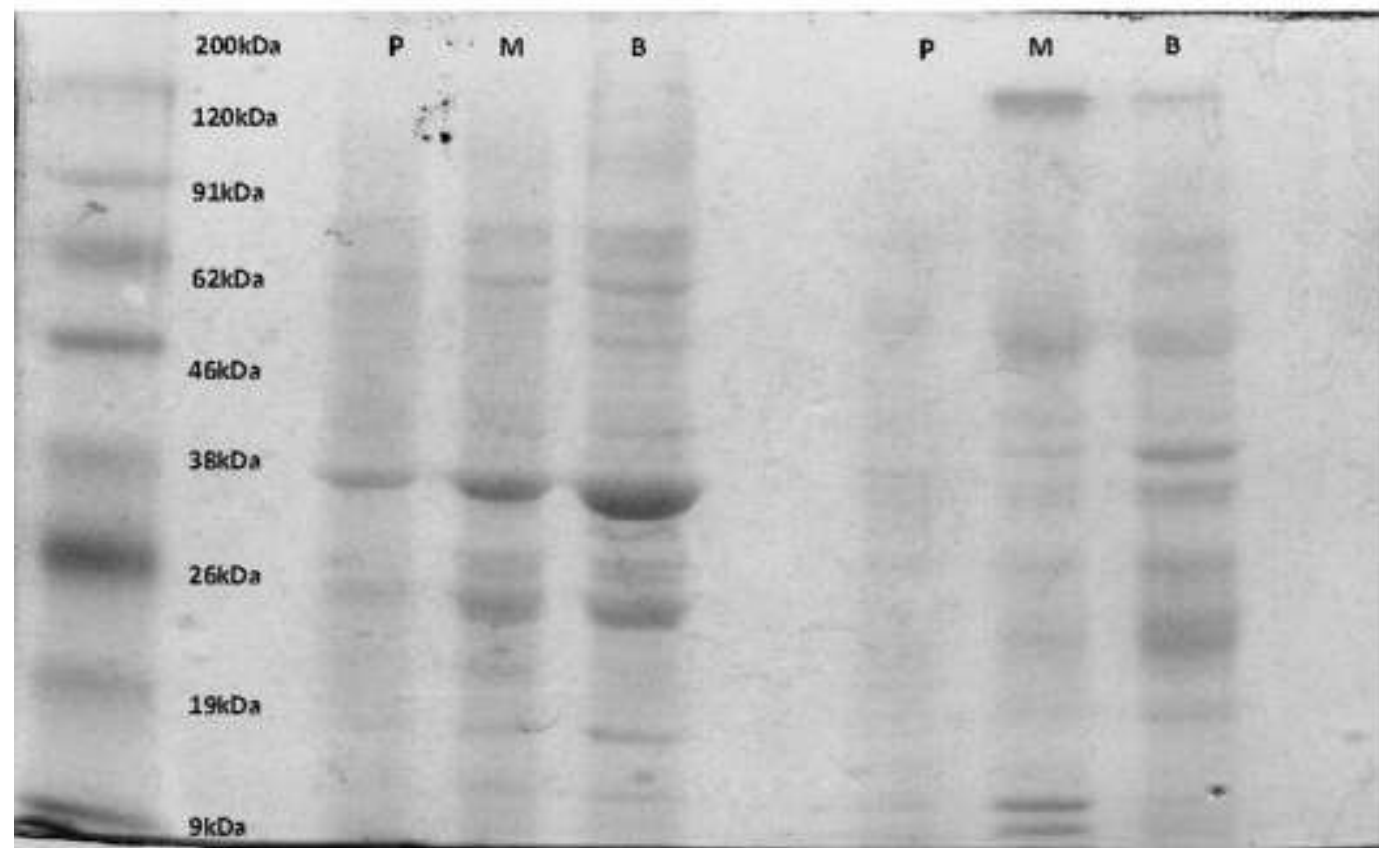

Figura 17. Electroforesis (SDS-PAGE) de extracto de la almeja comercial y de $P$. caroliniana. $P=$ pie; $M=$ manto y $B=$ branquia.

Los densitogramas correspondientes a estas electroforesis se presentan en las Figuras 18 a 21, donde se muestra la densidad de las bandas, la concentración de la proteína correspondiente y el valor de $\mathrm{Rf}$ (relación de migración de una sustancia en un proceso electroforético). A menor área bajo la curva, menor concentración de la proteína.

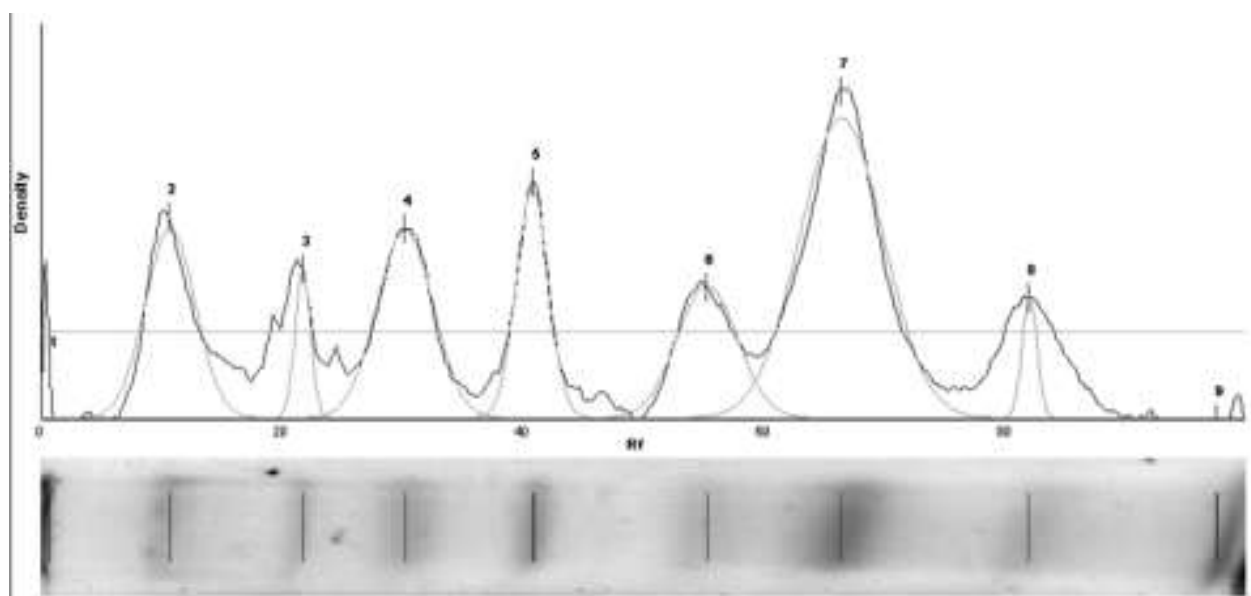

Figura 18. Densitograma de los pesos moleculares de marcadores. $1=$ miosina $200 \mathrm{kDa}, 2=\beta$ galactosidasa $112 \mathrm{kDa}, 3=$ suero de albumina $91 \mathrm{kDa}, 4=$ glutamato $62 \mathrm{kDa}, 5=$ ovoalbúmina $46 \mathrm{kDa}, 6=$ anhidrasa carbónica $38 \mathrm{kDa}, 7=$ mioglobina $26 \mathrm{kDa}, 8=\operatorname{lisosima} 19 \mathrm{kDa}$ y 9= aprotina 9 kDa. 


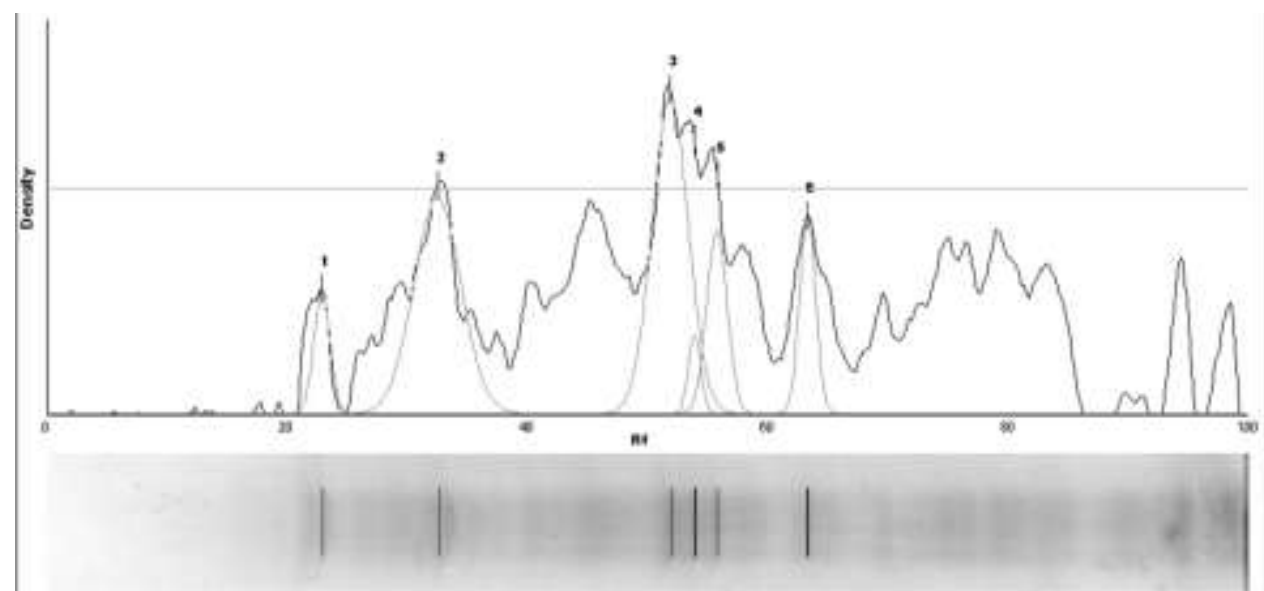

Figura 19. Proteínas en el pie de la almeja Polymesoda caroliniana. Los números en los picos corresponden al número de proteínas detectadas.

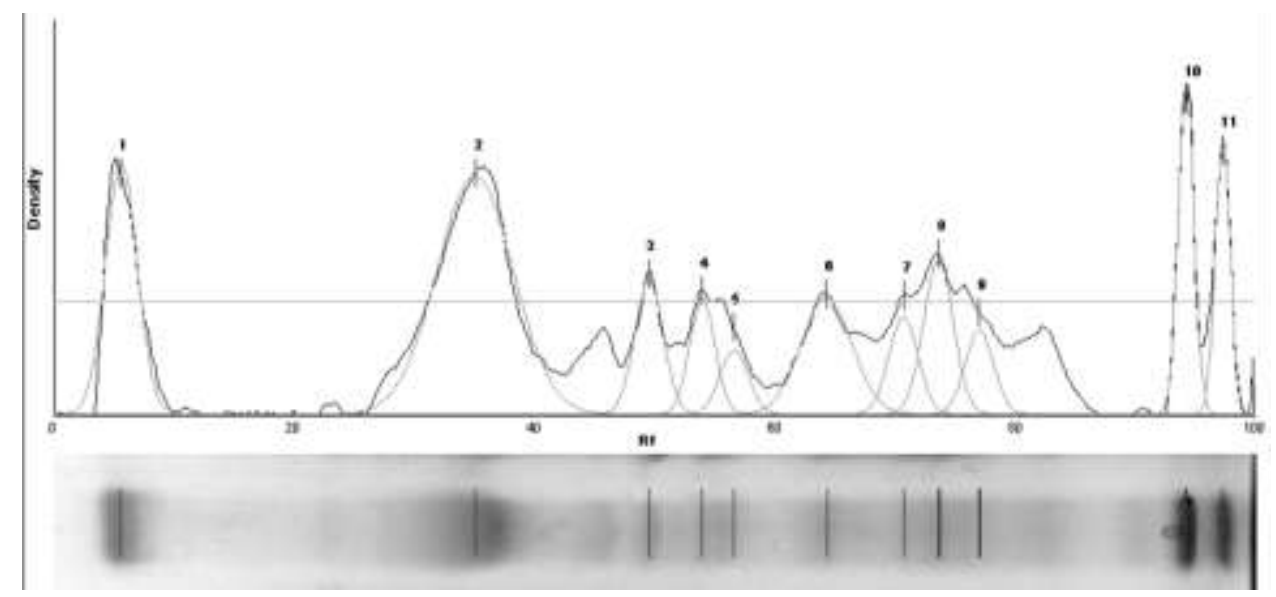

Figura 20. Proteínas en el manto de la almeja Polymesoda caroliniana. Los números en los picos corresponden al número de proteínas detectadas.

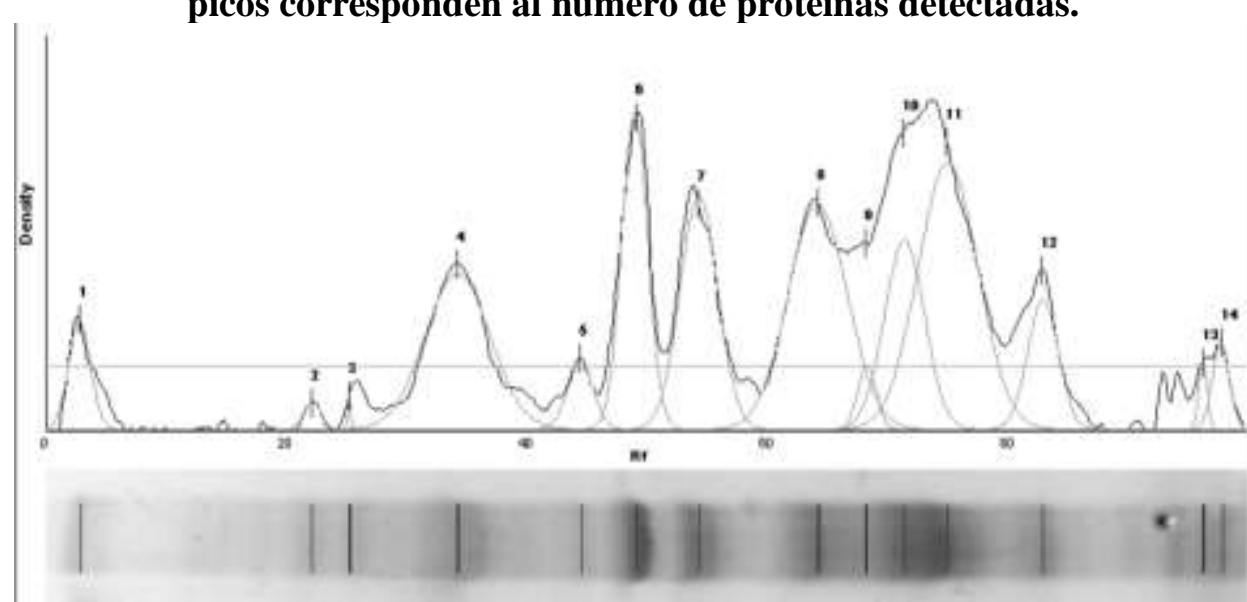

Figura 21. Proteínas en la branquia de la almeja Polymesoda caroliniana. Los números en los picos corresponden al número de proteínas detectadas. 


\section{Determinación del contenido proteíco por el método de Kjeldahl.}

La Tabla 7 muestra el contenido de nitrógeno y de proteína cruda en cada órgano objetivo.

El órgano con mayor contenido de nitrógeno y por lo tanto de proteína cruda fue el pie (\% $\mathrm{N}=1.2 ; \%$ proteína.= 7.9), seguido de la branquia $(\% \mathrm{~N}=1.1 ; \%$ proteína.= 6.6$) \mathrm{y}$ finalmente el manto (\% $\mathrm{N}=0.3 ; \%$ proteína $=2.2)$. Los datos de porcentaje de humedad y de materia seca resultaron ser homogéneos (ver Tabla 8), con bajo porcentaje de humedad para los tres tejidos.

\begin{tabular}{lccc}
\hline \multicolumn{4}{c}{ Tabla 7. Porcentaje de proteína para los tres órganos de la almeja } \\
Polymesoda caroliniana.
\end{tabular}

Tabla 8. Porcentaje de humedad y materia seca para los tres órganos de la almeja $P$. caroliniana.

\begin{tabular}{lccc}
\hline Órgano & Peso seco & \% Humedad & \% Materia Seca \\
\hline \hline Manto & 0.032 & 8.4 & 91.6 \\
Branquia & 0.029 & 8.5 & 91.5 \\
Pie & 0.043 & 8.4 & 91.6 \\
\hline
\end{tabular}




\section{Análisis Tisular.}

Se revisaron 60 laminillas que contenían cortes trasversales de los tres órganos estudiados: manto, branquia y pie.

\section{Descripción tisular.}

El manto es el órgano encargado de la secreción de la concha y del mucus, se encuentra en contacto constante con el medio y está compuesto principalmente de tejido conectivo con gran cantidad de hemocitos. Los epitelios de este órgano tienden a ser simples cuboidales aunque la forma de las células pueda cambiar de acuerdo a la región del manto que se analice (Figura 22 a \& b).

Las branquias son órganos que participan en el intercambio gaseoso y en la selección de partículas alimenticias, se trata de dos pares de laminillas en forma de placas a cada lado del cuerpo conformadas de diversos filamentos que favorecen la conducción del agua. En general los filamentos presentan células mucosas y microvellosidades que favorecen el movimiento del agua que lleva oxígeno al corazón. Presentan tejido conectivo y epitelial de tipo simple (Figura 23 a \& b).

El pie es una estructura que en la mayoría de los bivalvos tiene función locomotora, está formado principalmente por tejido muscular con paquetes de fibras longitudinales y transversales en una matriz de tejido conectivo. Los epitelios de recubrimiento son simples y con posibles presencias glandulares (Figura $24 \mathrm{a} \& \mathrm{~b}$ ).

\section{Análisis Histopatológico.}

En cuanto al análisis histopatológico; el manto, mostró la presencia de inclusiones esféricas en tonos marrones, gránulos de lipofuscina, secreciones vacuoladas eosinófilas (Figura 22: c-f) e inclusiones que refieren algún tipo de parásito (Figura 25: c \& d). En la 
branquia se presentó la presencia de gránulos de lipofuscina en diferentes números y tamaños (Figura 25: c-f) e inclusiones esféricas que recuerdan algún tipo de parásito (Figura 25: a \& b). El pie presentó secreciones eosinófilas y tejido conjuntivo laxo con separaciones entre el tejido para el pie (inflaciones) (Figura 24: c \& d), así como secreciones vacuoladas (Figura 24: e \& f).

La matriz construida a partir de las respuestas tisulares encontradas en los órganos estudiados (manto, branquia y pie) se presenta en la Tabla 9, en ella se puede observar en cuanto al manto porcentajes elevados de inclusiones esféricas en la época de lluvias (ZC1= $4 \% ; \mathrm{ZC} 2=8 \%$ ), un $8 \%$ de gránulos de lipofuscina en ZC1 (lluvias) y $2 \%$ en ZC2 (secas) y secreciones eosinófilas en la época de secas $(\mathrm{ZC} 1=2 \% ; \mathrm{ZC} 2=9 \%)$.

En la branquia, la respuesta que predominó fue la presencia de gránulos de lipofuscina, los cuales se encontraron en ambas zonas de colecta y en las dos épocas, siendo la ZC1 (lluvias) la que mostró el porcentaje más alto (21\%). Además, en este mismo órgano se encontró un porcentaje bajo de presencia de parásitos (2\%).

En el pie se encontraron secreciones eosinofilas sólo en la ZC1, de la época de secas (2\%), y las inflamaciones se presentaron en la zona de colecta 1 de ambas épocas $(\mathrm{ZC} 1=5 \%$; $\mathrm{ZC} 2=2 \%)$

De manera general, la zona de colecta 1 en la época de lluvias fue la que presentó mayor porcentaje de respuestas tisulares $(38 \%)$. 


\begin{tabular}{|c|c|c|c|c|c|}
\hline Órgano & Respuestas tisulares & $\begin{array}{c}\mathrm{ZC1} \\
\%\end{array}$ & $\begin{array}{c}\mathrm{ZC2} \\
\%\end{array}$ & $\begin{array}{c}\mathrm{ZC1} \\
\%\end{array}$ & $\begin{array}{c}\mathrm{ZC} 2 \\
\%\end{array}$ \\
\hline \multirow[t]{5}{*}{ Manto } & Inclusiones esféricas & 4 & 8 & 2 & $\mathrm{NO}^{*}$ \\
\hline & Gránulos de lipofuscina & 8 & NO* & 2 & $\mathrm{NO}^{*}$ \\
\hline & Secreciones vacuoladas eosinofilas & NO* & NO* & 2 & 9 \\
\hline & Presencia de parásitos & $\mathrm{NO}^{*}$ & NO* & $\mathrm{NO}^{*}$ & $\mathrm{NO}^{*}$ \\
\hline & Inflamaciones & $\mathrm{NO}^{*}$ & NO* & $\mathrm{NO}^{*}$ & NO* \\
\hline \multirow[t]{5}{*}{ Branquia } & Inclusiones esféricas & NO* & NO* & $\mathrm{NO}^{*}$ & $\mathrm{NO}^{*}$ \\
\hline & Gránulos de lipofuscina & 21 & 14 & 8 & 9 \\
\hline & Secreciones vacuoladas eosinofilas & $\mathrm{NO}^{*}$ & NO* & NO* & $\mathrm{NO}^{*}$ \\
\hline & Presencia de parásitos & $\mathrm{NO}^{*}$ & NO* & 2 & NO* \\
\hline & Inflamaciones & $\mathrm{NO}^{*}$ & NO* & $\mathrm{NO}^{*}$ & $\mathrm{NO}^{*}$ \\
\hline \multirow[t]{5}{*}{ Pie } & Inclusiones esféricas & $\mathrm{NO}^{*}$ & NO* & 2 & NO* \\
\hline & Gránulos de lipofuscina & $\mathrm{NO}^{*}$ & $\mathrm{NO}^{*}$ & NO* & $\mathrm{NO}^{*}$ \\
\hline & Secreciones vacuoladas eosinofilas & $\mathrm{NO}^{*}$ & NO* & $\mathrm{NO}^{*}$ & $\mathrm{NO}^{*}$ \\
\hline & Presencia de parásitos & $\mathrm{NO}^{*}$ & $\mathrm{NO} *$ & $\mathrm{NO}^{*}$ & NO* \\
\hline & Inflamaciones & 5 & NO* & 2 & NO* \\
\hline Total & 397 & 38 & 22 & 20 & 19 \\
\hline
\end{tabular}




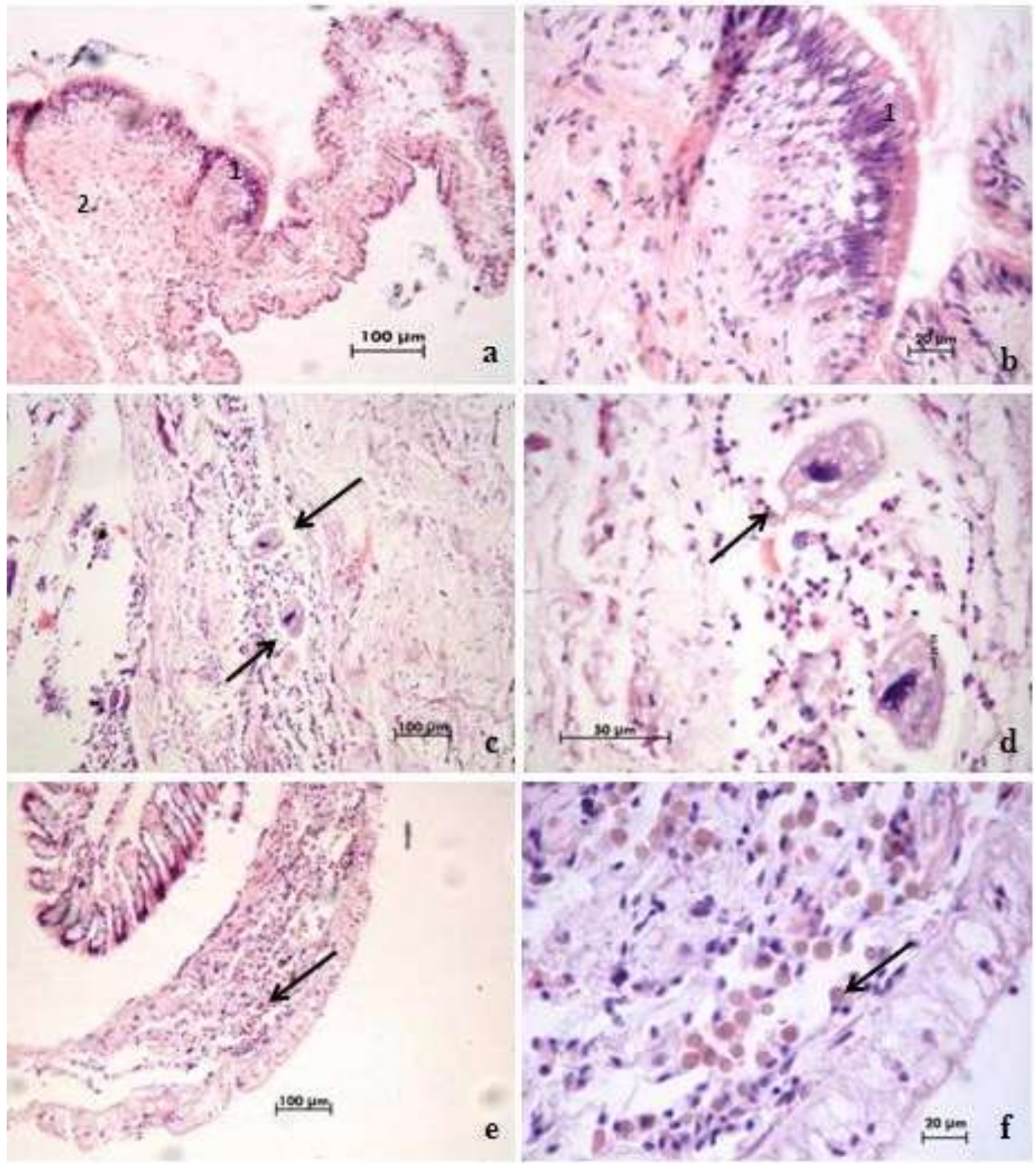

Figura 22. Fotomicrografías del manto. En a y b se detalla el manto en aparente estado normal de salud. En c y d se observan inclusiones eosinófilas, mientras que en e y f se observan inclusiones esféricas en tonalidades pardas. Cortes transversales. $5 \mu \mathrm{m}$. Tinción HE. 


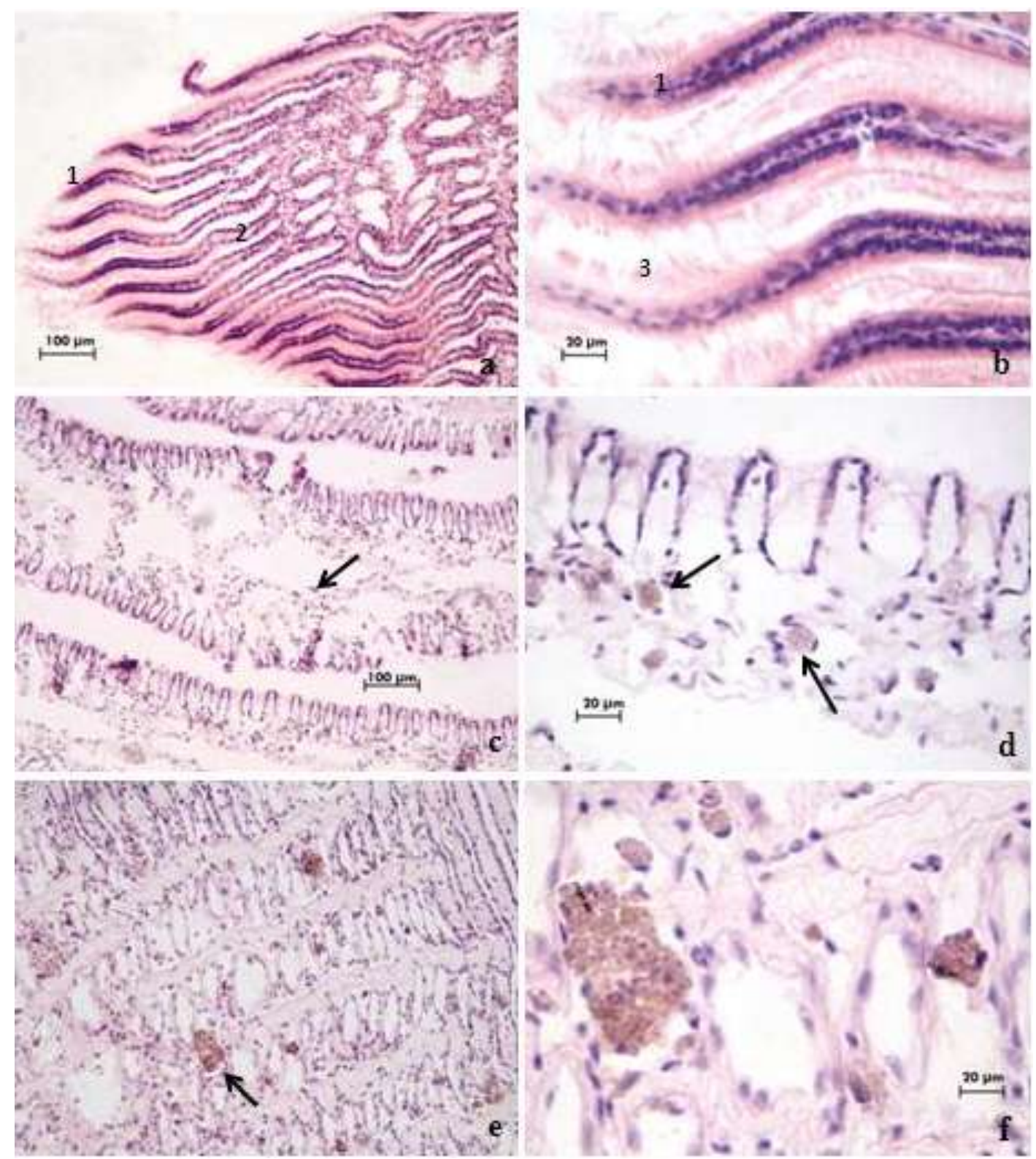

Figura 23. Fotomicrografías de branquia. Se observan láminas y filamentos branquiales en estado de salud normal (a y b). En c-f se detallan gránulos de lipofuscina en diferentes tamaños. Cortes transversales, tinción H-E, nivel de corte $5 \mu \mathrm{m}$. 


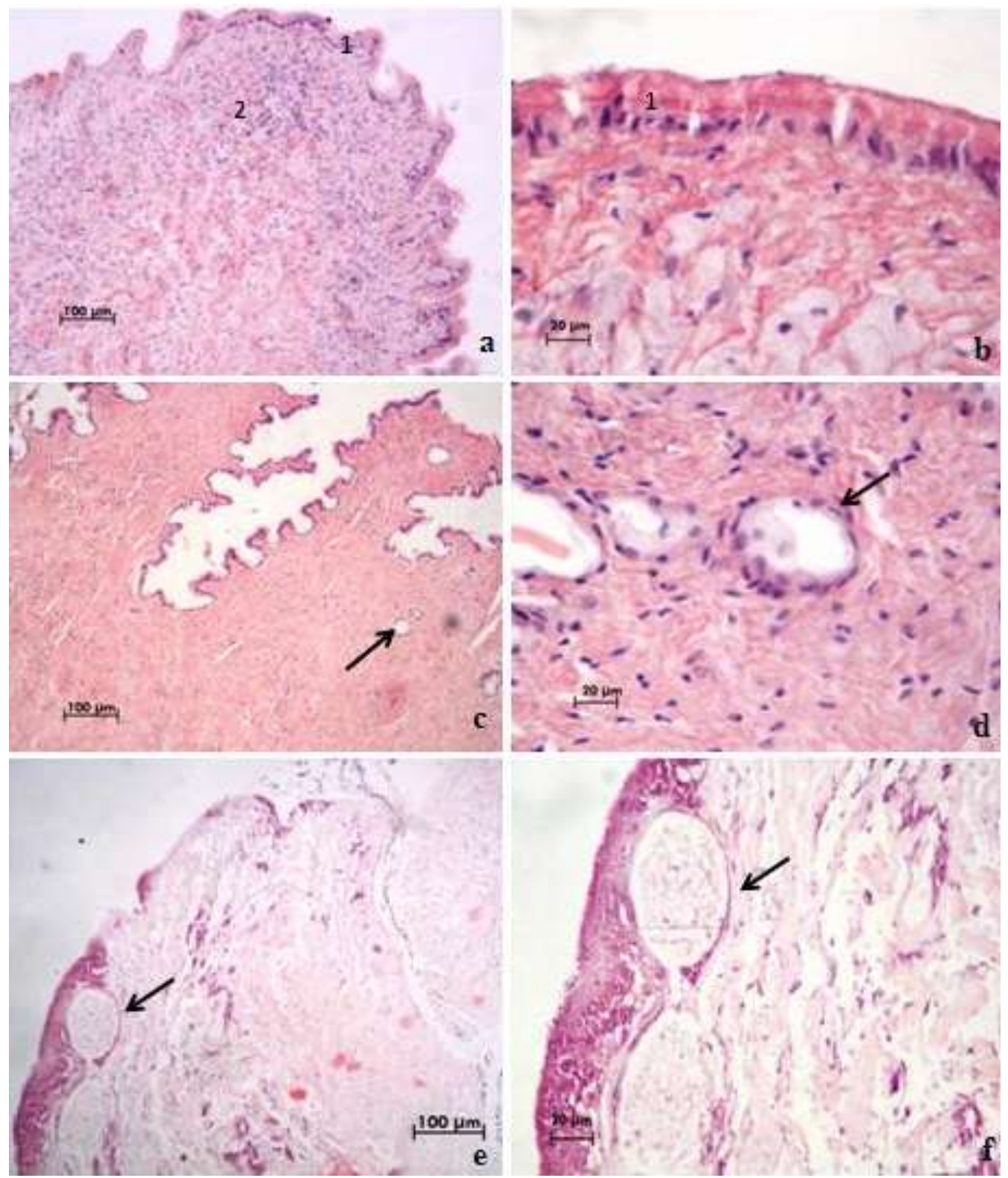

Figura 24. Fotomicrografías del pie. En a y b se observa la porción anterior el pie en estado normal de salud. En c y d se observa tejido conectivo laxo con separaciones importantes. En e y f se detallan secreciones vacuoladas eosinofilas. Cortes transversales. Tinción H-E. Nivel de corte $5 \mu \mathrm{m}$. 


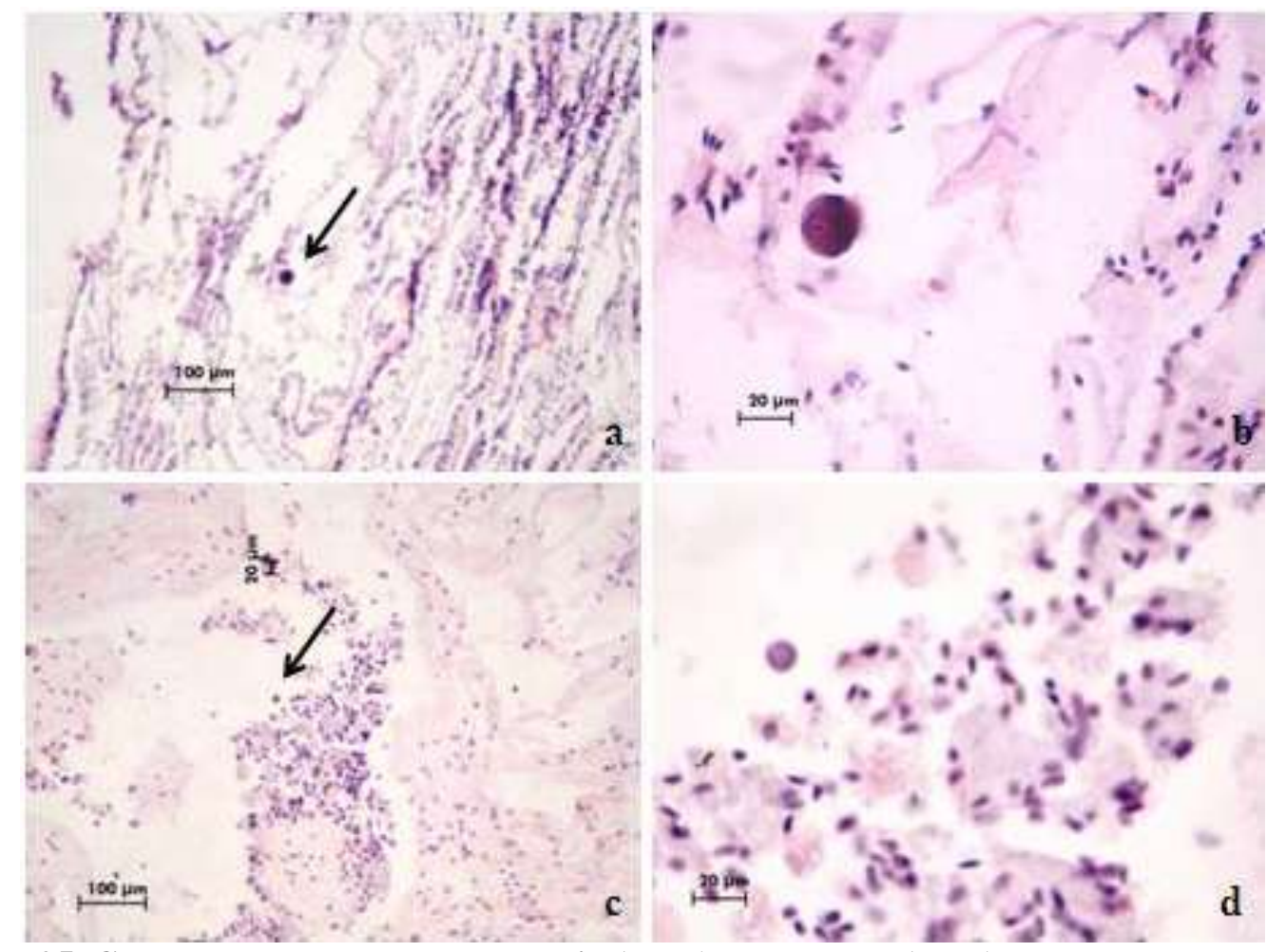

Figura 25. Cortes transversales de branquia (a y b) y de manto (c y d) en los que se muestran inclusiones esféricas en lo que pareciera ser un tipo de parasito. Tinción con H-E.

\section{Análisis de Evidencias.}

En la Tabla 10 se puede observar el análisis de las evidencias obtenidas para las respuestas tisulares, en donde se puede observar que todas las respuestas tisulares obtuvieron un factor entre 1 y 2 (mínina y moderada importancia respectivamente), sin que se haya hecho evidente la presencia de lesiones irreversibles en ningún ejemplar analizado. Las evidencias analizadas a partir de los análisis bioquímicos demuestran que tanto el pie como la branquia son los órganos con valores más altos de porcentaje de proteína, mientras que el manto se ubicó en valores medios. La concentración de proteínas solubles se ubicó en valores altos para los tres órganos y la actividad enzimática se observó con valores altos en manto y branquia y con valores medios en el pie (Tabla 11). 
Tabla 10. Análisis de evidencias de las respuestas tisulares en la almeja $P$. caroliniana.

\begin{tabular}{cccc}
\hline Respuestas tisulares & Manto & Branquia & Pie \\
Inclusiones esféricas & $\mathbf{1}$ & $\mathbf{0}$ & $\mathbf{1}$ \\
Gránulos de lipofuscina & 1 & 1 & $\mathbf{0}$ \\
Secreciones eosinofilas & $\mathbf{1}$ & $\mathbf{0}$ & $\mathbf{0}$ \\
Parásitos & $\mathbf{0}$ & $\mathbf{2}$ & $\mathbf{0}$ \\
Inflamación & $\mathbf{0}$ & $\mathbf{0}$ & $\mathbf{2}$ \\
\hline
\end{tabular}

En donde "1" se asoció a respuestas tisulares reversibles (mínima importancia), "2" se asoció a aquellas respuestas que son reversibles en la mayoría de los casos o el estresor es neutralizado (moderada importancia) y “3”. estuvo asociado a lesiones irreversibles (máxima importancia); finalmente la ausencia de respuestas se asoció a “0”

Tabla 11. Análisis de evidencias del análisis bioquímico en la almeja $P$. caroliniana.

$\begin{array}{cccc}\text { Porcentaje de proteína total } & \mathbf{1} & \mathbf{3} & \mathbf{3} \\ \text { Concentración de proteínas solubles (enzimas) } & \mathbf{3} & \mathbf{3} & \mathbf{3} \\ \text { Actividad enzimática } & \mathbf{3} & \mathbf{3} & \mathbf{2}\end{array}$

Porcentaje de proteína total; $\mathbf{1}=1-2 \% ; \mathbf{2}=3-4 \%$ y $\mathbf{3}=5-8 \%$. Concentración de proteínas solubles $(\mathrm{mg} / \mathrm{mL})$ : $\mathbf{1}=1-2 \mathrm{mg} / \mathrm{mL} ; \mathbf{2}=3-5 \mathrm{mg} / \mathrm{mL}$ y $\mathbf{3}=5-6 \mathrm{mg} / \mathrm{mL}$. Actividad enzimática: $\mathbf{1}=1-32 \mathrm{U} / \mathrm{mg} ; \mathbf{2}=33-64 \mathrm{U} / \mathrm{mg}$ y $\mathbf{3}=65-$ 27 U/mg. 


\section{Discusión.}

Los parámetros fisicoquímicos del agua registrados en las épocas climáticas de colecta fueron similares. La salinidad obtenida es típica de sistemas de agua salobre, mientras que el oxígeno disuelto y el pH coinciden con ambientes de tipo eurihalinos (Massol, 2011). Estos valores están reportados como valores que favorecen la reproducción y crecimiento normales de los bivalvos (Polanco \& Corral, 2001).

Los organismos asociados a las almejas se presentaron en mayor cantidad en la época de secas $(32 \%)$ y fueron del tipo de gusanos tubícolas y de cirrípedos. Estos organismos utilizan las conchas de los bivalvos como zona de resguardo; en este caso, las almejas por su forma de vida sésil favorecen su colonización (Vance, 1978). Se ha reportado que si la cantidad de organismos asociados aumenta de manera considerable en un organismo, esto puede ocasionar que la apertura de valvas sea limitada (Polanco \& Corral, 2001). El registro de los organismos asociados como parámetros biológicos, eventualmente representa un indicador de las relaciones ecológicas.

Los parámetros morfométricos de longitud $(30-50 \mathrm{~mm})$ y peso $(50 \mathrm{~g})$ coincidieron con la morfometría promedio reportada por García-Cubas \& Reguero, (2007) dentro de las claves de determinación taxonómica para la almeja Polymesoda caroliniana. De acuerdo al análisis estadístico realizado, las almejas son semejantes en longitud y peso pero no así, en ancho y alto, en donde presentan diferencias significativas. Los datos morfométricos sugieren que no existen patrones claramente definidos en relación entre el ancho y la altura, sin embargo esto no ocurre entre la longitud y el peso en donde no se observaron diferencias significativas. Estas relaciones muy probablemente se deban al modo de crecimiento de estos organismos ya que, por la disposición del asentamiento y la 
deposición de partículas de calcio en la concha, ésta no deja de crecer independientemente de la edad del molusco (Duque, 1993), de allí que las diferencias significativas se observen entre el ancho y el alto y no entre la longitud y el peso.

El índice de condición (IC) se ha reportado como un indicador del estado nutricional de las almejas (Crosby \& Gale, 1999 y Arrieche et al, 2002), si bien existe una gran diversidad de índices, es necesario optar por el más adecuado de acuerdo a la especie y los parámetros que deseemos utilizar. En el presente trabajo se utilizó el índice de Devenport \& Chen (1987) el cual fue elegido por la similitud de la especie y de los parámetros utilizados. Este índice propone rangos en donde valores de 1 a 2 representan un nivel nutritivo "bajo"; valores de 2 a 4 significan un estado "intermedio" y superiores a 4, representan valores de nutrición "altos". En el caso de los ejemplares procesados en este trabajo, los valores obtenidos de IC oscilaron entre 2 y 3 en promedio, lo que coloca a las almejas de Tecolutla en un estado "intermedio" de nutrición. Esto significa de acuerdo a Devenport y \& Chen (1987) que están teniendo los aportes necesarios de nutrientes sin evidenciar deficiencias y que además su metabolismo funciona de manera adecuada.

Al comparar los valores obtenidos entre zonas de colecta de cada época climática, se puede observar que no existieron diferencias significativas entre las zonas de cada época muestreada (secas: $\mathrm{t}=-1.7803 ; \mathrm{P}=0.09 ; \alpha=0.05$ y lluvias: $\mathrm{t}=-0.9332 ; \mathrm{P}=0.03630 ; \alpha=0.05$ ). Aunque existen algunos los valores más altos del IC que se presentaron en la época de secas respecto a la época de lluvias. El aumento de valores IC en la época de secas puede asociarse al desarrollo gonadal en donde la gónada puede ocupar hasta un $50 \%$ del peso corporal del bivalvo (De la Hoz, 2010). 
La determinación taxonómica utilizando claves de identificación, facilitó la búsqueda de información para el montaje de la técnica molecular. Las claves de determinación taxonómica de las especies son un método práctico, barato y de mucha tradición, sin embargo, hoy en día han cobrado interés las técnicas de determinación vía secuencias de ADN (López, 2004). La determinación genética utilizando secuencias de ADN es un método que resulta costoso y que requiere de cierta habilidad en el ejecutante, por tanto, el tiempo de montaje de ésta técnica puede prolongar la determinación de una especie. Sin embargo, ambas técnicas se seleccionan de acuerdo a la experiencia, y objetivos del estudio.

La determinación vía claves taxonómicas, evidenció que la almeja colectada en Tecolutla pertenece a la especie Polymesoda caroliniana o almeja negra. Este resultado se apoya con la determinación de la especie por medio de las secuencias de ADN, sin embargo al ser una técnica más elaborada se discutirán los aspectos que permitieron llegar a ese resultado.

Las extracciones de ADN realizadas, mostraron tanto en calidad como en cantidad, valores aceptables para poder ser utilizados en la amplificación de los genes empleados en este trabajo (r16S y 28S). Es importante tomar en cuenta que antes de amplificar cualquier gen se tiene que considerar la cantidad y la calidad del ADN extraído, esto con el fin de asegurar los productos amplificados durante la PCR (Falcón \& Valera, 2007). Respecto a los dos órganos utilizados en las extracciones (manto y branquia), el manto mostró una mayor cantidad de material genético (206 ng/ $\mu \mathrm{l})$, en relación a la branquia (172 ng/ $\mu \mathrm{l})$, estos resultados sugieren la importancia del manto en estudios similares como órgano de extracción de ADN (Folmer et al., 1994; Canapa et al., 2003; Taylor et al., 2007). El uso de este órgano en este tipo de estudios se apoya en su composición celular, al ser un órgano rico en mitocondrias, dispone en mayor cantidad del material genético a extraer (Vitellaro, 
et al., 1990 y Sick et al., 2007). La branquia, por el contrario es un órgano con pocas mitocondrias debido a su función, lo cual se traduce en valores menores de ADN extraído (Gómez et al., 2005). Aunque ambas extracciones resultaron óptimas se sabe que con el fin de obtener mayor certeza en el estudio, se prefiere el uso del manto respecto a la branquia, ya que los bivalvos son organismos filtradores y al realizar la extracción de ADN en este órgano es posible que ocurran errores por la presencia de ADN de otros organismos.

En las amplificaciones de las secuencias de genes específicos, se tienen que tomar en cuenta diversas variables para lograr amplificados de calidad y que nos proporcionen los resultados deseados. Evidentemente, los errores durante este proceso, conllevan a errores en la determinación de las especies. En cuanto a las amplificaciones del ADN extraído de la almeja del presente estudio, el gen r16S, amplificado a partir de tejido branquial; mostró amplificados tenues y bandas definidas además de bandas dobles de dímeros. Los amplificados tenues son resultado de la cantidad mínima de ADN extraído o de errores en cualquiera de las variables participantes en la PCR. Por otro lado, las bandas de dímeros se han reportado como un excedente en la cantidad de los oligos; lo que implican la autoanillacion de los mismos durante la PCR, y al ser moléculas de bajo peso molecular se observan en la parte inferior del gel electroforético. Esta situación se puede corregir si se modifican las cantidades de oligos usadas para el gen a amplificar, así como las temperaturas de anillamiento en la PCR (Falcón \& Valera, 2007).

Los productos obtenidos para la amplificación del gen $28 \mathrm{~S}$ utilizando el manto, evidenciaron bandas superiores a los productos amplificados en la electroforesis, además de poca definición de los productos amplificados. Las bandas superiores que se pueden observar en el gel a los productos amplificados pueden deberse a la proporción del material genético extraído. Las bandas superiores a los productos amplificados puede deberse a la 
presencia de moléculas de alto peso molecular que no fueron eliminadas en su totalidad durante los procesos de enjuagues en la fase la amplificación (Falcón \& Valera, 2007). Cabe resaltar que esta inconsistencia se eliminó casi en su totalidad en el proceso de purificación de las secuencias.

Después de la purificación de los productos amplificados a partir de los genes r16S y 28S se logró eliminar casi en su totalidad tanto las bandas de dímeros en el gen s16S, así como las bandas superiores observadas en el gel a los productos amplificados para el gen 28S. Las bandas de los productos purificados resultaron ser más tenues para el gen r16S a diferencia del gen $28 \mathrm{~S}$; lo que se puede explicar por el poco material genético obtenido en la branquia.

Durante la secuenciación se obtuvo una secuencia de aproximadamente 522 pb para el gen r16S, esta secuencia ya editada al compararse con la base de datos de GenBank arrojó un porcentaje de $77 \%$ de identidad con la almeja Corbicula colorata (JX399588.1) (Kang et al., 2012). Esta especie forma parte de la familia Corbiculidae a la cual pertenece también la almeja Polymesoda caroliniana (García-Cubas \& Reguero, 2007). Aunque este porcentaje resulta ser alto para una relación filogenética, sin embargo valores superiores a 90\% dan mayor certeza. Esta misma secuencia en la topología construida a partir del método de Máxima Verosimilitud mostró un alto porcentaje de soporte de $99 \%$ con miembros de la familia Corbiculidae.

Para la secuencia de 28S, se obtuvo un total de $233 \mathrm{pb}$, este número resulta ser bajo para un análisis de secuenciación ya que otros trabajos reportan valores superiores (Canapa et al., 1999; Chong-bo et al., 2011; Rintelen \& Matthias, 2011;) para el análisis de este gen (Taylor et al., 2007), sin embargo, con este número de pares de bases se logró tener certeza en la identidad de la especie. La topología construida mediante el método de Máxima 
Verosimilitud evidenció un alto soporte (99 \%) con la secuencia obtenida de GenBank de la especie Polymesoda caroliniana (AF131011) (Park y O’Foighil, 2000).

La almeja identificada como Polymesoda caroliniana, por medio de las dos técnicas, es una especie cuya distribución se ha reportado desde la costa de Carolina en los Estados Unidos y hasta el Golfo de México (García-Cubas \& Reguero, 2007). Estudios realizados por otros autores sobre la distribución de esta misma especie, han evidenciado registros en ciertas lagunas de Veracruz y Campeche (García-Cubas, 1981; Wakida-Kusunoki \& MacKenzie, 2004; García-Cubas \& Reguero, 2007), sin embargo dentro del estado de Veracruz no se menciona el municipio de Tecolutla como lugar de distribución de la almeja; esta información se suma a los registros que tiene el propio municipio de Tecolutla sobre su diversidad biológica, en donde no se enlista la presencia de esta especie de almeja rica en proteínas (Coordinación Estatal de Medio Ambiente, 2007)

Los datos obtenidos del porcentaje de proteínas en la almeja $P$. caroliniana coinciden con otros datos reportados por otros trabajos de bivalvos. Si bien no hay trabajos de análisis proximales en esta almeja, si existen para otras especies de bivalvos, por ejemplo, Reddy \& Flick, (1989) reportaron valores de $52 \%$ de proteína; Orban et al., (2006) reportaron porcentajes de 8 a $10 \%$ y Cruz et al., (2012) porcentajes de 7.2 a $57 \%$. El alto porcentaje de proteínas en el pie está relacionado con su estructura tisular, conformada por fibras musculares longitudinales y transversales así como por la presencia de colágeno y tejido conectivo, lo que lo hace un órgano rico en proteínas (Vitellaro et al., 1990). De manera análoga la branquia y el manto, presentan una estructura tisular rica en tejido conectivo y elementos proteínicos importantes (Gómez et al., 2005; Sick et al., 2007). Los valores similares de concentración de proteínas en los tres órganos, sugieren que en su 
composición podría existir una similitud en el contenido de proteínas solubles (Gómez et al., 2005 y Vitellaro, et al., 1990).

La determinación de la humedad se considera una prueba muy importante en el análisis de un producto como alimento. La materia seca, remanente después de la eliminación del agua, es conocida como sólidos totales y constituye un producto "saciador de bajo costo". El agua en los alimentos es considera también un factor importante en la estabilidad de los alimentos; así, se sabe que los porcentajes de humedad en los alimentos deben de ser lo más bajo posible sin alterar sus características de calidad, para evitar un manejo excesivo de agua en la producción y comercialización (Hernández-Ortiz, 1990). En el caso de las almejas de Tecolutla, la humedad fue baja entre los 7 y $8 \%$ en contraste otros productos marinos como el camarón (77\%). La concentración de proteínas fue similar en los tres órganos estudiados; a la vez, la baja cantidad de agua sugiere una calidad aceptable de la almeja como producto de consumo y comercialización.

Los valores altos de actividad enzimática en la branquia posiblemente se deban a las funciones de este órgano que involucran intercambio gaseoso, secreción de mucus, captura, selección y movimiento del alimento (Gómez et al., 2005), las cuales requieren de un alto aporte enzimático. El análisis de actividad enzimática a diferente $\mathrm{pH}$, mostró actividad en zonas de neutralidad a básicos, tanto para la almeja comercial como para $P$. caroliniana. De acuerdo con la literatura (Voet \& Voet, 2006 y Berg et al., 2007) este comportamiento a $\mathrm{pH}$ neutro corresponde a enzimas de tipo metaloproteasas o serín proteasas, involucradas en procesos digestivos La temperatura a la cual las enzimas presentaron mayor actividad enzimática (30 y hasta los $70{ }^{\circ} \mathrm{C}$ para la almeja $P$. caroliniana), son superiores a las que soporta en su medio natural sin afectar su metabolismo (Polanco \& Corral, 2005). El hecho de que la actividad enzimática esté presente en este intervalo amplio, se debe al estrés 
fisicoquímico al que estos organismos están expuestos y a los cambios que ha sufrido su entorno a lo largo de la evolución, por lo que han adaptado la actividad de sus enzimas a intervalos de temperatura y pH que los ajuste a dichos cambios (Haard \& Simpson, 2000). Con respecto a los electroferogramas, comparando los resultados de la almeja comercial con los de $P$. caroliniana, la primera evidenció en los tres órganos un número mayor de bandas. Sin embargo, de los tres órganos en la almeja de Tecolutla, el órgano con mayor número de bandas fue la branquia (19 a 120 kDA), la presencia de un número importante de bandas posiblemente esté asociado a la función que esta realiza (Gómez et al., 2005). Si bien hoy en día la biotecnología ha puesto su atención en el estudio de las enzimas proteolíticas de los organismos marinos, en el campo de los moluscos bivalvos, no hay suficientes estudios que caractericen este tipo de enzimas en el organismo con fines biotecnológicos. Sin embargo los trabajos que se han realizado sobre las enzimas de moluscos bivalvos, se han enfocado en el sistema digestivo con el fin de evaluar las enzimas presentes en procesos productivos que involucren la degradación de material proteíco (González de Canales \& Sarasquete, 1990 y Fernández et al., 2006).

La descripción tisular de cada órgano correspondió con la descrita en otros trabajos para moluscos bivalvos (Cáceres \& Alarcón, 2002). El pie fue descrito como un órgano de movimiento o fijación, compuesto por tejido conectivo laxo y una cantidad importante de fibras musculares longitudinales y transversales con epitelios simples (Vitellaro, et al., 1990); la branquia fue descrita como un órgano responsable del intercambio gaseoso y de la selección de partículas, que se encuentra compuesto por filamentos con células ciliadas formando lamelas, cada una con un seno que conduce hemolinfa (Gómez et al., 2005) y finalmente el manto, órgano responsable de la secreción de la concha y de la recepción de estímulos químicos del ambiente, está compuesto por tejido conectivo laxo con fibras de 
colágeno y epitelios simples con núcleos basales (Sick et al., 2007); cabe destacar que hasta este trabajo de investigación, la almeja Polymesoda caroliniana no había sido descrita tisularmente.

Dentro de las alteraciones más comunes que fueron observadas, la presencia de gránulos de lipofuscina, los cuales han sido descritos por diversos autores (Zaroogian \& Yevih, 1994 y Guzmán-García, 2007) como células cafés. Estas han sido involucradas en procesos de digestión y de diferente grado de diferenciación de acuerdo a la edad de las mismas (Kühnel, 2005). Estudios posteriores hacen referencia a estas mismas células como gránulos de lipofuscina (Gómez et al., 2005). La lipofuscina es un residuo no digerible limitado por una membrana que persiste tras la degradación lisosómica, por ello a los cuerpos residuales llenos de lipofuscina se les denomina gránulos de lipofuscina (Kühnel, 2005). Ambos trabajos coinciden en que estos gránulos además de las funciones antes descritas, participan en la desintoxicación ante la exposición a agentes contaminantes (Gómez et al., 2005). La presencia y alta frecuencia de esta respuesta biológica puede deberse a agentes tóxicos, ya que recientemente se han reportado niveles altos de toxicidad en los sedimentos de la zona de colecta 1 (González et al, 2011).

En la zona del pie se observaron inflamaciones, mismas que se presentan como una forma de defensa ante algún agente extraño. En las inflamaciones se pierde la conformación de los tejidos. Esta lesión puede ser reversible, siempre y cuando no rebase los niveles de defensa. Las secreciones eosinofilas no se han reportado en almejas de la especie objeto de estudio, este tipo de secreción es la segregación productos químicos que tienen afinidad a la eosina al exterior de las células; estas respuestas se han considerado como medidas de protección ante algún agente estresor (Sander, 1990). El estudio histopatológico del manto evidenció la presencia de inclusiones esféricas pardas y gránulos de lipofuscina. Se 
presume que estas inclusiones esféricas en tonalidades pardas, puedan ser gránulos protéicos o inclusiones lipídicas, que son propias del manto de un bivalvo (BardalesAzañero, 2008). A pesar de que el IC no mostró diferencia entre las zonas de colecta, el análisis histopatológico demostró que existen más alteraciones por órgano en las zonas de colecta 1 , siendo los porcentajes más altos en la época de lluvias.

El análisis de evidencias asociado al factor de importancia evidenció que no se observaron respuestas tisulares de nivel 3 o lesiones irreversibles que comprometan la salud del órgano o del organismo completo (Bernet et al., 1999), lo cual puede estar asociado a la buena calidad del agua que se encontró, ya que ésta es adecuada para el cultivo de moluscos; sin embargo, para el caso del sistema de defensa si se encuentran evidencias de estrés moderado al presentarse parásitos e inflamación en los organismos, lo que puede estar relacionado con la presencia de contaminantes en agua y sedimentos, no evaluados en este trabajo. La tabla de evidencias de los análisis bioquímicos deja ver un porcentaje alto de proteínas en branquia y pie, y valores bajos en el manto lo cual se puede asociar a su composición tisular. La evidencia de altas concentraciones de proteínas solubles y de actividad enzimática en branquia y manto se puede considerar como un parámetro que se podría considerar en estudios enzimáticos posteriores 


\section{Conclusiones.}

- Los parámetros fisicoquímicos del agua de ambas zonas de colecta y épocas, son valores óptimos para el desarrollo y cultivo de las almejas.

- Los parámetros biológicos como organismos asociados, no comprometen la salud ni el metabolismo de las almejas.

- Los parámetros morfométricos corresponden a los reportados en la literatura para la almeja $P$. caroliniana.

- Los parámetros morfométricos son un carácter que se puede considerar en la determinación taxonómica de la especie $P$. caroliniana por medio de claves.

- $\quad$ El IC demostró valores medios de nutrición para todas almejas colectadas en el sistema, lo que sugiere un estado nutritivo adecuado.

- La almeja colectada en Tecolutla es Polymesoda caroliniana, perteneciente a la familia Corbiculidae y que es conocida con el nombre común de almeja negra o almeja fango.

- Tanto las claves de determinación como el uso de secuencias de ADN, resultan adecuadas para conocer la identidad de la especie de estudio, siempre y cuando se tomen en consideración los pros y los contras de cada una, tales como costos, tiempos y experiencia.

- La almeja $P$. caroliniana es un recurso con potencial biotecnológico, dado que se evidenciaró un intervalo amplio de actividad enzimática a diferente $\mathrm{pH}$ y temperatura.

- La prevalencia de respuestas tisulares indica que la salud de estos organismos aún no se ve comprometida.

- La almeja Polymesoda caroliniana es un recurso potencialmente explotable con potencial biotecnológico y como alimento, además de ser un buen organismo bioindicador. 


\section{Bibliografía.}

Altschul, S.F., W. Gish, W. Miller, E.W. Myers \& D.J. Lipman. 1990. Basic local alignment search tool. Journal of Molecular Evolution 215(3): 403-10.

Anson, M.L. 1938. The estimation of pepsin, trypsin, papain and cathepsin with hemoglobin. The Journal of General Physiology 22: 79-78.

Arrieche, D., B. Licet, N. García, C. Lodeiros, \& A. Prieto. 2002. Índice de condición, gonádico y de rendimiento del mejillón marrón Perna perna (Bivalvia: Mytilidae), del Morro de Guarapo, Venezuela. Interciencia 27(11): 613-619.

Banni, M., J. Jebali, M. Daubeze, C. Clerandau, H. Guerbej, J.F. Narbonne, \& H. Boussetta 2005. Monitoring pollution in Tunirian coast; application of a classification scale based on biochemical markers. Biomarkers 10: 105-116.

Bardales-Azañero, J.R. 2008. Isoformas de la proteína quinasa dependiente de AMPc en el molusco bivalvo Mytilus galloprovincialis: purificación, caracterización funcional $y$ distribución tisular. Universidad de Santiago de Compostela Servicio de Publicaciones e intercambio científico España, pp. 61-63.

Barriga-Sosa, I.D.L.A., K. Beckenbach, B. Hartwick \& M.J. Smith. 1995. The Molecular Phylogeny of live Eastern North Pacific Octopus species. Molecular Phylogenetics and Evolution 4(2): 163-174.

Barriga-Sosa, I.D.L.A.M., Y. Pérez-Ramírez, F. Soto- Aguirre, M. Castillo-Rivera \& J.L. Arredondo-Figueroa. 2005. Ineter-specific variation of the mitochondrial r16s gene among silversides "Peces Blancos" (Atherinopsidae: Menidiinae) and utilization for species identification. Aquaculture 250(3/4): 637-651.

Barriga-Sosa, I.D.L.A., M. A. Rodríguez-Serna, C. Carmona-Osalde, C. Gárnica-Rivera, P. Acuña-Gómez \& J.L. Arredondo-Figueroa. 2010. Genetic identity and diversity of 
Procambarus llamasi (Decapoda, Astacidae, Cambarinae) from the Yucatan Peninsula, Mexico. Crustaceana 83(9): 1035-1053.

Battaner, A.E. 1993. Biomoléculas. Ediciones Universidad Salamanca, 421 p.

Berg, M.J., L. Stryer \& J.L. Tymoczko. 2007. Bioquímica. Editorial Revertè S.A. 1026 p.

Bernet, D., H. Schimidt, W. Meir, P. Burkhard-Holm \& T. Wahli. 1999. Histopathology I fish: proposal for a protocol to assess aquatic pollution. Journal of Fish Diseases 22(199): 25-34.

Cáceres, C. \& J.F. Alarcón. 2002. Estudios histológico e histoquímico del sistema digestivo de la almeja catarina Argopecten ventricosus (Sowerby, 1842). Boletín. Instituto Español de Oceanografía 18(1-4): 289-292.

Canapa, A., M. Isolina, F. Rollo \& E. Olmo. 1999. The small subunit rRNA Gene Sequences of Venerids and the Phylogeny of Bivalvia. Journal of Molecular Evolution 48: 463-468.

Canapa, A., S. Schiaparalli, I. Marota \& M. Barucca. 2003. Molecular data from the 16 S rRNA gene for the phylogeny of Veneridae (Mollusca: Bivalvia). Marine Biology 143(2003): 1125-1130.

Capó-Martí, M. 2007 Principios de Ecotoxicología, Diagnóstico, Tratamiento y Gestión del Medio Ambiente. Editorial Tebar. Madrid, España, pp. 139-140.

CBOL. 2011. Consortium for the Barcode of Life. En inglés: available online at http://www.barcoding.si.edu/ (downloaded February 13, 2011).

Chong-bo, H., W. Jian, G. Xiang-Gang, S. Wen-Tao, L. Hong-Jun, L. Yun-Feng, L. WeiDong \& S. Hao. 2011. The complete mitochondrial genome of the hard clam Meretrix meretrix. Molecular Biology Report 38: 3401-3409. 
Coordinación Estatal de Medio Ambiente. 2007. Área Natural Protegida del Fuerte. Programa de Manejo. Secretaría de Desarrollo Regional. Tecolutla, Veracruz, México, pp. 15-23.

Crosby, M.P. \& L. Gale. 1990. A review and evaluation of bivalve condition index methodologies with a suggested standard method. Journal of Shellfish Research 9(11): 233-237.

Cruz, R.A., R.C. Fonseca \& S.F. Chavarria. 2012. Comparación de la composición química proximal de la carne de Anadara tuberculosa y A. similis (Bivalva: Arcidae) de Chomes, Puntarenas, Costa Rica. Revista Ciencias Marinas y Costeras 4: $95-103$.

De la Lanza-Espino, G., S. Hernández-Pulido \& J.L. Carbajal-Pérez (comps.). 2000. Organismos Indicadores de la Calidad del agua y de la Contaminación (Bioindicadores). Editorial Plaza y Valdés. México, 633 p.

De la Hoz, A.M.V. 2010. Condición somática de la almeja Polymesoda solida (Veneroida: Corbiculidae) durante el periodo lluvioso en el Parque Natural Isla de Salamanca, Caribe Colombiano. Revista de Biología Tropical 58(1): 131-145.

Delbert, L.S. \& M.C. Weissburg. 2006. Hard clams (Mercenaria mercenaria) evaluate predation risk using chemical signals from predators and injured conspecifics. Journal of Chemical Ecology 32(3): 605-619.

Devenport, J. \& X. Chen. 1987. A comparison of methods for the assessment of condition in the mussel (Mytilus edulis L.). Journal of Molluscan Studies 53: 293-297.

DOF. Diario Oficial de la Federación. 2006. Carta Nacional Pesquera. Secretaria de Agricultura, Ganadería, Desarrollo Rural, Pesca y Alimentación. Segunda sección, México, pp. 19. 
Dondero, F.D.A., H. Jonsson, F. Capri, L. Gastaldi \& A. Viarengo. 2006. Assessing the occurrence of a stress syndrome in mussels (Mytilus edulis) using a combined biomarker/gene expression approach. Aquatic Toxicology 78: S13-S24.

Duque, P. 1993. Algunos aspectos de la biología y ecología de Polymesoda arctata (almeja) en la Bahía de Mar Marirrio (Golfo de Urabá). Tesis Biología, Universidad de Antioquia, Medellín, Antioquia, Colombia, 200 p.

Falcón, L.I. \& A. Valera. 2007. Extracción de ácidos nucleicos. Capítulo 16. In: Eguiarte, L.E., V. Souza \& X. Aguirre. 2007. Ecología molecular. Instituto Nacional de Ecología. SEMARNAT. México, pp. 449-515.

Farris J.L. \& J.H. Van Hassel. 2007. Freshwater Bivalve Ecotoxicology. Editado por SETAC (society), pp. 270-281.

Felsenstein, J. 1985. Confidence limits on phylogenies: An approach using the bootstrap. Evolution 39: 783-91.

Fernández, R.M.J., U. Labarta \& J.M. Navarro. 2006. Actividad lipasa intracelular (Argopecten purpuratus) mediante cromatografía de capa fina-densitometría. Ciencias Marinas 32(2): 1-9.

Folmer, O., M. Black, W. Hoeh, R. Lutz \& R. Vrijenhoek. 1994. DNA primers for amplification of mitochondrial cytochrome $c$ oxidase subunit I from diverse metazoan invertebrates. Molecular Marine Biology and Biotechnology 3(5): 294299.

García-Pérez, M. 2000. Electroforesis en geles de poliacrilamida: fundamentos, actualidad e importancia. Universo Diagnóstico. La Habana, Cuba 1(2): 31-34.

García-Cubas, A. 1981. Moluscos de un sistema lagunar tropical en el sur del Golfo de México (Laguna Términos de Campeche). Publicaciones especiales Instituto de 
Ciencias del Mar y Limnología. UNAM, México. En español disponible en http://biblioweb.tic.unam.mx/cienciasdelmar/especiales/1981-5/articulo458.html (consultado el 10 agosto de 2011).

García-Cubas, A. \& M. Reguero. 2007 Catalogo Ilustrado de Moluscos Bivalvos del Golfo de México y Mar Caribe. Universidad Nacional Autónoma de México. México D.F., pp. 11-15 y $70-79$.

Gabrieldes, G. 1997. The MED POL Biomonitoring program concerning the effects of pollutants on marine organisms along the Mediterranean coast. Athens, UNEP (OCA)/MED W.G.: 132-133.

Garate-Lizárraga, L.I., J.J. Bustillos-Guzmán, K. Erter \& M. Muñeton-Gomiz. 2004 Paralytic shellfish toxins in chocolata clam Megapitaria squalida (BivalvaVeneridae) en Bahía de la Paz Baja California, Golfo de California Revista Biología Tropical 52(1): 33-40.

Goldberg, E.D. \& K.K. Bertine. 2000. Beyond the Mussel Watch - new directions for monitoring marine pollution, Science Total Environmental 247: 165-174.

Gómez, M.A., M. Elizondo, P. Venier, \& M.P. Cajaraville. 2005. Characterization of mussel gills cell in vivo and in vitro. Cell Tissue Research 321: 131-140.

González de Canales, M.L. \& M.C. Sarasquete. 1990. Enzimas hidrolíticas en el aparato digestivo de las almejas Ruditapes decussatus (Linnaeus, 1758) y Ruditapes philippinarum (Adams \& Reeve, 1850) (Pelecipoda: Veneridae). Scientia Marina 54(1): 89-93.

González, R.S., X. Guzmán-García, P. Ramírez-Romero \& I. Matadamas-Guzmán. 2011. Toxicological analysis of water and sediment of Tecolutla, Ver., Mexico. SETAC. Merida, Yucatan. 
Guzmán-García, X. 2007. Empleo de biomarcadores para evaluar el proceso de daño en ostión Crassostrea virginica y su respuesta ambiental. Tesis de Doctorado en Biología Experimental. Universidad Autónoma Metropolitana. Unidad Iztapalapa, México, pp. 82-84.

Haard, N.F. \& B.K. Simpson. 2000. Seafood enzymes: utilization and influence on postharvest seafood quality. Ed. Marcel Dekker. New York, USA, 681 p.

Harrison, F.W. 1997 Microscopic anatomy of invertebrates Volume 6A Mollusca II. Editorial Wiley-liss. Inc. USA, pp. 1-118.

Hasegawa, M., H. Kishino \& T. Yano. 1985. Dating of the human-ape splitting by a molecular clock of mitochondrial DNA. Journal Molecular Evolution 22(2): 160164.

Hernández-Sámano, A.C. 2010. Identificación y Caracterización de Proteasas del Pepino de Mar. Tesis de Maestría en Biotecnología. Universidad Autónoma Metropolitana. Unidad Iztapalapa, México, pp. 107-108.

Hernández-Ortiz, V. 1990. Autoproteólisis de la cabeza del camarón (Litopeneaus vannamei) como una alternativa en la obtención de repetidos con actividad antioxidante. Tesis de especialización. Universidad Autónoma Metropolitana. Unidad Iztapalapa, México, 75 p.

Hickman, C.P., L.S. Roberts, A. Larson, H. I’Anson \& D.J. Eisenhour. 2005 Principios Integrales de Zoología. Editorial McGraw-Hill Interamericana. 13a Edición. España, pp. 392-298.

Hosoi, M., H. Shoko, S. Hideki, U. Masahiro, T. Haruhiko \& H. Isao. 2004. Sequence and polymerase chain reaction-restriction fragment length polymorphism analysis of the 
large subunit rRNA gene of bivalve: Simple and widely applicable technique for multiple species identification of bivalve larva. Fisheries Science 70: 629-637.

Kang, J.H., J.Y. Park, J.E. Jeong, J.S. Lee, H.S. Ko, \& Y.S. Lee. 2012. Corbicula colorata 16S ribosomal RNA gene, partial sequence; Mitochondrial. Biotechnology Research Division, National Fisheries Research and Development Institute, Shirang-ri 408-1,Kijang-eup, Kijang-gun, Busan 619-902, Republic of Korea. En inglés: available online at http://www.ncbi.nlm.nih.gov/nuccore/JX399588 (downloaded February 20, 2012).

Koeman, H.J. 1991. From comparative physiology to toxicological risk assessment. Comparative Biochemistry Physiology A100C: 7-10.

Kühnel, W. 2005. Atlas a color de citología e histología. Editorial Médica Panamericana. 11va edición. España, pp. 66-67

Kunitz, M. 1946. Crystalline soybean trypsin inhibitor II. The Journal of General Physiology 30: 291-310.

Lewbart, G.A. 2010 Medicina de los Invertebrados. Acribia Editorial. Zaragoza, España, pp. 111-135.

López, S.J. 2004. Técnicas de biología molecular aplicadas a la taxonomía y filogenia de moluscos. Spira 1(4): 23-33.

Massol, A. 2011. Manual de Ecología Microbiana. En español disponible en: http://www.uprm.edu/biology/profs/massol/manual/p2-salinidad.pdf (consultado el 10 agosto de 2011).

Martínez-Jerónimo, F. 1991 El papel del bioensayo en la evaluación de la toxicidad acuática. In Figueroa, M., C. Álvarez, A. Esquivel \& M. Ponce (eds.). 
Fisicoquímica y Biología de las lagunas Costeras Mexicanas. "Grandes temas de la Hidrobiología" UAM-I, pp. 57-65.

Mendoza, C.A., P. Ramírez-Romero \& Y. Pica-Granados. 2007 Environmental legislation and aquatic ecotoxicology in Mexico: Past, present and future scenarios. Journal of Environmental Science and Health Part A42, pp. 1343-1348.

Mikkelsen, P.M \& R. Bieler. 2007. Seashells of Southern Florida: living marine mollusks of the Florida keys and adjacent regions: Bivalves. Editorial Cloth. USA, 520 p.

Mille-Pagaza, S.M., A. Parra \& M. de J. Pérez-Chi. 1993 Guía de identificación de invertebrados. Editorial Trillas. México, pp. 155-157.

Narbonne, J.F., N. Arab, C. Clerandeau, M. Daubeze, J. Narbonne, O. Champeau \& P. Garrigues. 2005. Scale of classification base on biochemical markers in mussels: application to pollution monitoring in Mediterranean coast and temporal trends. Biomarkers 10: 58-71.

Orban, E., G. Di Lena, T. Nevigato, I. Casini, R. Caproni, G. Santorini \& G. Guiulini. 2006. Nutritional and commercial quality of the striped venus clam, Chamelea gallina, from De Adriatic Sea. Food Chemistry 101(2006): 1063-1070.

Park, J.K. \& D. O' Foighil. 2000. Sphaeriid and corbiculid clams represent separate heterodont bivalve radiations into freshwater environments Molecular Phylogenetics and Evolution 14(1): 75-88.

Polanco, T.E. \& M.L. Corral. 2001. Impulso, Desarrollo y Potencialización de la Ostricultura en España. Fundación Alfonso Martín Escudero. Madrid, España, pp. 22-64.

PRONAME. 2007. Programa de Monitoreo y Evaluación de Sustancias Toxicas, Persistentes y Bioacumulables. En español disponible en: 
http://siscop.inecc.gob.mx/descargas/proname_vdic.pdf (consultado 13 agosto de 2011).

Redy, N.R. \& G. Flick. 1989. Composition, flavor extract, protease, and glycosidases of clam Bellies collected from clam processing plants. Journal Agricultural and Food Chemistry 32(2): 341-345.

Rintelen, V.T. \& G. Matthias. 2011. Rapid evolution of sessility in an endemic species flock of the freshwater bivalve Corbicula from ancient lakes on Sulawesi, Indonesia. Biology letters 2: 73-77.

Ryan, J.A. \& L.E. Hightwer. 1996. Stress protein as molecular biomarkers for environmental toxicology, In Feige U., R.I.M., I. Yahara \& B. Polla ed. StressInducible Cellular Response, Birkhauser Verlag Basel/Switzerland. Germany, pp. 492.

Salazar, M.H. \& S.M, Salazar. 1991. Assessing site-specific effects of TBT contamination with mussel growth rates. Marine Environmental Research 32: 131-150.

Sander, B. 1990. Stress proteins: potential as multitiered biomarkers. In: McCarthy, J.F. \& L.R. Shugart (eds): Biomarkers of Environmental Contamination. Lewis Publishers, Boca Raton, FL., pp. 165-192.

Sick, L.J., J.J. Young \& P.J. Jung. 2007. Histology and ultraestrcutureof the mantle epidermis of the equilateral Venus, Gomphina veneriformis (Bivalvia: Veneridae). National Shellfisheries Research 26(2): 413-421.

Simon, C., A. Franke \& A.P. Martin. 1991. The polymerase chain reaction: DNA extraction and amplification. In: Hewitt GM, Johnston AWB, Young JPW, eds. Molecular techniques in taxonomy. New York: Springer Verlag, 329-355. 
Stagg, R.M. 1998. The development of international program for monitoring the biological effects of contamination in the OSPAR convention area. Marine Environmental. Research (46): 307-313.

Tanja, S., M. Woltt \& D.F. Sinsel. 2006. Population dynamics of Megapitaria squalida (Bivalva-Veneridae) at Magdalena Bay, Baja California Sur, México. Revista Biología Tropical 54(3): 1003-1017.

Tamura, K.P., D., Peterson, N., Stecher, G. Nei, M. \& S. Kumar. 2011. MEGA5: Molecular evolutionary genetics analysis using maximum likelihood, evolutionary distance, and maximum parsimony methods. Molecular Biology and Evolution 28(10): 2731-2739.

Tamura, K.P., M. Nei. 1993. Estimation of the number of nucleotid substitutions in the control region of mitochondrial DNA in humans and chimpanzees. Molecular Biology and Evolution 10: 512-526.

Taylor, J.D, T.W. Suzanne, A.G. Emily \& P. Dyal. 2007. A molecular phylogeny of heterodont bivalves (Mollusca: Bivalvia: Heterodonta): new analyses of $18 \mathrm{~S}$ and 28S rRNA genes. Zoologica Scripta 36(6): 587-606.

U.S. EPA. 1996. National listing of fish advisories. Environmental Protection Agency, Washington D.C.

Vance, R.R. 1978. A mutualistic interaction between a sessile marine clam and its epibionts. Ecology 59(4): 679-685.

Vázquez, H., M.S. Manzano \& A.R. Ortega. 2011. Relación entre las capturas de Megapitaria squalida (Bivalva-Veneridae) y la temperatura superficial del mar en la Bahía de la Paz Baja California Sur, México. Revista Biológica Tropical 59(1): 151-157. 
Villanueva, S.F. \& A.V. Botello. 1998. Metal pollution in coastal areas of Mexico. Reviews Environmental Contamination and Toxicology 157: 53-94.

Villalejo, F.M., M.M. Arellano, V. Ceballos \& D.F. García. 2000 Ciclo reproductivo de la almeja chocolata Megapitaria squalida (Sowerby, 1835) (Bivalva-Veneridae) en Bahía Juncalito, Golfo de California México Hidrobiológica 10(2): 165-168.

Vitellaro, Z.L., S. De Biasi \& A. Amadeo. 1990. Immunocytochemical demonstration of neurotransmitters in the nerve plexus of the foot and the anterior byssus retractor muscle of the mussel Mytilus galloprovincialis. Cell Tissue Research (1990)261: 467-476.

Voet, D. \& J.G. Voet. 2006. Bioquímica. Editorial Media Panamericana. 1700 p.

Wakida-Kusunoki, A. \& C. MacKenzie Jr. 2004. Rangia and Marsh Clams, Rangia cuneata, R. flexuosa, and Polymesoda caroliniana, In Eastern México: Distribution,-Biology and Ecology, and Historical Fisheries. Marine Fisheries Review 66(3): 13-19.

Yamaguchi, T., Y, Yashita, I., Takeda \& H. Kiso. 1983. Proteolytic enzymes in Green asparagus kiwi fruit and miut: Occurrence and partial characterization. Agricultural and Biological Chemistry 46 (8): 1983-1986.

Zaroogian, G. \& P. Yevich. 1994. The Nature and function of the brown cell in Crassostrea virginica. Marine Environmental Research 37: 355-373. 


\section{ANEXOS}

Anexo 1. Datos biológicos de la muestra.

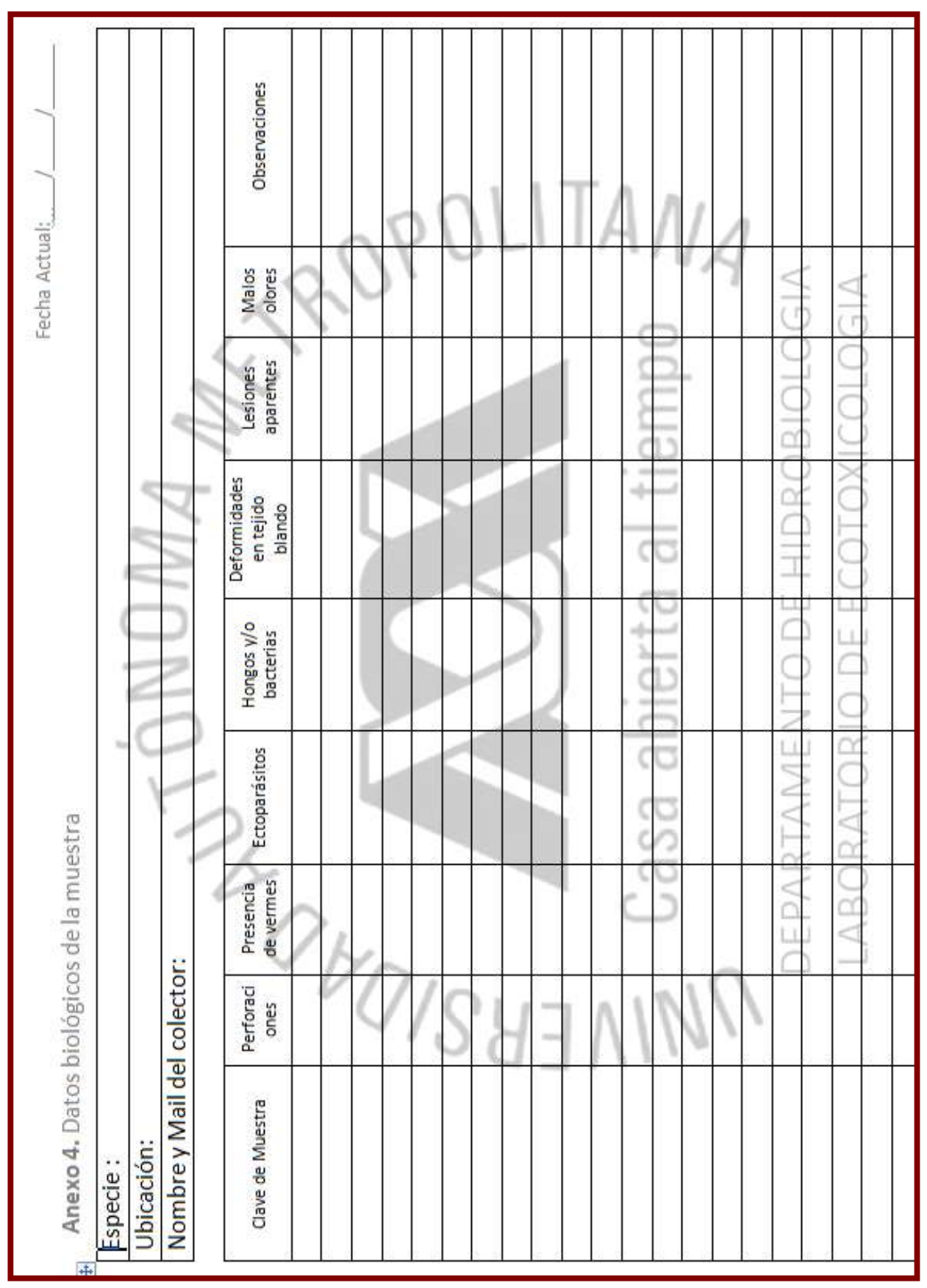


1. Cortar el tejido ( $\leq 10 \mathrm{mg}$ a $25 \mathrm{mg}$ ) e introducir en un tubo eppendorf de $1.5 \mathrm{ml}$.

2. Añadir $180 \mu 1$ del buffer ATL*.

3. Añadir $20 \mu \mathrm{l}$ de Proteinasa $\mathrm{K}^{*}$ y mezclar.

4. Incubar a $56^{\circ} \mathrm{C}$ hasta completar la digestión.

5. Añadir $200 \mu l$ de buffer $\mathrm{AL}^{*}$ y mezclar.

6. Añadir $200 \mu 1$ de etanol al $96 \%$ y mezclar.

7. Colocar la mezcla en una columna DNEASY MINI SPIN* y ésta en un tubo colector de $2 \mathrm{ml}$.

8. Centrifugar a $8000 \mathrm{rpm}$, durante 1 minuto, descartar el sobrenadante.

9. Añadir $500 \mu \mathrm{l}$ de buffer AW1* y centrifugar a $8000 \mathrm{rpm}$, durante 1 minuto, descartar el sobrenadante.

10. Añadir $500 \mu \mathrm{l}$ de buffer AW2* y centrifugar a $14000 \mathrm{rpm}$, durante 3 minutos, descartar el sobrenadante.

11. Trasferir la columna a un nuevo tubo eppendorf de $1.5 \mathrm{ml}$ y añadir $100 \mu \mathrm{l}$ de buffer AE en el centro de la membrana de la columna.

12. Incubar por 10 minutos a temperatura ambiente.

13. Centrifugar a $8000 \mathrm{rpm}$, durante 1 minuto.

14. Las muestras se conservan en congelación a $-20{ }^{\circ} \mathrm{C}$ hasta su procesamiento. *= Productos incluidos en el kit. 
Anexo 3. Protocolo de Purificación (WIZARD ® SV Gel and PCR Clean-Up System de PROMEGA ®).

1. Colocar una minicolumna en un tubo eppendorf de $1.5 \mathrm{ml}$.

2. En la minicolumna agregar el producto amplificado y $21 \mu \mathrm{l}$ de Membrane Binding Solution* e incubar por 1 minuto a temperatura ambiente.

3. Centrifugar a $16000 \times g$, durante 1 minuto, descartar el sobrenadante. Transferir la minicolumna a un tubo colector de $2 \mathrm{ml}$.

4. Añadir $700 \mu \mathrm{l}$ de Membrane Wash Solution (ethanol added)* y centrifugar a 16000 $x g$, durante 1 minuto, descartar el sobrenadante.

5. Repetir el paso anterior con $500 \mu \mathrm{l}$ Membrane Wash Solution (ethanol added)* y centrifugar a $16000 \times \mathrm{g}$, durante 5 minutos, descartar el sobrenadante.

6. Transferir la minicolumna a un tubo eppendorf de $1.5 \mathrm{ml}$ y añadir $30 \mu \mathrm{de}$ Nuclease Free Water*.

7. Incubar a temperatura ambiente durante 10 minutos y centrifugar a $16000 \mathrm{x}$ g por 1 minuto.

8. Descartar la minicolumna y conservar la muestra de $-20{ }^{\circ} \mathrm{C}$ a $4{ }^{\circ} \mathrm{C}$, hasta su procesamiento.

*= Productos incluidos en el kit. 


\section{Anexo 4. Protocolo de Purificación (QIAQUICK ® PCR Purification Kit de QIAGEN ®).}

A) Previo a la purificación.

1. Preparar un gel de agarosa al $1.2 \%$

2. Transferir el producto amplificado a un tubo eppendorf de $1.5 \mathrm{ml}$ y procesar en vacofuga hasta que disminuya el contendió del tubo hasta $15 \mu \mathrm{l}$ aproximadamente.

3. Realizar una electroforesis durante 1 hora.

4. Cortar las bandas obtenidas con ayuda de lámpara de rayos UV y colocarlas en tubos eppendorf de $1.5 \mathrm{ml}$.

B) Purificación.

1. Añadir al tubo eppendorf anterior, un volumen igual de buffer $\mathrm{QG}^{*}$, mezclar e incubar $55^{\circ} \mathrm{C}$ durante 10 minutos (hasta disolver el gel).

2. Agregar un volumen igual de isopropanol $\left(-20^{\circ} \mathrm{C}\right)$ y mezclar. Transferir a minicolumna.

3. Centrifugar a $13000 \mathrm{rpm}$, durante 1 minuto y descartar sobrenadante.

4. Añadir $500 \mu \mathrm{l}$ de buffer $\mathrm{QG}^{*}$, centrifugar a $13000 \mathrm{rpm}$, durante 1 minuto y descartar sobrenadante.

5. Añadir $750 \mu \mathrm{l}$ de buffer $\mathrm{PE}^{*}$ e incubar 3 minutos a temperatura ambiente.

6. Centrifugar a $13000 \mathrm{rpm}$, durante 1 minuto y descartar sobrenadante.

7. Centrifugar nuevamente y pasar la minicoluma a un tubo eppendorf de $1.5 \mathrm{ml}$.

8. Agregar $48 \mu \mathrm{l}$ de agua inyectable y dejar incubar 15 minutos a temperatura ambiente.

$*=$ Productos incluidos en el kit. 


\title{
Anexo 5. Secuencias utilizadas en el análisis filogenético.
}

\section{a) Secuencias utilizadas con el gen r16S.}

\author{
Spisula subtruncata (Mactridae). AJ548774. \\ 001 ggctctctgg ttgcagttgc ataggatagg gagtcgggce tgcccggtga tgttgtgttt \\ 061 aacggctgca agtaactttg tgctaaggta gcgcagtcac tcgtctttta attggagaaa \\ 121 ggtatgaatg gtttgacgag ggaaalctg tctcaaggat atgggctaaa gttttctttt \\ 181 aagtgaaaag acttaaattt ttaaataaga agagaagacc ccggcgagct tgatgattat \\ 241 tgttgcggga tgtgtaatga cagctaagtt ttgatggggc atcaggaaaa gaaaaaatc \\ 301 ttttacctag ggtatgaaga tcccctattg agggaagcaa gcaaaagcta ccgcggggat \\ 361 aacagcgcta tctcttcata gagttctaat cgaaaagag aacttgcgac ctcgatgttg \\ 421 gattaaagac tcgctttggt gcaggggcta aagtggatga gactgttcgt ctttaaatc \\ 481 ttt
}

Tresus keenae (Mactridae). JX399585.

001 gcaataaatc gtcctttaat tggggaaagg tatgaatggc ttgacgagag agtgactgtc

061 tcgggagtaa cctttgaagt tttcttttaa gtgaaaagac ttaaatttta aaataagacg

121 agaagacccc ggtgagcttg attaggttaa atttttaat gaaaactaaa gtttggttgg

181 ggcaacagga agggaagaaa aatccttctg acatagttaa agatcccatt tgatggaacc

241 gagcaaaagc taccacgggg ataacagcgt tatcccttt tagagatcaa atcaagaaag

301 gggcttgcga cctcgatgtt ggattagagt ttccttttgg tgcagaagct aaatggaga

361 gactgttcgt ctttaattc tctacgtgat ct

Callista brevisiphonata (Veneridae). JN969934.1.

001 cgcctgttta ttaaaacat ggcttttgc aaggtgtcat aaaaagtcgg actctgtcca
061 ctgattagtt tatttaaatt taaaggctgc agttatctgt acaaaggtag cgcaataagt
121 agcccctaa ttgggggatg gtatgaatgg tttgacgtgg agatgctgtt tctagtgtag
181 tttaaatgaa atttcttct aggtgaaaa gcctaggttt ttgtaagaga tgagaagacc
241 ctatcgaact tgattatata gaagcaatta aaataggttt ttgacttatt aaattttctt
301 agtttgaagt tttactgggg cagtaaaggg ttatgcaata cctttttaa taaataaag
361 agccttttag atggaaaaaa gcaaaagtta ccgtagggat aacagcgtaa ttttatcccc
421 taaagatctt attaagggga gagtgtgcga cctcgatgtt gaattaaagg ggctttttgg
481 ttggagatgc taaaaaggcg aaactgttcg ttttttaatc ctttacatga tctgagttca
541 gaccgg

Timoclea sp. (Veneridae). HM124734.1.

001 tgcaatgagg agttgtacta aggtagcgcg ataattagtc tcttaattgg agaatggtat 061 gaatgatttg acgtggatta actgtcttta aaaattaat tgaagtttcc attttggtga

121 aaggccaaa atttttgtaa aagacgagaa gaccctgtcg agcttaatta gagtttttaa

181 cactttaggt attaattaat tgaattttta ttggggcaat aagcactaaa ataacagtgt

241 tgttatttat aaagatcctc tttgagagaa gtcagcagaa gctaccgcag ggataacagc

301 gttatccttt ttgggagatc gaattgagga aagggtttgc gacctcgatg tttggattat

Corbicula japonica (Corbiculidae). AB522684.1. 
001 ggcettttga aaatttatat aaaaggttgg gcctgcccgg tgatctgaaa tggtttaacg 061 gctgcgattg aaaccgtact aaggtagcat aataatttgc cctttaattg ggggagagaa 121 tgaatggttt gacggtaaaa aagctgtttt aaaaataatt aaagaagtta acttttaagt 181 gaaaaggctt aagtttttat aaaagacgag aagaccccgt cgagcttaat taggatagct 241 ttatttaaaa gatatctaaa attttattgg ggcaatagaa aatgaaaaga atcattttt 301 tatagaataa ggatccagtt ttgactgaaa aaagcaaaag ctaccgcggg gataacaggg 361 taatttttc tgagagttca tatttaagag aaagtttgct acctcgatgt tggattaaaa 421 tttcttatg cttgc

\section{Geloina erosa (Corbiculidae). HM236291.1.}

001 catgaaggtt tagcctgccc ggtgattgaa agaatttaac ggctgcggtt ttgtactaag 061 gtagcataat aatttgcctt ttaagtgggg gatggaatga atggttggat ggtaaagaag 121 ctgtgtttt aatattgat gaagtttact ttaaagtgaa aaggctttaa ttgtttaaa 181 agacgagaag accccgtcga gcttgatttg aaatgttgtt ttgtggtgag taagcagttt 241 taaagttttg ttggggcaac aataacggtt aaacgttgtt taattttaag ttttgatcca 301 gtaagattga aaaagaaaa agctaccgcg gggataacag ggtaattttt tttgagagtt 361 caaatctaaa atgaagattg ctacctcgat gttggattag gatagttttg tgcttgcagg 421 aggtatata ataggactct ctctactgta ac

b) Secuencias utilizadas con el gen $28 \mathrm{~S}$.

\section{Polymesoda caroliniana (Corbiculidae). AF131011.1.}

001 aacaaggatt ccctcagtaa cggcgagtga agcgggaaga gcccagcacc gaatctcccg 061 gccatgcggg cggcgagaaa tgtggtgtac aggcggccga ttgttgccgc gtccggcgct 121 caagtcctcc tgatcgtggc cttgcccaga gcgggtgtca ggccettggc ggcgcgggat 181 gcggtggctt cgagcctcct tggagtcggg ttgtttggga atgcagccca aagcgggtgg 241 taaactccac ctaaggctaa atacaggcac gagtccgata gcggacaagt accgtgaggg 301 aaagttgaaa agaactttga agagagagtt caatagtacg tgaaaccgca tagaggcaaa 361 cgggtggatc cgcagagtcg acccggggaa ttcagccgag ccgcgccaga gcccgcaaag 421 tccggatccg caaggaccgg gccagtggtg ccatggcgtg gcacggtgca ctttctccgc 481 ggtcgagtgc cacgaccggt tccgcggcgg tcacaagcce ggtgggaagg tagcgctgcc 541 tcttcggggg taccgtgtta tagaccaccg cggtggactc gctgtgggac cgaggacgct 601 tgccgcgtcg agcggtctcg ggccgtcttg ggaggttcga cctcggatgc actgctttgc 661 agagcaccgt aaccgccgcc tgagtacggg ctcgtacgcc gccgacgctt cgggtcagtg 721 gcgaatcggt cggtcctcca cccgacccgt cttgaaacac ggaccaagga gtctaacatg 781 tgcgcgagtc atggggtctt tacgaaaccc aaaggcgcaa tgaaagtgaa ggcctcctcc 841 ggatggccca ggcaagatcc cggcccctcg cgggctggge gcactgccgg cccgcctcga 901 cggcatcgcc cgtgaggcgg agcaagagcg cacacgttgg gacccgaaag atggtgaact 961 atgtctgagt aggacgaagt caggggaaac tctgatggag gtccgcagcg attctgacgt 1021 gcaaatcgat cgtcaaactt ggatataggg gcgaaagact aatcg

\section{Polymesoda maritima (Corbiculidae). AF131010.1.}

001 aacaaggatt ccctagtaa cggcgagtga agcgggaaaa gcccagcacc gaatctcccg 061 gccatgcggg cggcgagaaa tgtggtgtat aggcggccga ttgccgccgt ttccggcgct 121 caagtcctcc tgatcgtggc cttgcccaga gcgggtgtca ggccettggc ggcgctggaa 181 tcggtggttt cgagcctcct tggagtcggg ttgtttggga atgcagccca aagcgggtgg 241 taaactccac ctaaggctaa atacaggcac gagtccgata gcggacaagt accgtgaggg 
301 aaagttgaaa agaactttga agagagagtt caatagtacg tgaaaccgca tagaggcaaa

361 cgggtggatc cgcagagtcg acccggggaa ttcagccgag ccgcgtcaga gcccgcaaag

421 tctggatccg caaggaccgg gccagtggtg cctctgcgtg gcatggtgca ctttctccgc

481 ggtcgagtgc cacgaccggt tctgtggcgg tcacaagccc ggtgggaagg tagcgctgcc

541 ccttcggggg taccgtgtta tagaccaccg cggtggactc gctgcgggac cgaggacgct

601 tgccgcgtcg tgcggtctcg ggccgtcttg ggaggttcga cctcggatgc actgctttgc

661 agagcaccgt aaccgccgcc cgagtacggg ctcgtacgcc gccggcgctt cgggtcagtg

721 gcgaatcggt cggtcctcca cccgacccgt cttgaaacac ggaccaagga gtctaacatg

781 tgcgcgagtc atggggtctt tacgaaaccc aaaggcgcaa tgaaagtgaa ggcctcctcc

841 ggatggccca ggcaagatcc cggcccctcg cgggctggge gcactgccgg cccgtctcaa

901 tggcatcgcc catgaggcgg agcaagagcg cacacgttgg gacccgaaag atggtgaact

961 atgtctgagt aggacgaagt caggggaaac tctgatggag gtccgcagcg attctgacgt

1021 gcaatcgat cgtcaaact ggatataggg gcgaaagact aatcg

\section{Neocorbicula limosa (Corbiculidae). AF131012.1.}

001 aacaaggatt ccctcagtaa cggcgagtga agcgggaaga gcccagcacc gaatctcccg 061 gccatgcggg cggcgagaaa tgtggtgtat aggcggccga ttgccgccgc gtccggcgct 121 caagtcctcc tgatcgtggc cttgcccaga gcgggtgtca ggccettggc ggcgctggaa 181 gcggtggttt cgagcctcct tggagtcggg ttgtttggga atgcagccca aagcgggtgg 241 taaactccac ctaaggctaa atactggcac gagtccgata gcggacaagt accgtgaggg 301 aagttgaaa agaactttga agagagagtt caatagtacg tgaaaccgca tagaggcaaa 361 cgggtggatc cgcaaagtcg acccggggaa ttcagccgag ccgcgtcagg gcccgcaaag 421 tccggatccg caaggaccgg gcgagtggcg cctctgcgtg gcacggtgca ctttctccgt 481 ggtcgagtgc cacgaccggt ttcgcggcgg tcacaagccc ggtgggaagg tagcgctgcc 541 tcctcggagg tgccgtgtta tagaccaccg cggtggactc gccgcgggac cgaggacgct 601 tgccgcgtcg agcggtctcg ggccgtcttg ggaggttcga cctcggatgc actgctctgc 661 agagcaccgt aaccgccgcc cgagtacggg cccgtacgcc gccggcgett cgggtcagtg 721 gcgaatcggt cggtcctcca cccgacccgt cttgaaacac ggaccaagga gtctaacatg 781 tgcgcgagtc atggggtctt tacgaaaccc aaaggcgcaa tgaaagtgaa ggcctccttc 841 ggtggcccag gcaagatccc ggtccctcgc ggactgggcg cactgccggc ccgtctcgac 901 ggcatcgccc gcgaggcgga gcaagagcgc acacgttggg acccgaaaga tggtgaacta 961 tgtctgagta ggacgaagtc aggggaaact ctgatggagg tccgcagcga ttctgacgtg 1021 caatcgatc gtcaaacttg gatatagggg cgaaagacta atcg

\section{Corbicula fluminea (Corbiculidae). AM779732.1.}

001 tatcagtaag cggaggaaaa gaaactaacc aggattcccc cagtaacggc gagtgaagcg
061 ggaagagccc agcaccgaat ctcccggcct cgcgggcggc gagaaatgtg gtgtataggc
121 ggccgattgt tgccgggtcc ggcgctcaag tcctcctgat cgtggccttg cccagagcgg
181 gtgtcaggcc cgtggcggcg ctggaaacgg cggcttcgag cctccttgga gtcgggttgt
241 ttgggaatgc agcccaaagc gggtggtaaa ctccacctaa ggctaaatac tggcacgagt
301 ccgatagcgg acaagtaccg tgagggaaag ttgaaaagaa ctttgaagag agagttcaag
361 agtacgtgaa accgcataga gccaaacggg tggatccgca gagtcgaccc ggggattca
421 gcccggccgc cagcggcgct cgcaaagttc ggatccgcaa ggaccgggcc agcgggacgt
481 ccgcgtggca gggtgcactt tctccgcggt cgagtgctac gaccggtttc gaggcggtca
541 gaagcccggc ggaaaggtag cgccgccctt cggggtgtcg tgttataggc cgccgcggtg
601 gactcgccgc gagaccgagg acgcttgccg cgccgagcgg tcccgggccg tcttgggagg
661 ttcgacctcg gctgcactgc tccgcagagc accgtaaccg ccgccctagc acgggtccgg
721 agactgccgg cgcctcgggt cagtagcgaa tcggtcggtc ctccacccga cccgtcttga


781 aacacggacc aaggagtcta acatgtgcgc gagtcatggg gtccgtacga aacccaaagg

841 cgcaatgaaa gtgaaggcct cctccggatg gcccaggcaa gatcccggcc ccgcgcgggc

901 tgggcgcact gccggcccgt ctcggcggca tcgtccgcga ggcggagcaa gagcgcacac

961 gttgggaccc gaaagatggt gaactatgtc tgagtaggac gaagtcaggg gaaactctga

1021 tggaggtccg cagcgattct gacgtgcaaa tcgatcgtca aacttggata taggggcgaa

1081 agactaatcg aaccatctag tagctggttc cctccgaagt ttccctcagg atagctggca

1141 ctgaatcgca gttttatccg gtaaagcgaa tgattagagg ccttggggac taaatgacct

1201 caacctattc tcaaacttta aatgggtaag aaggactact cgctcgactg gagcagttcc

1261 tcgaatgcet agtgccaagt gggccacttt tggtaagcag aactggcgct gtgggatgaa

1321 ccaaacgccc ggttaaggcg cccgatgctg acgctcatca gataccataa aaggtgttgg

1381 ttgatataga cagcaggacg gtggccatgg aagtcggaac ccgctaagga gtgtgtaaca

1441 actcacctgc cgaatcaacc agc

\section{Venus verrucosa (Veneridae). HE965801.1.}

001 gcatcgatga agagcgcagc cagctgcgtg aattaatgtg aattgcagga cacactgaac

061 atcgacacct tgaacgcaca ttgcggctct ggctcactgc cagagccacg cctgtccgag

121 ggtcggcgaa caagtcatcg ccgcagaccg attcgcttcg gtctcggcgc gttggcgagt

181 cgcgcgggca cagcgtcccg ctcgtccgcc gtagacttca gcctctctct tggcggccat

241 gtgaagtggc gcagggacag ggctcgaacg ggcettctgt ttagcgcacg tctgcgacgg

301 aaacgtagcg gacgaccttc tcctttggca gccccaagcc cctatcttgg gggagagaga

361 gcgcggctt aataaggccg cgaacaagag acgcactcgc ttgcccgctt gcgcggtgca

421 gagagtagtc tcgcacatcc gacctcggat cagacgggga tacccgctga atttaagcat

481 atcagtaagc ggaggaaag aaact 
a) Extracción.

1. Buffer de fosfatos $20 \mathrm{mM}, \mathrm{pH} 7$, compuesto de:

- Fosfato de sodio bibásico $20 \mathrm{mM}, \mathrm{pH} 7$.

- Fosfato monobásico 20 mM, pH 7.

b) Determinación de concentración de proteínas.

Reactivo de biuret para $225 \mathrm{ml}$.

- Mezclar durante 1 minuto a temperatura ambiente: $50 \mathrm{ml}$ de sulfato de cobre $\mathrm{CuSO}_{4}$, con $200 \mathrm{ml}$ de tartrato de sodio-potasio $\mathrm{KNaC}_{4} \mathrm{H}_{4} \mathrm{O}_{6} .4 \mathrm{H}_{2} \mathrm{O}$ y $75 \mathrm{ml}$ hidróxido de sodio $\mathrm{NaOH}$.

c) Electroforesis vía SDS-PAGE.

1. Preparación de geles de poliacrilamida al $12 \%$

- Gel de separación.

i. $\quad 2.5 \mathrm{ml}$ de Tris- $\mathrm{HCl}, 1.5 \mathrm{M}, \mathrm{pH} 8.8\left(4^{\circ} \mathrm{C}\right)$

ii. $\quad 3.4 \mathrm{ml}$ de Agua destilada.

iii. $\quad 4 \mathrm{ml}$ de Acrilamida/Bis $30 \%$

iv. $\quad 0.1 \mathrm{ml}$ de SDS (dodecilsulfato sódico) $10 \%$.

- Gel de concentración.

i. $\quad 2.5 \mathrm{ml}$ Tris- $\mathrm{HCl} 0.5 \mathrm{M}, \mathrm{pH} 6.8\left(4^{\circ} \mathrm{C}\right)$

ii. $\quad 3.4 \mathrm{ml}$ de Agua destilada.

iii. $\quad 4 \mathrm{ml}$ de Acrilamida/Bis $30 \%$

iv. $\quad 0.1 \mathrm{ml}$ de SDS (dodecilsulfato sódico) $10 \%$.

2. Buffer de la muestra (para $8 \mathrm{ml}$ ).

i. $\quad 4 \mathrm{ml}$ de agua destilada.

ii. $\quad 1 \mathrm{ml}$ de Tris $\mathrm{HCl} 0.5 \mathrm{M}$.

iii. $\quad 0.8 \mathrm{ml}$ de Glicerol.

iv. $\quad 1.6 \mathrm{ml}$ de SDS (dodecilsulfato sódico) $10 \%$

v. $\quad 0.4 \mathrm{ml} 2-\beta$ mercaptoetanol.

vi. $\quad 0.2 \mathrm{ml}$ de bromofenol azul $0.05 \%$

3. Buffer de corrida stock $5 \mathrm{x} \mathrm{pH} 8.3\left(4^{\circ} \mathrm{C}\right)$ para $600 \mathrm{ml}$ 
i. $\quad 9 \mathrm{~g}$ de Tris $\mathrm{HCl} 0.5 \mathrm{M}$

ii. $\quad 43.2 \mathrm{~g}$ Glicina.

iii. $\quad 3 \mathrm{~g}$ SDS (dodecilsulfato sódico)

iv. $\quad 600 \mathrm{ml}$ de agua destillada.

4. Tinción.

- Solución de teñidora: mezcla de metanol, agua destilada, ácido acético y azul de Coomassie R250 al $1 \%$.

- Solución desteñidora: mezcla de mezcla de metanol, agua destilada y ácido acético. 
Anexo 7. Secuencia de Deshidratación, Infiltración y Aclaramiento.

Secuencia de Deshidratación, Infiltración y Aclaramiento.

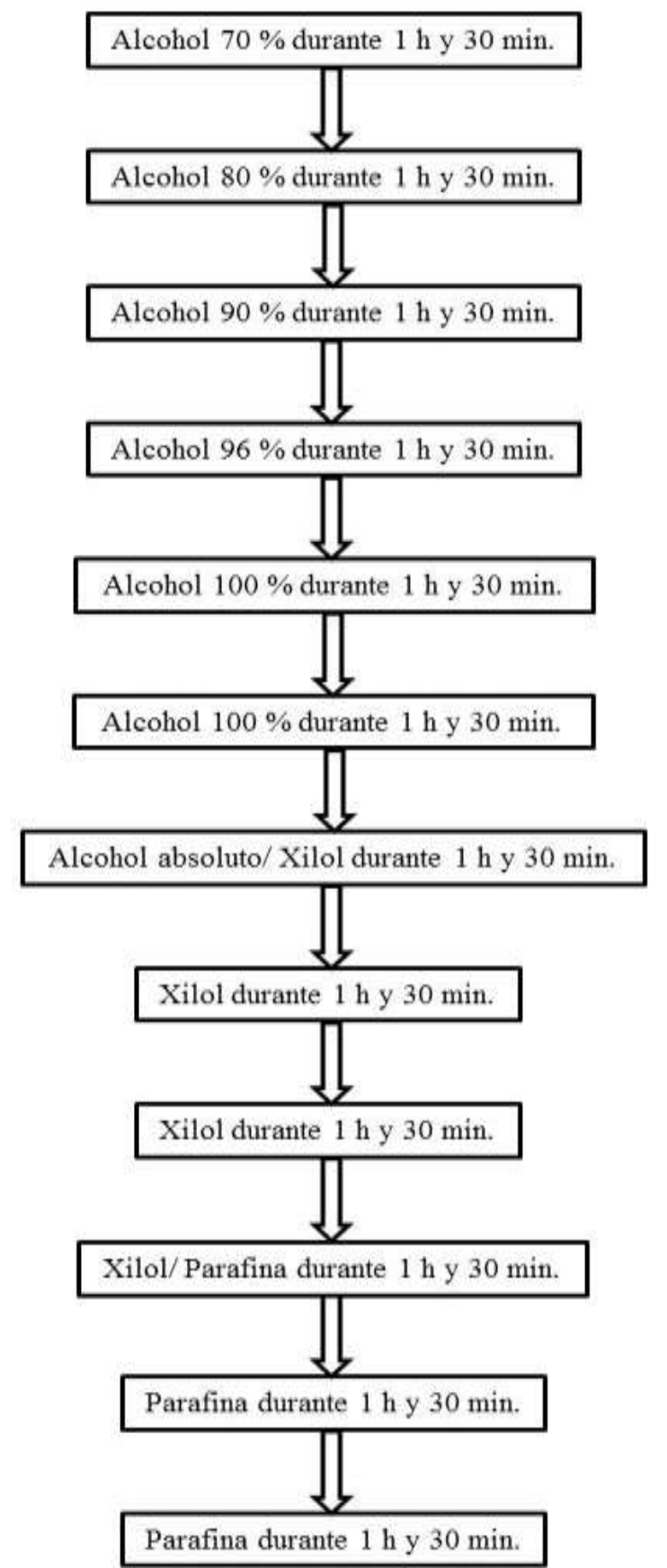

Duración Total $=18 \mathrm{hs}$. 
Anexo 8. Secuencia de Tinción.

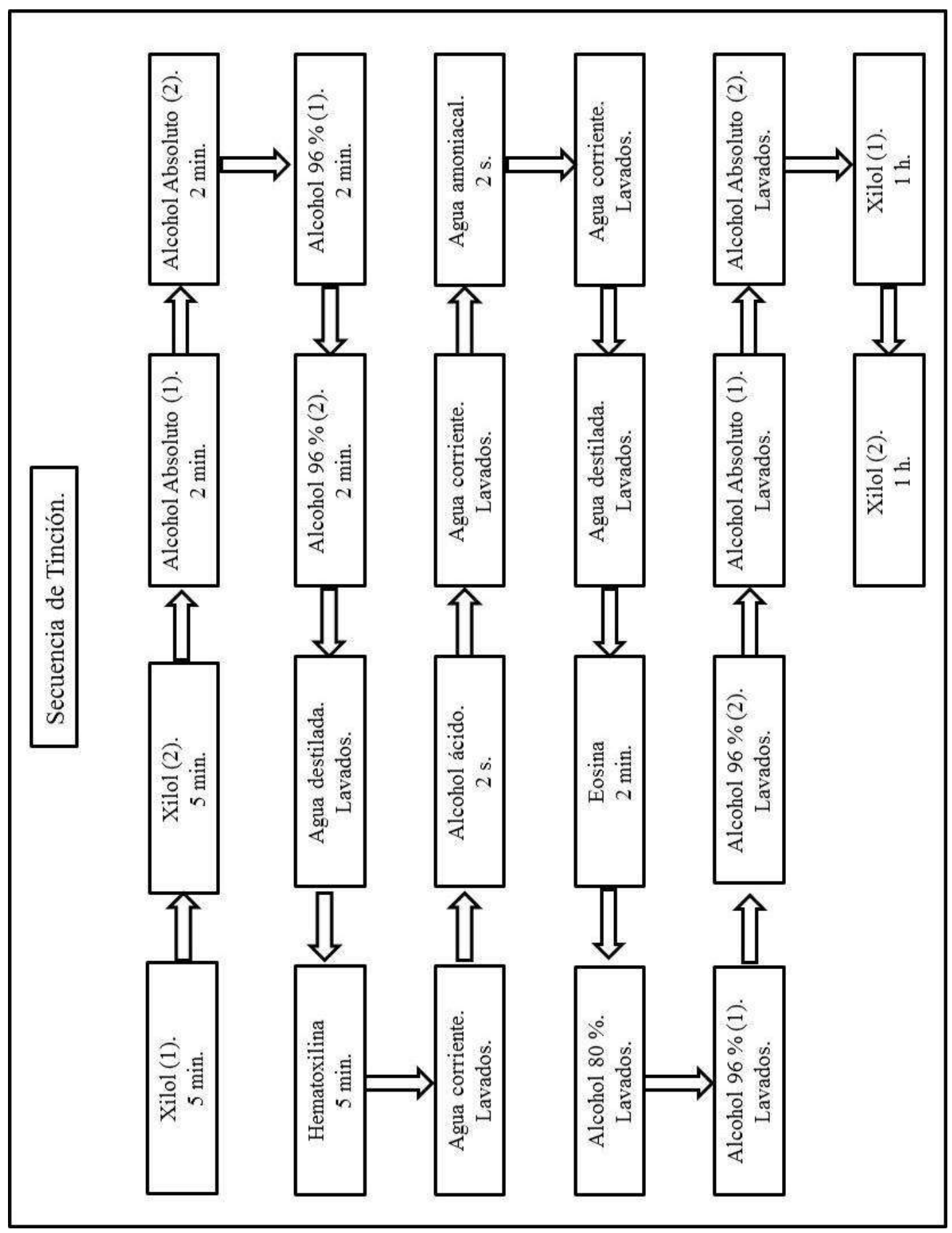


BIOMARCADORES DE SALUD Y CALIDAD APLICADOS A LA

ALMEJA POIYmesoda

caroliniana (BOSC, 1801)

(BIVALVA: CORBICULIDAE) DE

TECOLUTLA, VERACRUZ.
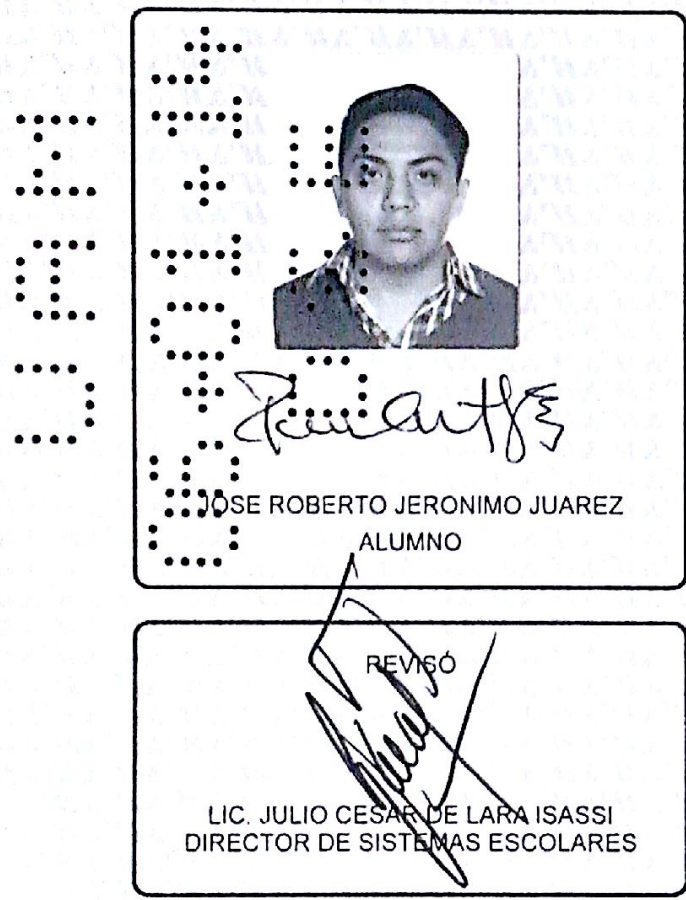

Bajo la presidencia de la primera y con carácter de Secretaria la última, se reunieron para proceder al Examen de Grado cuya denominación aparece al margen, para la obtención del grado de:

MAESTRO EN BIOLOGIA

DE: JOSE ROBERTO JERONIMO JUAREZ

y de acuerdo con el artículo 78 fracción III del Reglamento de Estudios Superiores de la Universidad Autónoma Metropolitana, los miembros del jurado resolvieron:

\section{Aprobar}

Acto continuo, la presidenta del jurado comunicó al interesado el resultado de la evaluación y, en caso aprobatorio, le fue tomada la protesta.
Mexico, se presentaron a las 11:00 horas del dia Iztapalapa de la Universidad Autónoma Metropolitana, los DRA. IRENE DE LOS ANGELES BARRIGA SOSA

PATRICIA RAMIREZ ROMERO

DRA. RAQUEL GARCIA BARRIENTOS

DRA. GUADALUPE BARRERA ESCORCIA
DIRECTORA DE LA DIVISIÓN DE CBS

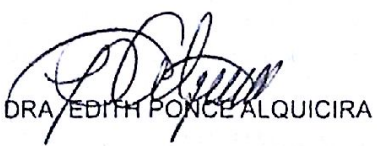

